\title{
Inventario del archivo del conde de Bornos
}

\author{
Pedro A. Porras Arboledas
}

\section{INTRODUCCIÓN}

Mi primer contacto con esta Casa se remonta a algunos años atrás, cuando me llamó la atención un documento muy interesante, publicado a comienzos del presente siglo por el ilustre erudito ubetense don Alfredo Cazabán, por el que los Reyes Católicos hacían merced a su secretario y jefe de la artillería real durante la Guerra contra Granada, Francisco Ramírez de Madrid, personaje madrileño de origen cántabro, de una heredad en término de Jaén -el coriijo de Bornos- por sus grandes esfuerzos en la conquista de las plazas, hasta el momento inexpugnables, de Cambil y Alhabar ${ }^{1}$. Posteriormente, al realizar un estudio sobre el régimen señorial en el Reino de Jaén ${ }^{2}$, intenté localizar los archivos de las diferentes casas nobiliarias asentadas en esta provincia, gracias a lo cual pude saber que la documentación del Condado de Bornos se hallaba en Madrid, bien en la Biblioteca Nacional o en el Archivo Histórico, ya que el actual Conde, el Excmo. Sr. Don Ignacio Ramírez de Haro, así me lo comunicó en marzo de 1983.

En el invierno de 1989, cuando por fin pude desembarazarme de otros quehaceres y de investigaciones más urgentes, decidí proceder a la localización exacta de tal Archivo; mis pesquisas en la Sección de Manuscritos de la Biblioteca Nacional resultaron infructuosas, no así las que realicé en el Archivo Histórico, en cuya Sección de Diversos apareció el Archivo de Bornos. Las parcas indicaciones que se me dieron en dicha sección fueron \footnotetext{
38.

1 Alfredo Gazabán Laguna: Jaén como base de la conquista de Granada, Jaén, 1904, pp. 37-

2 Pedro A. Porras: «El legado de la Edad Media: el régimen señorial en el Reino de Jaén (siglos XV-XV|II)», En la España Medieval, IV-2, 1984.
} 
que dicho fondo estaba sin inventariar, pero que, si quería verlo, podía proceder a examinar los casi 900 legajos de que constaba, dentro de la subsección de Títulos y familias (concretamente, los comprendidos entre los números 1.142 y 1.964 , además de otros legajos sueltos de numeración posterior). La finalidad de dicha búsqueda no era otra que realizar un estudio sobre la personalidad del fundador de la Casa de Bornos, el mencionado secretario; para localizar la documentación re!ativa a este personaje realicé varias catas al azar, obteniendo la impresión, que luego pude confirmar plenamente, de que el Archivo de Bornos estaba totalmente desordenado. Ello me obligó a revisar sistemáticamente todos los legajos, cuyo contenido fui registrando a fin de evitar a otros investigadores la penosa labor de volver a examinarlos sin ninguna ayuda previa En esta labor estuve ocupado entre los meses de febrero a junio de 1989, inventariando una media diaria de quince a veinticuatro legajos, en función de la cantidad que me era servida.

Por fortuna, cuando el trabajo ya estaba mediado coincidí en el Archivo Histórico con el Profesor inglés Edward Cooper, el cual me facilitó una copia del inventario reducido que él mismo había elaborado en 1972, cuando se le permitió trabajar directamente en los depósitos. En ese inventario se relacionaban parte del Archivo de Bornos (los legajos comprendidos entre 1.579 y 1.918), algunos del de Guevara (899 a 909), que resultaron ser también de Bornos, y varios de los Condados de Maceda y Alba de Yeltes (legajos 2.282 a 2.315). Gracias al mismo pude localizar el grueso de la documentación de Francisco Ramírez entre esos legajos, sin embargo, preferí coronar el inventario que tenía ya muy avanzado, por lo que también revisé sistemáticamente los legajos que Cooper se había visto, apreciando, así algunas divergencias entre ambos listados, divergencias que he anotado en el texto.

En la actualidad, y manteniendo las mismas signaturas, el Archivo del conde de Bornos ha sido íntegramente trasladado al Hospital Tavera de Toledo, donde ha quedado instalada la sección de Nobleza del Archivo Histórico Nacional.

\section{ORGANIZACIÓN DEL ARCHIVO}

A pesar de estar desorganizado en la actualidad, se aprecia con claridad que hasta su incautación por el Estado debió de permanecer bien ordenado; desde antiguo los archivos de los distintos linajes de la Casa debieron de estar en orden, ya que aún hoy aparecen grandes bloques de información seguidos. En el caso concreto de los Ramírez de Haro, 
señores y, luego, condes de Bornos, sus documentos aparecen dentro de carpetas rotuladas en el siglo XVIII bajo el epígrafe de Ramírez. EI resto de los linajes originales de Bornos aparecen rotulados del mismo modo: Enríquez, Ramírez de Arellano, Guevara y Olivares. Por lo que se refiere al Marquesado de Villanueva de Duero, todos sus documentos se incorporan bajo el Título, sin referirse a los linajes que lo componían, al contrario de lo que sucede con los Condes de Villaverde, cuyas carpetas son rotuladas como Ramírez de Guzmán. Finalmente, los papeles del Condado de Villariezo son los que presentan una organización más deficiente, si bien son los que tienen una mejor catalogación en libros aparte.

La última labor importante del antiguo archivero de Bornos fue realizada a comienzos del presente siglo cuando realizó inventarios mecanografiados de los distintos documentos incluidos en cada legajo, dividiéndolos por títulos y linajes. Tras la adjudicación judicial de los bienes de la última Condesa de Bornos, de la línea principal, al que fuera su secretario, don Juan Español, conde de Guevara, se producirá una disociación entre los títulos propiamente dichos, que fueron adjudicados al sobrino de aquélla, don Fernando Ramírez de Haro Patiño, abuelo del actual Conde, en tanto que los bienes y, por consiguiente, el Archivo paraban en manos del conde de Guevara. Al parecer, tras la guerra civil —los últimos documentos están fechados en 1931- los sucesores de éste perdieron o enajenaron los papeles del Archivo, si bien la policía impidió que se malvendieran en el Rastro madrileño, procediendo a su incautación.

A la altura de 1946 el Archivo pasó por el Ministerio de Hacienda, como nos indican gran número de papeles oficiales utilizados como señales dentro de los legajos. Probablemente, fue trasladado a la Biblioteca Nacional, aunque finalmente acabó siendo destinado al Archivo Histórico; aquí los legajillos en que estaba dividido fueron numerados correlativamente sin atender a criterio alguno, si exceptuamos el hecho de que los pergaminos y los árboles genealógicos de gran formato, así como los libros fueron dejados para el final, en tanto que el grueso de la documentación en papel era numerada en primer lugar. A partir de esa numeración de carpetas y legajillos se procedió a la actual ordenación de los legajos, a razón de dos a cuatro legajillos por cada uno de éstos, aproximadamente.

\section{TITULOS Y LINAJES}

Existen tres grandes bloques de documentación correspondientes a los tres títulos principales, los cuales incorporan otros títulos y mayorazgos en buen número. 
El más antiguo título será el de los Condes de Murillo de Río Leza, de apellido Ramírez de Arellano, rama segundona de los señores de los Cameros. Incorpora, además, los siguientes linajes: Ledesma, PortilloCalderón (de Valladolid), Pérez (de Guadalajara), Rueda-Herrera-Zuazo (de Logroño) y de la Torre-Andino, así como los mayorazgos de Ahumada (de Medina del Campo), Barrasa (de Talavera de la Reina), Butrón, Calchetas, Navamorcuende, Ávila y Cuadra (los tres de Ávila) y Sellán y Cavero (de Logroño).

En 1713 se incorporó a la Casa de Murillo el Condado de Peñarrubia, por extinción de la línea principal, en tanto que a fines del mismo siglo se unía por matrimonio al Condado de Murillo el Marquesado de Villacastel de Carrías, cuya documentación principal radica en la provincia de Santander y, en particular, en las fábricas de Liérganes y La Cavada. Respectivamente, correspondían a los apellidos Guevara y Olivares; Villacastel contó con otros linajes, como Brito-Bande, Cepeda, Garay, Moneda-Lerma-Temiño, Quevedo (de Reinosa), Salazar y Salcedo.

El título más moderno en el tiempo de los tres bloques principales es el Marquesado de Villanueva de Duero, ya que fue fundado en el primer tercio del siglo XVIII, si bien conserva documentación muy anterior; el linaje titular sería el de Contreras, en sus dos ramas, andaluza y castellana, aunque inmediatamente sería sustituido por el de Rojas; otros linajes emparentados serían los Castrillo, Hierro y Mitarte, con documentación procedente de Castilla la Vieja y Jaén, fundamentalmente, en tanto que los mayorazgos de Moreno y Trasmiera-Lorca recaerían respectivamente, sobre Segovia y Madrid.

A la línea principal se añadirían casi inmediatamente a su fundación el señorío de Villamarciel, el Vizcondado de Villagonzalo de Pedernales y, sobre todo, el Condado de Villariezo; este título se corresponde con el linaje de los Riaño-Orovio, aunque también incorpora muchos otros, como Carvajal (de Cáceres), Dávila, Gaceta, Guzmán, Lantadilla, Mazuero, Menchaca, Meneses, Mercado, Robles, Tapia, Tello y Toledo, asentados especialmente en la Castilla Vieja. Dos mayorazgos formaban parte del Condado, los de Brizuela y de Suárez de Toledo. A través del linaje de los Meneses, fue adquirido tras pleito en 1803 el Condado de Villaverde, del linaje de los Ramírez de Guzmán toiedanos.

El título de Bornos será el principal de la Casa, de acuerdo con los deseos expresados en su testamento por Francisco Ramírez de Madrid, a pesar de no ser el más antiguo ni el más importante desde el punto de vista económico; ello es debido a que todos los demás títulos fueron incorporados por matrimonio, quedando la línea masculina por los Ramírez de Haro. Este es el linaje principal desde el tercer señor de 
Bornos, el cual adoptó los apellidos de ambos padres como apellido único. Otros linajes quedaron incorporados a esta línea, Adsor, Jaques y Pagés, y con anterioridad los Gaytán de Ayala, con los que emparentaron en dos ocasiones, y los Losada, con abundante documentación; éstos, a su vez, incorporaban un largo número de linajes, Pimentel, Sarmiento, Caduérniga, Porras, Docampo, Luzón o Ludeña.

A comienzos del siglo XVIII Bornos absorbió el Condado de Montenuevo, de apellido Enríquez, aunque originariamente fue el de Cárdenas. En el mismo siglo se incorporaron los títulos de Murillo y agregados (PEÑARRUBIA y VILLACASTEL) y en 1814 el Marquesado de Villanueva de Duero, junto con los títulos condales de Villariezo, Villamarciel y Villaverde.

\section{CLASE DE DOCUMENTACIÓN}

De los legajos registrados prácticamente todos corresponden a la Casa de Bornos, sin embargo, algunos presentan ciertas peculiaridades, así por ejemplo, los legajos 1.229, 1.230 y 1.233 parecen corresponder al Ducado de T'Serclaes de Tilly, en tanto que el 902 pertenecería al Condado de Guevara ${ }^{3}$, lo que induce a pensar que los documentos de esa Casa -que debieron enajenarse al tiempo que los de Bornos- se extienden desde ese número hasta el inicio de los de Bornos.

La organización interna de estos antiguos Archivos, incluidos en el de Bornos, parece ser bastante similar entre sí a pesar de proceder de archiveros y épocas distintas; así se aprecia una doble división, por un lado, los documentos organizados por administraciones y, por otro, clasificados por linajes o familias. En este último sentido, la organización correspondería al siguiente esquema:

- árboles genealógicos

- partidas de bautismo, confirmación y matrimonio

- capitulaciones matrimoniales, dotes, tutelas, alimentos y otros documentos familiares

- compraventas, permutas, censos y arrendamientos

- mayorazgos y derechos jurisdiccionales

3 No debe confundirse a los Guevara, condes de Peñarrubia, título integrado en el condado de Murillo, con los condes de Guevara. 
- bulas y patronatos

- testamentos, herencias y particiones

- poderes y tomas de posesión

- cartas de pago, cuentas y créditos

- apeos y registros de bienes-pleitos, concordias, ejecutorias (memoriales impresos), ejecutorias de hidalguía, informaciones judiciales y requerimientos

- dictámenes de letrados

- reales provisiones, documentos de servicios prestados en la Administración, el Ejército, etc.

- inventarios de documentos e índices de legajos

Desde el otro punto de vista, se agrupan por sucursales territoriales o administraciones todos los documentos de carácter burocrático, en una doble división, la correspondencia entre la Casa y el administrador o viceversa y las cuentas rendidas periódicamente por aquél; ocasionalmente aparecen también expedientes relativos a cuestiones muy concretas, como expropiaciones, enajenaciones, etc.

En torno a 1853 existian las siguientes administraciones territoriales, que se mantendrían así hasta, al menos, principios de siglo ${ }^{4}$ :

\begin{tabular}{l|l}
\hline Administración & Estado \\
\hline - Motril & Bornos \\
- Cambil & Bornos \\
- Salinas de Trafalcaci (Móril) & Bornos \\
- Salinas de Duernas (Córdoba) & Murillo \\
- Tomilloso (Llerena) & Bornos \\
- Huerta de Atocha y Pradera de San Isidro (Madrid) & Bornos \\
- Logroño, Alcanadre y Ausejo & Murillo \\
- Talavera de la Reina & Murillo \\
- Segovia & Murillo \\
\hline
\end{tabular}

4 AHN, Diversos, TyF, leg. 1.228. Aunque no tiene consideración de administración, así debe considerarse la notable cantidad de datos conservados sobre el Hospital madrileño de la Latina. 


\begin{tabular}{|c|c|}
\hline Administración & Estado \\
\hline - Burgos & Murillo \\
\hline - Encomienda de Castellanos & Murillo \\
\hline - Abadía de Rueda & Murillo \\
\hline - Reinosa & Murillo \\
\hline - Torrelobatón & Murillo \\
\hline - Valmaseda & Murillo \\
\hline - Salinas de Añana & Murillo \\
\hline - Arguedas & Murillo \\
\hline - Cintruénigo & Murillo \\
\hline - Tudela de Duero & Murillo \\
\hline - Minas de Ojos Negros & Murillo \\
\hline - Guadalajara & Murillo \\
\hline - Alerre & Murillo \\
\hline - Casas en Madrid & Murillo \\
\hline - Medina del Campo & Murillo \\
\hline - Valladolid & Murillo \\
\hline - Zamora (2 admones.) & Bornos \\
\hline - Jaén & Vva. de Duero \\
\hline - Cabañas de ganado (2 admones.) & Vva. de Duero y Villariezo \\
\hline - Talavera de la Reina & Villariezo \\
\hline - Segovia & Vva. de Duero \\
\hline - Burgos & Villariezo \\
\hline - Tordesillas & Villariezo \\
\hline - Ávila & Villariezo \\
\hline - Aranda de Duero & Vva. de Duero \\
\hline - Pueblanueva & Vva. de Duero \\
\hline - Guadalajara & Vva. de Duero \\
\hline - Olmedo & Vva. de Duero \\
\hline - Sepúlveda & Vva. de Duero \\
\hline - Marchamalo & Vva. de Duero \\
\hline - Toledo & Villaverde \\
\hline
\end{tabular}




\begin{tabular}{l|l}
\hline Administración & Estado \\
\hline - Valencia & Villariezo \\
- Arévalo & Villariezo \\
- Casas en Madrid & Villariezo \\
- Loja & Vva. de Duero \\
- Ronda & Vva. de Duero \\
- Zamora & Vva. de Duero \\
- Orellana & Vva. de Duero \\
\hline
\end{tabular}

Por desgracia, no se conserva toda la documentación completa, dándose el caso de administraciones de las que sólo queda esta referencia o poco más; la cronología de estas series por administraciones suele ser bastante moderna, aunque hay algunas, como la de Motril, cuyos inicios se remontan al siglo XVI:

\begin{tabular}{|c|c|c|c|}
\hline \multicolumn{2}{|c|}{ Cuentas } & \multicolumn{2}{c|}{ Correspondencia } \\
\hline fechas & legajo & fechas & legajo \\
\hline 1565 y 1594-99 & 1.410 & $1762-71$ & 1.395 \\
$1597-1693$ & 1.475 & $1767-75$ & 1.394 \\
$1697-1729$ & 1.476 & 1781 & 1.630 \\
1724 & 1.434 & $1782-83$ & 1.720 \\
$1745-54$ & 1.304 & 1783 & 1.651 \\
$1755-57$ & 1.303 & 1785 & 1.162 \\
$1758-63$ & 1.294 & 1786 & 1.433 \\
$1764-65$ & 1.440 & 1788 & 1.477 \\
1767 & 1.733 & $X 1 X$ & 1.624 \\
1768 & 1.734 & & \\
$1769-71$ & 1.739 & & \\
$1776-79$ & 1.199 & & \\
$1779-82$ & 1.198 & & \\
1784 & 1.383 & & \\
1824 & 1.451 & & \\
1902 & 1.209 & & \\
$1908-14$ & 1.668 & & \\
1923 & 1.521 & & \\
& & & \\
\hline
\end{tabular}


Sin embargo, en la mayoría de los casos los datos se inician en el siglo XVII y, sobre todo, XVIII. Por lo que se refiere a los documentos clasificados por linajes, las series se inician en muchos casos en el siglo $X V$, abarcando hasta la Segunda República; concretamente, el documento original más antiguo es la fundación del mayorazgo de García de Tormes, obispo de Burgos, en 1384 (pergamino, legajo 1.866). El documento real original más antiguo es la donación de las salinas cordobesas de Duernas a Juan Carrillo por parte de Enrique III en 1401 (privilegio rodado, legajo 1.866). Es decir, el cúmulo de documentación de este Archivo se sitúa entre los siglos XV y. XIX, aunque se encuentren traslados de documentos desde el siglo $\mathrm{Xl}$, referentes, en su mayoría, a la Abadía de Alcanadre y otros señoríos del Estado de Murillo; en realidad, los papeles fechados entre los siglos XI y XIV son escasos, ya que la fundación de los distintos señoríos englobados en la Casa de Bornos es posterior a ese último siglo.

Como antes decía, el Archivo de Bornos no se conserva, ni mucho menos, en su totalidad, tal y como se encontraba a comienzos del presente siglo; aunque el archivero que mecanografió los distintos índices en las dos primeras décadas de esta centuria ya advertía de la falta de algunos documentos, lo cierto es que el grueso de las pérdidas debió de producirse con la enajenación del mismo y durante el tiempo que se halló expuesto en el Rastro. El expolio es especialmente sensible en los documentos más antiguos, sobre todo, los de los señoríos del Estado de Murillo de los siglos XIV y XV y alguno de Francisco Ramírez de Madrid. De este personaje han desaparecido, entre otros muchos, una cuarentena de escrituras arábigas de compraventas en Motril, así como dos rendiciones de cuentas voluminosas sobre sus actuaciones como obrero de los Alcázares de Sevilla y como capitán general de la artillería castellana durante la Guerra de Granada.

Por fortuna, las pérdidas no son totalmente irreparables, ya que se han conservado inventarios de documentos de los distintos señoríos bastante completos; la relación por linajes sería la siguiente ${ }^{5}$ :

\footnotetext{
5 He señalado con asterisco aquellos legajos que contienen inventarios importantes. Debe advertirse que en los inventarios de los linajes principales frecuentemente se incluyen los documentos de otros linajes de la Casa.
} 
BORNOS

\begin{tabular}{|l|c|c|}
\hline Mayorazgos & Fecha inicial & \multicolumn{1}{|c|}{ Legajos } \\
\hline Bornos & XV & $\begin{array}{l}1578-1890-1887 \\
1431-1612\end{array}$ \\
\hline
\end{tabular}

\section{MONTENUEVO}

\begin{tabular}{|l|l|l|}
\hline Montenuevo & XV & 1431 \\
\hline
\end{tabular}

\section{MURILLO}

\begin{tabular}{|l|l|l|}
\hline Abadía de Alcanadre & XI & 1492 \\
Ahumada & XVI & 1605 \\
Ausejo & XIV & 1350 \\
Barrasa & XVII & 1361 \\
Butrón & XV & $1178-1491-1553$ \\
Calchetas & XVI & $1511-1571-1572$ \\
Capitán Navarro & XVII & 1481 \\
Dávila & XVI & 1943 \\
Ledesma & XV & $1535-1536$ \\
Murillo & XI & $1316^{*}-1357-1408-1487$ \\
& & $1501-1520-1521-1526$ \\
& & $1561-1565-1841-1904$ \\
Portillo & & $1956^{*}$ \\
Portillo-Calderón & XVI & 1492 \\
Pérez & XVI & 1544 \\
Sellán y Cavero & XV & $1502-1551$ \\
de la Torre & XVI & $1350-1630$ \\
Zuazo & XV & $1350-1566$ \\
\hline
\end{tabular}

PEÑARRUBIA

\begin{tabular}{|l|l|l|}
\hline Peñarrubia & XIV & $1350-1490-1491-1861$ \\
\hline
\end{tabular}


VILLACASTEL

\begin{tabular}{|l|c|c|}
\hline Mayorazgos & Fecha inicial & Legajos \\
\hline Moneda-Lerma & XVI & $1204-1486-1596-1891$ \\
& XVI & 1925 \\
Quevedo & XIV & $1296-1489-1491-1522$ \\
Villacastel & & $1553-1554-1609-1799$ \\
& & $1814^{*}-1919^{*}$ \\
\hline
\end{tabular}

VILLANUEVA DE DUERO

\begin{tabular}{|l|l|l|}
\hline Moreno & XV & 1919 \\
Trasmiera & XV & $1531-1533-1534-1789$ \\
& & 1943 \\
Vva. de Duero & XIV & $1253-1487-1593-1794$ \\
& & $1795-1915^{*}-1919$ \\
\hline
\end{tabular}

VILLARIEZO

\begin{tabular}{|l|l|l|}
\hline Brizuela & XVII & 1812 \\
Carvajal & XV & 1580 \\
Meneses & XV & 1956 \\
Tello-Meneses & XII & 1904 \\
Villariezo & XIV & $1299-1360-1492-1531$ \\
& & $1561-1588-1591-1861$ \\
& & 1914 \\
Idem (libros-registro) & & $1825-1826-1827-1847$ \\
& & $1872-1889-1890-1891$ \\
& & $1892-1895-1905-1906$ \\
& & $1908-1909-1949-1950$ \\
\hline
\end{tabular}

VILLAVERDE

\begin{tabular}{|l|l|l|}
\hline Villaverde & XIV & $\begin{array}{c}1243-1291-1493-1511 \\
1531-1572-1575-1588^{*}\end{array}$ \\
\hline
\end{tabular}

OTROS

\begin{tabular}{|l|c|c|}
\hline Castro, de Madrid & XV & 1448 \\
Robles & XVI & 1178 \\
Borja & XVIII & 1952 \\
Villoslada & XV & 1850 \\
Coscojales & XVI & 1561 \\
\hline
\end{tabular}


Por lo que respecta a la distribución geográfica, no cabe duda de que la mayor parte de la documentación viene referida a los antiguos territorios castellanos, en especial a las dos Castillas y Andalucía. Veamos los lugares representados en este Archivo por regiones:

ANDALUCÍA

Provincia

Córdoba

Granada

Jaén

Málaga

Sevilla

\section{Localidades}

\section{Córdoba}

Granada, Motril y Salobreña

Jaén y Cambil y Alhabar

Antequera y Ronda

Sevilla y Alcalá de Guadaira

\section{EXTREMADURA}

\begin{tabular}{ll} 
Provincia & Localidades \\
\hline Badajoz & $\begin{array}{l}\text { Cabeza de Buey, Castuera, Fuente de Cantos, Puebla } \\
\text { de Alcocer y Zafra } \\
\text { Cáceres y Miajadas }\end{array}$ \\
\hline CASTILLA-LA MANCHA Y MADRID \\
\hline Ciudad Real & $\begin{array}{l}\text { Almodóvar del Campo, Calzada de Calatrava } \\
\text { y Castellanos }\end{array}$ \\
Guadalajara & $\begin{array}{l}\text { Guadalajara, Alimonacid, Cabanillas, Cañizar y Molina } \\
\text { de Aragón }\end{array}$ \\
Madrid & $\begin{array}{l}\text { Madrid } \\
\text { Toledo, Lavadero de Rojas, Gamonal, Navamorcuende, } \\
\text { Oropesa, Pueblanueva, Talavera de la Reina y } \\
\text { Villaverde }\end{array}$ \\
\hline
\end{tabular}

CASTILLA-LEON Y CANTABPIA

$\begin{array}{ll}\text { Ávila } & \text { Ávila y Arévalo } \\ \text { Burgos } & \begin{array}{l}\text { Aranda de Duero, Mazuelo de Candemuño, Medina de } \\ \text { Pomar, Rabé de las Calzadas, Tardajos, Villagonzalo } \\ \text { de Pedernales, Vllamarciel y Villariezo }\end{array} \\ \text { Palencia } & \text { Palencia } \\ \text { Salamanca } & \text { Salamanca } \\ \text { Santander } & \text { Santander, Liérganes y La Cavada y Reinosa }\end{array}$


Segovia

Soria

Valladolid

Zamora
Segovia, Cuéllar, Encinillas y Sepúlveda

Soria, Burgo de Osma y Valdenarros

Valladolid, Almenara, Brahojos, Medina del Campo,

Olmedo, Tordesillas, Torrelobatón, Tudela de Duero,

Villalón y Villanueva de Duero

Zamora, Montamarta y San Cebrián de Castrotorafe

RIOJA Y PAIS VASCO

Álava

Salinas de Añana

Logroño

Logroño, Abadía de Rueda, Alcanadre, Ausejo, Calahorra, Castañares y Murillo de Río Leza

Vizcaya Valmaseda

ARAGÓN, NAVARRA Y VALENCIA

Provincia

Localidades

Huesca

Alerre

Navarra

Arguedas y Cintruénigo

Valencia

Valencia

Deben reseñarse como localidades con más información, tanto desde el punto cuantitativo como cualitativo, las siguientes: Arévalo, Motril, Cambil, Madrid, fábricas de Liérganes y La Cavada, Talavera de la Reina y el conjunto formado por Medina del Campo, Olmedo, Tordesillas y Torrelobatón, así como las distintas localidades riojanas, navarras y aragonesas pertenecientes al Estado de Murillo.

\section{DOCUMENTOS NOTABLES}

Obviamente cualquier archivo señorial con documentación acumulada durante más de cinco siglos es una fuente de información para trabajos muy variados, tanto de carácter histórico como geográfico o económico, así, por ejemplo, la existencia de series bastante completas de cuentas de las distintas administraciones permite el estudio estadístico de producciones agrícolas y cabañiles durante varios siglos.

El valor, por tanto, de este Archivo de Bornos es alto en información, aunque no sea comparable a los de Casas más importantes, como Alba u Osuna. Desde el punto de vista de la Historia del Derecho este Archivo es 
muy interesante, con series muy amplias de documentos de Derecho privado, organizadas por linajes, como antes se ha expuesto; también son de interés el gran número de memoriales impresos referentes a pleitos por la sucesión de mayorazgos. Asimismo, se conservan algunos procesos criminales (legajos 1.175 y 1.558) y otros pleitos de interés para el Derecho Procesal Mercantil (legajos 900,1.175, 1.502 y 1.868). Pero, sin duda, el cúmulo de información juridica más interesante está compuesto por los dictámenes de letrados que asesoraron a la Casa que se conservan en gran cantidad entre los siglos XVI y XX, lo que demuestra cómo los archivos señoriales junto a los municipales son primordiales para el conocimiento de esta fuente jurídica ${ }^{6}$.

Por período cronológicos, puede decirse que prácticamente toda la Historia de España se halla representada en este Archivo, desde la Guerra de Granada hasta la Restauración borbónica, como se podrá apreciar en el listado de documentos curiosos que vamos a transcribir más abajo. Destacan interesantes noticias sobre el caciquismo de ese último período (legajo 1.622) y, en especial, sobre los preámbulos y desarrollo de la Guerra de la Independencia: para los años inmediatamente anteriores a la invasión napoleónica son de gran interés las correspondencias de los distintos títulos desde los Reales Sitios (legajos 1.267, $1.268,1.710,1.711$ y 1.712) y para el desarrollo de la Guerra interesan las numerosas noticias recogidas en las correspondencias de las distintas administraciones, que dan cuenta, en el caso de Jaén, de la ocupación y destrucción causada en esa ciudad por los franceses (legajo 1.319).

Entre los documentos más curiosos, tanto por su posible origen como por su contenido, se destacan los siguientes:

- Libro de protocolos notariales de Madrid (1522-1527). legajo 1.894.

- Memorial genealógico de los Tello de Meneses; libro de 1696 que contiene documentación del linaje desde el siglo XII.

legajo 1.904.

- Residencia de Francisco de Riaño y Gamboa, como gobernador y capitán general de La Habana (1633-1640).

legajo 1.927.

- Pedro A. PorRas: «El letrado de Concejo y la aplicación del Derecho (Jaén, 1476-1523)», Revista de la Facultad de Derecho de la Universidad Complutense de Madrid, LXXIV, 1989. 
- Nombramiento de Catedrático en Decretales en la Universidad de Alcalá de Henares a favor de Pedro Manzano (1666).

legajo 1.525.

- Residencias tomadas a los oficiales de Villanueva de Duero (1628 a 1757).

legajos 1.576 y 1.577.

- Recibos de gastos secretos de orden del Secretario Pedro de Contreras (1623-1628).

legajo 1.893.

- Cuaderno de fotografías de familia (siglo XIX). legajo 1.716.

- Actas y otros documentos del proceso en varias instancias del conde de Guevara con el conde de Bornos por el testamento de la condesa difunta (1915-1916).

legajos $1.501,1.537,1.539$ y 1.704 .

- Relación de pobres que recibieron limosna del Conde de Villariezo (1765-1807). legajo 1.784 .

- Libro de salarios de los trabajadores del trapiche de Motril (1764). legajo 1.440.

- Inventarios de los libros de la biblioteca del Conde (siglos XVI al XIX). legajo 1.176.

- Libro horadado de la Contaduría real sobre juros (XVI). legajo 1.619.

- Pruebas de limpieza de sangre de Francisco Rodríguez de Valcárcel, obispo de Cartagena de Indias (1637). legajo 1.783.

- Memoriales de pleitos por el mayorazgo de Colón, impresos. legajos $1.866,1.867$ y 1.925 .

- Caciquismo en Motril e informe reservado sobre el administrador (1914). legajo 1.622

- Información de testigos sobre la santidad de la madre Mariana de Jesús, de la Merced descalza (1627). legajo 1.831.

También se hallan representadas en este Archivo instituciones como la Inquisición, la Mesta o las Sociedades de Amigos del País; por lo que se refiere a los sellos de documentos, se conservan pocos y en mal estado, 
destacando dos de placa del Maestre de la Orden de San Juan de 1607 y 1608 (legajo 1.525). Los planos también han sufrido especialmente el expolio, conservándose sólo algunos de edificios, bosques, puentes, etc. de los siglos XVIII-XIX. Finalmente, los árboles genealógicos son muy abundantes y se encuentran tanto por separado como cosidos a los distintos memoriales.

\section{RELACIONES CON OTRAS CASAS}

Además de la documentación de los linajes de la Casa de Bornos, se encuentran papeles referentes a otras casas, con las que se pleiteó por la sucesión de algún mayorazgo, con las que se mantuvo correspondencia o se emparentó; también las relaciones pudieron venir por la celebración de compraventas o por el establecimiento de censos.

El listado sería el siguiente:

$\begin{array}{lll}\text { Alba de Liste } & \text { Foncalada } & \text { Peñaflorida } \\ \text { Alcudia } & \text { Frías } & \text { el Real } \\ \text { El Arco } & \text { Fuensalida } & \text { San Gil } \\ \text { Ariza } & \text { Griñón } & \text { San Román } \\ \text { Belveder } & \text { Guevara } & \text { Sardeñola } \\ \text { Bélgicia } & \text { Heredia-Spínola } & \text { Sotomayor } \\ \text { Camarasa } & \text { Jabalquinto } & \text { Torrejón } \\ \text { Castrillo } & \text { Maceda } & \text { Urquijo } \\ \text { Castromonte } & \text { Mondéjar } & \text { Valdefuentes } \\ \text { Colomera } & \text { Montijo } & \text { Valparaíso } \\ \text { Estepa } & \text { Osuna } & \text { Veragua } \\ \text { Falces } & \text { Palazuelos } & \text { Villafranca de Gaytán } \\ \text { Fefiñanes } & \text { Paredes } & \end{array}$




\section{ARBOLES GENEALÓGICOS}

RAMÍREZ DE HARO, CONDES DE BORNOS ?

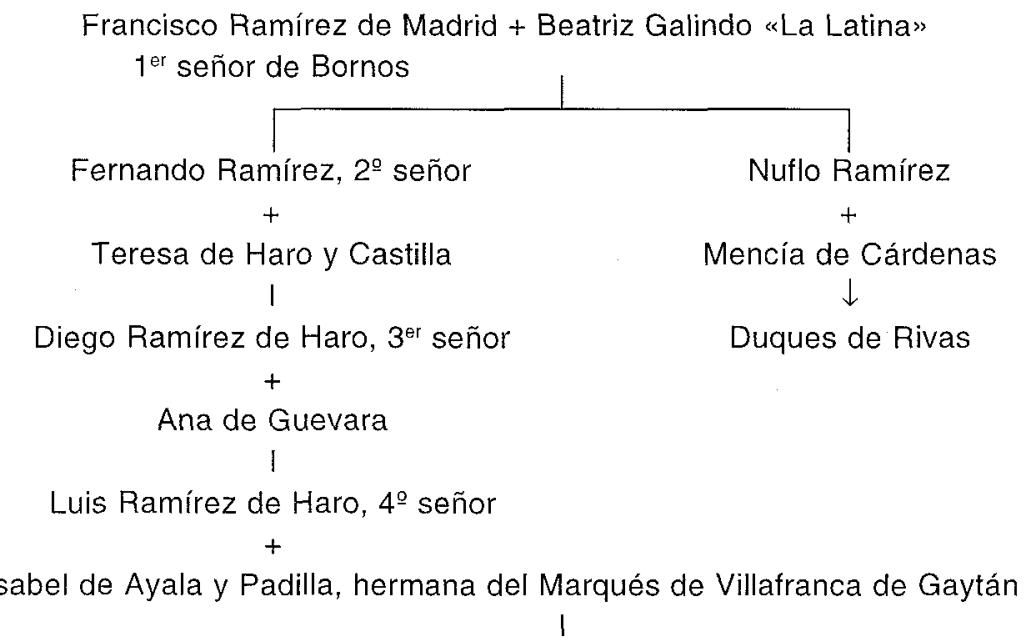

Diego Ramírez de Haro Gaytán de Ayala, Conde de Bornos por Felipe IV en 1642

(fallece sin sucesión, le sucede su hermano)

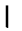

Francisco Ramírez de Haro Gaytán de Ayala, $2^{\circ}$ conde

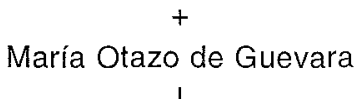

Antonio Ramírez de Haro y Otazo de Guevara, $3^{\text {er }}$ conde

(fallece sin sucesión, le sucede su hermana)

।

Angela Ramírez de Haro y Otazo de Guevara, $4^{\circ}$ conde

Alonso de Losada Pimentel

1

Inés Ramírez de Haro y Losada, $5^{\mathrm{a}}$ condesa

$1 ㅇ+$

7 Estos árboles se han elaborado con datos propios del Archivo y con el diccionario de los Carraffa (Alberto y Arturo GaRCIA CARRAFFA: Diccionario heráldico y genealógico de apellidos españoles y americanos, Madrid, 1956, tomo 75, 7-9 y 25-29). 
Carlos Losada (sin sucesión)

$2^{\circ}+$

Antonio de Córdoba Laso de la Vega

I

Ignacio de Córdoba Ramírez de Haro, $6^{\circ}$ conde

$1^{\circ}+$

Antonia Venegas, $4^{\circ}$ condesa de Luque

$2^{\circ}+$

Isabel María de Córdoba

$3^{\circ}+$

Francisca María Belvís de Moncada

1

Onofre Francisco de Córdoba Ramírez de Haro

$7^{\circ}$ conde de Bornos y $3^{\circ}$ de Montenuevo

(hijo de Isabel María de Córdoba)

$10+$

María Clara de Adsor y Pagés

$2^{\circ}+$

Antonia María Rodríguez de Eván

$10^{\mathrm{a}}$ marquesa de Falces

Joaquín María de Córdoba Adsor Ramírez de Haro, $8^{\circ}$ conde

Josefa Ramírez de Arellano y Olivares

$6^{\circ}$ condesa de Murillo y Peñarrubia

y marquesa de Villacastel

Antonio Ramírez de Haro y Ramírez de Arellano, 9º conde

(muerto sin sucesión, le sucede su hermano)

José María Ramírez de Haro y Ramirez de Arellano, $10^{\circ}$ conde $+$

María Asunción Belvís de Moncada y Rojas marquesa de Villanueva

de Duero y condesa de Villariezo, Villamarciel y Villaverde I

Manuel Jesús Ramírez de Haro y Belvís de Moncada, $11^{\circ}$ conde

María Francisca Crespi de Valldaura

I

María Asunción Ramírez de Haro y Crespí de Valldaura, 12ª condesa (última titular de la línea primogénita, muere soltera en 1915 y le sucede su primo carnal Fernando) 
Fernando Ramírez de Haro Patiño Belvís de Moncada, $13^{\circ}$ conde

Inés Alvarez de Toledo y Caso

1a marquesa de Cazaza

I

Fernando Ramírez de Haro y Alvarez de Toledo, $14^{\circ}$ conde

$+$

María Dolores Pérez de Guzmán y Sanjuán

hija de los duques de T'Serclaes de Tilly

I

Ignacio Fernando Ramírez de Haro y Pérez de Guzmán, actual conde ${ }^{8}$

\section{RAMÍREZ DE ARELLANO, CONDES DE MURILLO ${ }^{9}$}

Juan Ramírez de Arellano, señor de Cameros, Arellano, etc. ricohombre de la época de Juan II y Enrique IV

Isabel Enríquez, hermana del Almirante don Fadrique

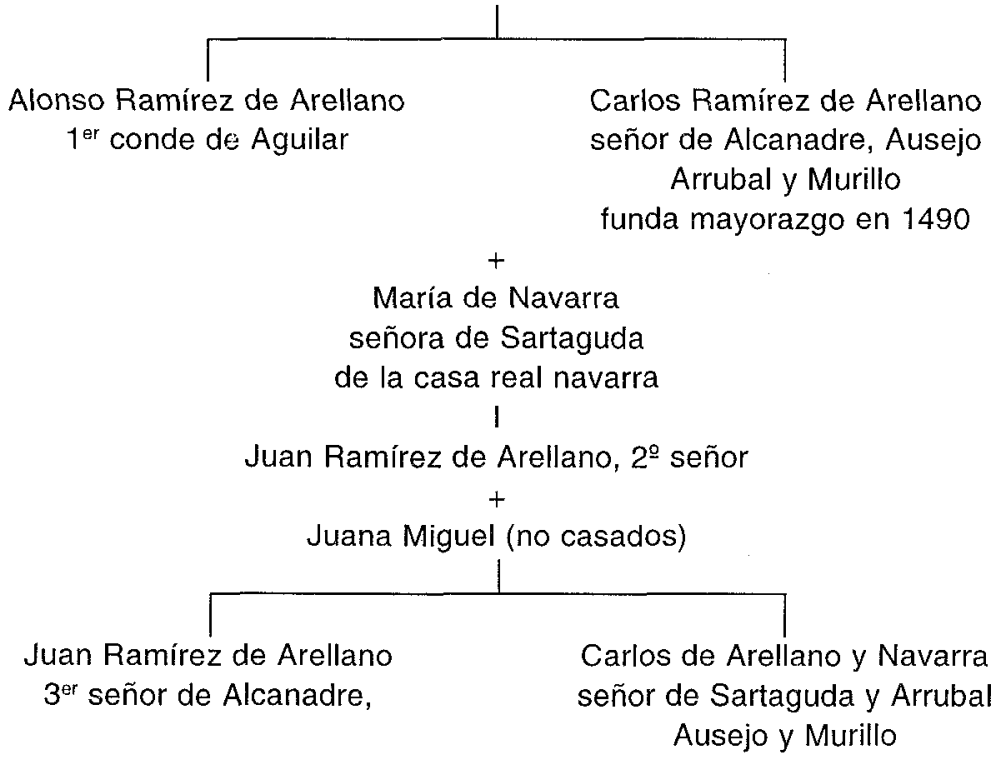

Ausejo y Murillo

8 Según me comunica el actual conde, su hijo mayor es Fernando Ramírez de Haro y Valdés, conde de Murillo, y el hijo mayor de éste, que cuenta con 19 años, es Fernando Ramírez de Haro y Aguirre.

9 CaRRafFA, Madrid, 1923, tomo 11, pp. 18-19 y 30-33. 


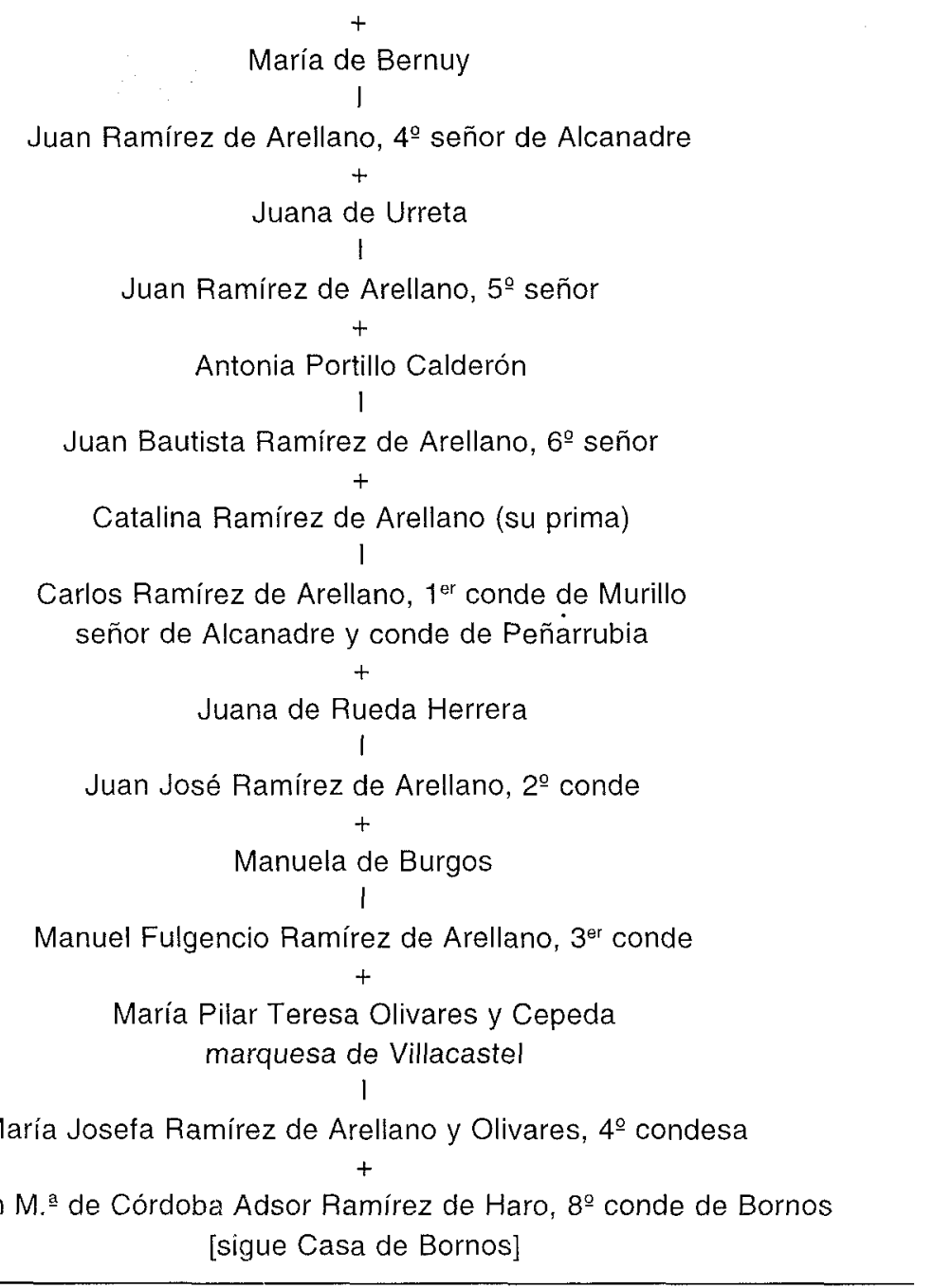

ROJAS-CONTRERAS, MARQUESES DE VILLANUEVA DE DUERO 10

Martín Rojas Manrique

heredado en el Repartimiento de Antequera

$+$

10 Carraffa, Madrid, 1957, tomo 79, pp. 202-203 y 206-208. 


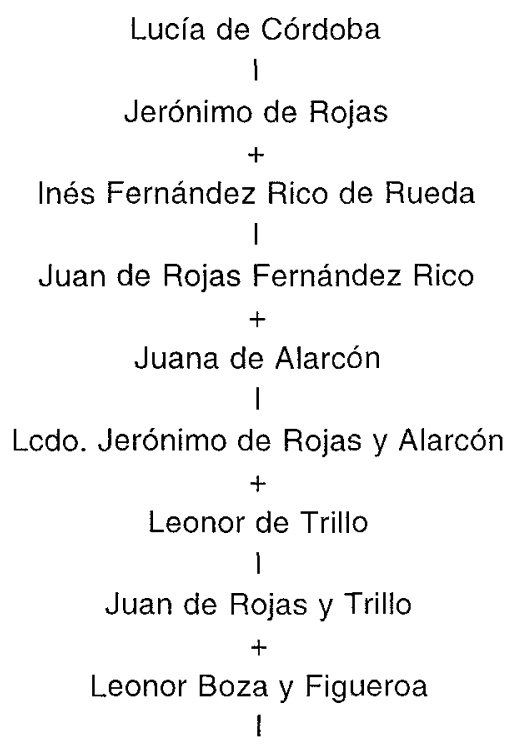

Alonso de Rojas y Boza, señor del Rincón de Herrera y Alimanes $1^{\circ}+$

María Antonia de Rojas Padilla

$2^{\circ}+$

Jerónima Ortega

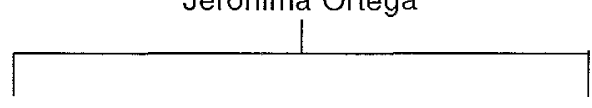

Juan de Rojas Diego de Rojas Ortega Jacinta de Rojas

María de Contreras y Contreras

marquesa de Villanueva de Duero y señora de Villamarciel y otros lugares (hija de Pedro Romualdo de Contreras y de María Ventura de Contreras) I

Pedro de Rojas Contreras marqués de Vva. de Duero

Maria Teresa de Rojas y Robles, su sobrina

Francisco Javier de Rojas, marqués 1

María Asunción Belvis de Moncada y Rojas marquesa de Vva. de Duero 


\title{
OLIVARES, MARQUESES DE VILLACASTEL DE CARRÍAS ${ }^{11}$
}

\author{
Miguel de Olivares \\ $+$ \\ Jerónima Morán \\ I \\ Juan de Olivares y Morán \\ $+$
}

María Ana Brito

(casada en segundas nupcias con Jorge de Bande, dueño de las

fábricas de artillería de Liérganes y La Cavada, que no tuvieron sucesión)

Juan de Olivares y Brito

$+$

Clara de Quevedo

Nicolás de Olivares y Quevedo

Catalina de la Moneda Garay y Hurtado de Mendoza

1

Joaquín de Olivares y de la Moneda

Marqués de Villacastel de Carrias por concesión real de 1709

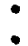

-

María Pilar Teresa Olivares y Cepeda

marquesa de Villacastel

$+$

Manuel Fulgencio Ramírez de

Arellano conde de Murillo

RIAÑO-OROVIO, CONDES DE VILLARIEZO 12

Francisco de Lantadilla y Riaño

$+$

Magdalena de Mazuelo

11 CarrafFa, Madrid, 1949 , tomo 62, pp. 38-39.

12 Carraffa, Madrid, 1956, tomo 66, pp. 8-10. En este mismo diccionario pueden encontra. se genealogías de otros linajes incluidos en la Casa de Bornos: 


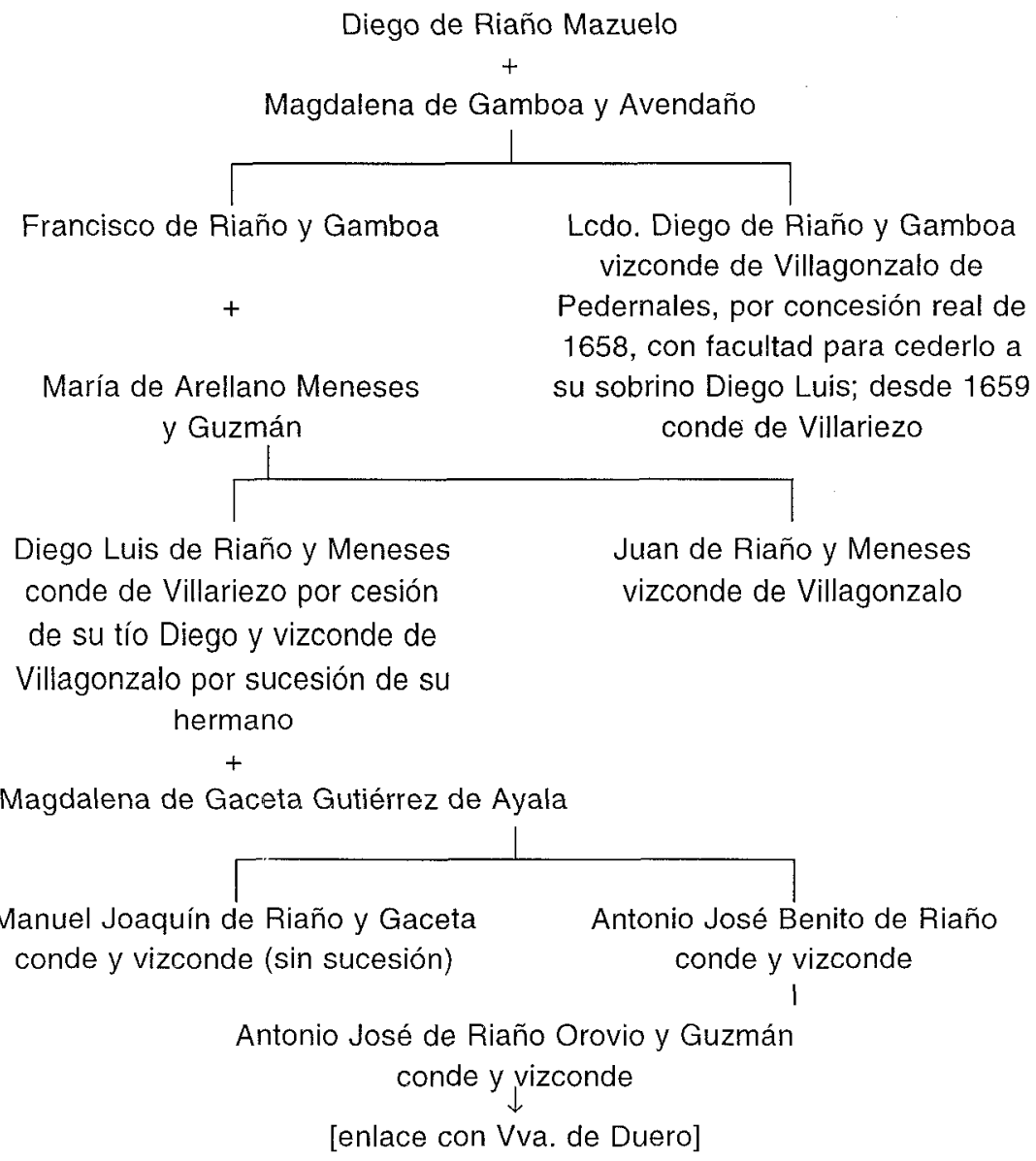

\begin{tabular}{lcc}
\hline \multicolumn{1}{c}{ Apellido } & Año de edición & Tomo \\
\hline - Crespi de Valldaura & 1927 & 25 \\
- Enriquez & 1927 & 25 \\
- Losada & 1934 & 49 \\
- Gaytán de Ayala & 1930 & 34 \\
- Meneses & 1935 & 54 \\
- Tapia & 1961 & 84 \\
- Portillo & 1954 & 72 \\
- Quevedo & 1955 & 73 \\
- Rueda-Herrera & 1958 & 78 \\
- Moneda & 1936 & 56 \\
- Mercado & 1935 & 54 \\
\hline
\end{tabular}


899 - Cuentas de fincas rústicas y urbanas (1931).

- Correspondencia de Motril (XIX).

- Papeles sueltos del Hospital de la Latina (1775-85).

- Pleitos del Edo. de Murillo (XVII).

900 - Papeles de los Mercado, Tello, Menchaca y conde de Villariezo (XVI-XVII).

- Señoríos y alcabalas del señorio de Villamarciel, del Edo. de Villanueva de Duero (XVIII) Sólo las carpetas.

- Pleitos del Edo. de Murillo (XVII).

- Concurso de acreedores de Sebastián Larrauri, regidor y ex-depositario general del concejo de Burgos (Burgos, 9-X-1609). Proceso completo encuadernado.

901 - Pleitos de los Ramírez y los de la Torre (XVI-XIX).

- Obras pías de los de la Torre (XIX).

- Transacciones de los Enríquez (XVII-XVIII).

- Almoneda de bienes de Inés de Oviedo (Coca, 1587).

902 - Documentación del Condado de Guevara (XVI-XVII).

903 - Correspondencia de varias administraciones, Córdoba, Zamora, cabañas, fincas rústicas y urbanas, etc. $(X X)$.

- Compraventa y donación de bienes en Talavera (XVI).

904 - Censos redimidos del Edo. de Peñarrubia (XVI-XIX).

- Cartas de pago del Edo. de Peñarrubia (XVII).

- El cabildo de la Catedral de Segovia da a censo a Aseito el Moro Calderero, vecino de Segovia, unas casas en el Berrocal contra el pago de 145 mrs. y 2 gallinas anuales (1439, abril 29. Segovia). Original en pergamino y transcripción moderna.

1142 - Documentos sobre Ausejo, del Conde de Murillo (1780-1791).

1143 - Correspondencia sobre Burgos (1770-1902).

1144 - Documentos diversos mezclados: políticos de la Restauración; administrativos de Cambil (1925), etc.

1145 - Cuentas de las fincas rústicas y urbanas en Madrid (XIX).

1146 - Censos sobre diversas casas en Madrid (XVIII-XIX).

- Documentos judiciales del Conde de Villaverde (XVII-XVIII)

- Correspondencia varia (XVIII-XIX).

1147 - Correspondencia de Segovia (1820-1847).

1148 - Correspondencia de Segovia (1798-1819).

1149 - Cuentas del Lavadero de Rojas (1917-1918).

1150 - Cuentas de cabaña (1829-30).

- Papeles del fallecimiento de don José Ramírez de Haro (1834).

- Bienes matrimoniales del Edo. de Villanueva de Duero (XVIII).

1151 - Cuentas del Hospital de la Latina (XVIII).

- Arrendamientos de la Abadía de Rueda (XIX).

1152 - Patrones de bordados.

- Correspondencia suelta (XVIII).

- Poderes de los Salcedo (XVIII-XIX). 
1153 - Correspondencia del conde don Onofre Francisco Ramírez de Haro desde Pampiona (XVIII).

1154 - Cuentas de Valmaseda (1773-1878).

- Correspondencia de Talavera (1816-26).

1155 - Correspondencia de Talavera (1826-40).

1156 - Correspondencia de Talavera (1841-54).

1157 - Cuentas deTalavera (1803-41).

1158 - Cuentas de Talavera (1787-1802).

- Correspondencia diversa: Hospital de la Latina (1837), con el mayordomo y el contador de Madrid y del Lavadero de Rojas (1837).

- Justificantes de caja (1919).

1159 - Cuentas y expedientes de Torrelobatón, Tordesillas, etc. (XIX).

1160 - Correspondencia de Segovia (1788-97).

- Cuentas de Bornos (1891).

1161 - Correspondencia de Segovia (1637-1775).

1162 - Cuentas de esquileo (1834-35).

- Correspondencia de Motril (1785).

1163 - Correspondencia y cuentas de Villanueva de Duero (1748-53).

1164 - Correspondencia de Sepúlveda (1766-1850).

1165 - Cuentas de cabañas (1825-26).

- Documentos del Edo. de Murillo, en especial de la Abadía de Rueda (XVIXVIII).

1166 - Arrendamientos de la Pradera de San Isidro, en especial de su lavadero de ropa, $y$ de fincas urbanas en Madrid (XVIII-XIX).

- Documentos judiciales del Edo. de Villanueva de Duero (XVII). [documentos de los Contreras de Jaén].

1167 - Cuentas de la casa de Bornos (1842-46).

- Memorias de las rentas de doña Mencía Suárez, en Talavera (1862-1900).

1168 - Memorias de las rentas de doña Mencía Suárez, en Talavera (18271961).

1169 - Correspondencia de la Condesa de Bornos (1856-57).

- Documentos judiciales de los Ramírez (XV-XIX).

- Documentos de fundaciones del Edo. de Villariezo (XVII).

1170 - Arrendamientos rústicos, en especial de Medina del Campo y Torrelobatón (XVI-XIX).

- Documentos de cuentas y papeles del Hospital de la Latina (XVIII). Un memorial de 1767 sobre los documentos de la fundación y rentas del Hospital.

- Documentos de fundaciones clel Edo. de Villariezo (XVII-XIX).

1171 - Fundaciones del Edo. de Villariezo (XVII).

- Cuentas de Villanueva de Duero (XVI-XVIII).

- Testamentarías del Edo. de Villanueva de Duero y Villariezo (1848-52).

- Memoriales ajustados de los Ramírez.

1172 - Herencia de Bornos (1912).

- Índice del antiguo legajo 14 de Ramírez, sobre títulos de propiedad posteriores a la desvinculación. 
- Cartas de pago de varios Edos. (XVI-XVIII).

- Sentencias de los Ramírez (XVI-XVIII).

- Testamentarías de Bornos (1813 y 1819).

1173 - Árbol genealógico de los Olivares-Brito.

- Testamentarías de los Ramírez (XIX).

1174 - Testamentarías de los Ramírez (XIX).

- Copias de documentos del Edo. de Villariezo (XVI).

1175 - Testamentos del Edo. de Villanueva de Duero (1766).

- Pleitos de los Salcedo (XVII-XVIII).

- Pleito criminal por concurso de acreedores, particiones y posesiones de linajes diversos (XVI-XVII).

- Fundaciones del Edo. de Villariezo: un memorial sobre los mayorazgos que poseía el conde (XVIII).

1176 - Apeos del Edo. de Villanueva de Duero, en Medina del Campo y Tordesillas (XV-XVIII).

- Documentos de los Meneses y los Tapia (XVII).

- Breve de Urbano VIII a María Suárez de Guzmán (1631).

- Inventario de biblioteca del Conde (XVI-XIX).

- Índice del antiguo legajo del Edo. de Villanueva de Duero (XV|I-XV|II).

- Testamentos, ejecuciones y sentencias varias (XVII y XIX).

1177 - Pleito de Hacienda (Burgos, 1661).

- Amojonamientos del Edo. de Villanueva de Duero, de Toledo (XIX).

- Mayorazgos del Edo. de Villariezo, con genealogías (XVI).

1178 - Arrendamientos en Motril (XVI-XVII).

- Papeles del mayorazgo de Pedro de Robles, fundado en 1530, manuscritos e impresos, con genealogías (XVI-XVIII).

- Memoriales del pleito del Conde de Murillo con el marqués de Sardeñola sobre el mayorazgo de Butrón, fundado en 1449 (XVIII). Muchos ejemplares impresos.

- Ídem en segunda suplicación (XVIII).

- índice del antiguo legajo 2 de Murillo, sobre el mayorazgo de Butrón (XVXVIII).

1179 - Pleitos del mayorazgo de Trasmiera y otros del Edo. de Villanueva de Duero (XVII-XVIII).

- Arrendamientos de los Ramírez, en Motril, Bornos y Bates el Viejo (XVIXVIl).

1180 - Documentos diversos de Marchamalo, Trasmiera y Villariezo (XVII).

- Testamentaría de Carlos Ramírez de Arellano (XVII).

- Índice del antiguo legajo 23 de Ramírez, de arrendamientos (XVI-XVIII).

- Arrendamientos de tierras en la Algaida (Motril, 1600).

- Arrendamientos del Edo. de Murillo (XVIII-XIX).

- Capitulaciones matrimoniales del Edo. de Murillo (XV-XVIII).

- Carta de dote de Murillo (1564).

1181 - Papeles de contaduría de Bornos (XIX).

1182 - Papeles de varias administraciones, en especial de Salinas de Añana y Miranda de Ebro (XIX). 
1183 - Cuentas de pagaduría (1878).

1184 - Apeos de tierras en Almenara, mayorazgo de los Mercado, del Edo. de Villariezo (XV-XVIII). Muchos documentos del siglo XV. Planta de una casa en Almenara.

- Cartas dotales de los Helguero, Olivares y Herrera (XVIII).

- Capitulaciones matrimoniales de los Salcedo, Cepeda y Bande (XVII-XVIII).

- Tasación de 3 casas en Madrid, en la Plazuela de Antón Martín, en la calle Alcalá y en la de las Torres (1771). Sin planos.

1185 - Arrendamientos de los Olivares (XVII-XVIII).

- Redención de censos de los Olivares (XVII-XVIII).

- Relación de bienes del Edo. de Murillo en Medina del Campo y Torrelobatón (XVIII-XIX).

- Índice del antiguo legajo 6 de los Ramírez, sobre herencias e inventarios.

1186 - Fianzas del Edo. de Villanueva de Duero (XVII-XIX).

- Hijuelas de los de la Torre, en Torrelobatón (XVI-XVII).

- Juros de los Olivares (XVI-XVII).

- Censos sobre Liérganes (XVIII).

- Títulos de propiedad de los Ramírez (XV-XVI).

1187 - Compraventas, permutas y testamentos de los de la Torre, en Medina del Campo y Torrelobatón (XVI-XVII).

- Documentos de los Guevara (XVII).

- Cuentas de 1860.

- Relaciones de fincas sueltas.

1188 - Censos contra los Perea, y sus herederos, los Olivares (XVI-XVII).

- Fundación del Edo. de Villanueva de Duero (1613-65); un libro que falta.

- Amojonamiento de bienes de Villariezo, en Olmedo (1511-1825).

1189 - Censos de los Ramírez vinculados en Motril (XVIII-XIX).

1190 - Censos de los Ramirez vinculados en Motril (XVIII).

- Cuentas del Hospital de la Latina (1853).

- Cuenta de las obras hechas en el Hospital de la Latina, bajo la dirección del arquitecto Antonio Herrera de la Calle (1853). Sin planos.

- Apeos de distintas heredades del Edo. de Villariezo (XVI-XVIII).

- Planos de Talavera: dos plantas coloreadas de la casa principal en la c/. Empedrada, y un plano de la dehesa Espinosillo (XVIII).

- Testamento de Luisa de Villamartín, en Medina del Campo (1599).

1191 - Cuentas y correspondencia de cabañas y mayoral (1830-31).

- Correspondencia de Arévalo (1866).

- Correspondencia de Reinosa, Calzada de Calatrava, Canarias y Guadalajara (XVIII).

- Expediente de venta de casa en Almodóvar del Campo (1900).

1192 - Cuentas de las memorias de don Antonio Meneses, en Talavera, para dotación de huérfanas (1882-1900).

1193 - Cuentas de las memorias de don Antonio Meneses, en Talavera (18871892).

- Cuentas de don Francisco Oliver al conde de Bornos por sus mayorazgos (1729-32). 
1194 - Cuentas de don Francisco Oliver (1733-44).

1195 - Cuentas del Hospital de la Latina (1786-88).

- Justificantes de caja (1928).

- Cuentas de Bornos (1898).

1196 - Cuentas del Tomilloso (1845-71).

1197 - Cuentas del Tomilloso y Bodegón (1872-82).

1198 - Cuentas de Motril (1779-82).

1199 - Cuentas de Motril (1776-79).

1200 - Arrendamientos en Talavera de la Reina (XVI-XIX).

- Documentos judiciales, Torrelobatón (XVII).

- Poderes, Burgos (XIX).

1201 - Poderes del Conde de Villariezo y de Foncalada (XVII-XIX).

- Cuentas de Cambil (XX).

- Documentos judiciales del Edo. de Villaverde (XVI-XVII).

1202 - Documentos judiciales y poderes del Conde de Villaverde, Murillo y Peñarrubia (XVI-XIX).

1203 - Pleitos de los Condes de Peñarrubia (XVII-XVIII).

- Mandamientos judiciales de Guevara y Peñarrubia (XVII-XVIII).

- Concordias de Guevara y Peñarrubia (XVII-XVIII).

1204 - Tomas de posesión del Edo. de Villariezo (XVII-XVIII).

- Índice del antiguo legajo 4 del mayorazgo de los de la Moneda y Lerma, del condado de Murillo (XVI-XIX).

- Poderes de Bornos (XIX).

- Papeles de pleitos (Burgos, XVII y XIX).

- Papeles de los Ramírez, de consignación de viudedades y alimentos (XVI$\mathrm{XIX).}$

1205 - Tomas de posesión del Edo. de Villariezo (XVI-XVIII).

- Compraventas en Torrelobatón, Medina del Campo y Villalón (XVI). En gran número.

1206 - Censos del mayorazgo de Pérez, en Guadalajara (XVI-XVII).

- Compraventas en Torrelobatón (XVI).

- Papeles varios (XVII).

1207 - Censos del mayorazgo de Pérez, en Guadalajara (XVI).

- Compraventas en Torrelobatón (XVI).

1208 - Censos de casas en Madrid (XIX).

- Cuentas de la reparación de los lavaderos de la Pradera de San Isidro (1868-70).

1209 - Reales despachos (comienzos del XIX).

- Solicitud de la Cruz de San Fernando (1816).

- Cuentas de Motril (1902).

- Cuentas de casas en Madrid (1831-32).

- Cuentas de la demolición y reedificación de las casas de la c/. Santiago, no 18 , Madrid, por José Rodrigo de Vilches (1830-32). Sin planos.

1210 - Cuentas de fincas urbanas en Madrid (1915).

- Correspondencia de Talavera (1861-70). 
1211 - Cuentas de Alcanadre (1895-1902).

- Correspondencia de Talavera (1871-79).

- Papeles del Hospital de la Latina (1871)

1212 - Censos de la memoria de doña Alberta Barranco contra el duque de Veragua $(X \mid X)$.

- Otros papeles de la administración de Salinas de Añana (XIX).

- Papeles de la administración de la Abadía de Rueda (XIX).

1213 - Cuentas de Bornos (1873).

- Cuentas de esquileo (1895).

- Cuentas de inquilinato de una tienda en la Plazuela de la Cebada (1872).

1214 - Cuentas de pagaduría (1877).

1215 - Cuentas de Logroño (1806-31).

1216 - Cuentas de Logroño (1830-53).

- Papeles de la administración de Motril (XIX): expediente de demolición por el ayuntamiento en 1877 de la casa de la c/. Espadero, $n^{\circ} 2$, del Edo. de Bornos, con pequeño plano de situación.

1217 - Correspondencia del Tomilloso y Abadía de Rueda (XIX).

1218 - Cuentas de Bornos (1893).

- Presupuestos de gastos mensuales (1837-47).

1219 - Cuentas de la Huerta de Atocha (1809-12).

- Gastos del marqués de Villanueva de Duero (1781-1819).

1220 - Cuentas de Bornos (1902).

- Justificantes de caja (1919).

- Expediente de construcción de una almazara en Cambil (1879), con catálogo impreso de ingenios de la fábrica Piferrer, de Barcelona.

1221 - Cuentas de varios tesoreros de Bornos (1702-07).

1222 - Cuentas de fincas urbanas (1917).

- Justificantes de caja (1921).

- Cuentas de cabañas y portazgos y correspondencia varia (XIX).

1223 - Correspondencia y cuentas mezcladas de dehesas (del Tomilloso y Matanzas (Toledo), de cabañas, de fincas urbanas (XIX) y del Hospital de la Latina (1866).

1224 - Papeles de Mesta y ganaderos (1825-47).

- Correspondencia con Jacobo Sarjent, desde Granada y Sevilla (1800-20).

1225 - Correspondencia de la administración de Alerre (1844-1900).

1226 - Historia de los valores en papel del Estado, de Bornos (1809-78).

- Acciones del banco de San Fernando (1814-53).

- Vales reales (1804-36).

- Acciones de la Real Compañia de Toledo (XVIII).

- Diezmos (1816-78).

- Liquidaciones de efectos de Bornos contra Madrid (1813-79).

- Sueldos atrasados y viudedades (1821-35).

1227 - Correspondencia de Talavera (1800-08 y 1814-15).

1228 - Cuentas del Lavadero de Rojas (1920).

- Papeles hallados en el Lavadero (1853): varias cartas y noticias, sonetos y décimas y bulas papales (XIX). 
1229 - Papeles de los Villegas, en la Puebla de Sancho Pérez (XVII-XVIII).

1230 - Papeles de la Puebla de Sancho Pérez (XVI-XIX).

1231 - Cuentas de la Huerta de Atocha (1799-1804).

- Cuentas de Reinosa (1915).

- Justificantes de caja (1917).

1232 - Presupuesto de Bornos (1856).

- Empréstitos de Bornos, en Almodóvar y Abadía de Rueda (1879).

1233 - Censos de varios mayorazgos extremeños, heredados por el conde de Tilly (XVII-XVIII).

1234 - Cuentas de fincas urbanas (1912).

- Cuentas de Cambil (1905).

- Correspondencia de Olmedo (1841-91).

1235 - Cuentas de caja de Bornos (1872).

1236 - Arrendamientos y testamentarías de los Ramírez (XV-XIX).

1237 1) - Arrendamientos de Ramírez en Motril (1601-07).

- Noticias y genealogías de varios apellidos: Rojas, Moreno, Castrillo y Mitarte.

- Memorial impreso con genealogía, de petición de Grandeza por Francisco Javier de Rojas y Hierro, marqués de Villanueva de Duero (1783). Dos ejemplares.

2) - Relación de escudos de armas de los Rojas, Contreras, etc

- Noticias genealógicas de los Contreras de Castilla la Vieja y de Jaén.

1238 - Papeles sueltos (documentos y mapa militar del XIX).

- Arrendamientos de los Ramírez en Motril (XVI-XVII).

1239 - Cuentas varias de Bornos (1860-66).

- Documentos de Talavera (1421) y Arévalo (XVI).

- Títulos de propiedad de fincas de los Enríquez (XVII-XVIII).

- Pleito en Mazuelo de Cardemuño (Burgos, 1524).

- Cuentas modernas de los Contreras (XVII-XVIII).

1240 - Fundación de colegio de jesuitas en Arévalo por el comendador Fernando Tello (1777).

- Requerimiento (Burgos, 1537).

- Ejecutoria a favor de Gómez de Quintanadueñas, vecino de Burgos, contra el concejo de Villariezo por un censo (1549-1616).

- Entrada de caudales del Edo. de Villariezo (1859).

- Leonor Gómez de Quintanadueñas compra calleja entre huertos en Villariezo (1502).

- Obras pías de María Tello, hermana del comendador Fernando Tello, incluyendo libro en pergamino con donación del comendador (1590).

1241 - Indice del antiguo legajo 33 de Ramírez, de asuntos judiciales (XVIII).

- Asuntos judiciales de los Ramírez (XVIII).

- Poderes de los Olivares (XVII-XVIII).

- Bienes de los Herrera (1680).

- Ventas de los Olivares (1661-1737).

- Aniversarios de los Moneda (XVIII). 
- Compras de los Brito-Bande (1649).

- Obras pias de los Brito-Bande (1646-71), incluyendo dictámenes de letrados sobre la dotación de estudios de Gramática en los jesuitas de Santander por Jorge de Bande (1671).

- Patronatos de Herrera, Olivares, Brito, etc. en Santander (XVII-XVIII).

- Capellanías de los Olivares y Bande (XVII-XVIII).

1242 - Censos de los Enríquez (XVIII).

- Documentos judiciales de los Ramírez (XVIII).

- Certificado de los arquitectos Colubí y Guallart sobre la casa de la Plaza de la Cebada (1867). Un plano de situación.

1243 - Reales cédulas de los Olivares (1644).

- Informaciones judiciales de los Olivares (1617).

- Cartas de pago de Villacastel (XVIII).

- Pleitos de Liérganes y La Cavada (XVIII-XIX).

- Pleito de la marquesa de Villacastel y condesa viuda de Murillo con el conde de Colomera sobre los bienes de la madre de ambos (1793). Impreso.

- Otro prontuario impreso de los Olivares (XVIII).

- Documentos del Edo. de Villaverde (XV-XVIII), sobre dotes, testamentos y peticiones, con índice antiguo (XIV-XVII).

1244 - Disposiciones testamentarias y vínculos del Edo. de Villanueva de Duero (XVII-XIX).

- Censos del Edo. de Murillo, en Logroño (XVI-XVII).

1245 - Pleitos de los Dávila, Tello, Villacastel y otros linajes (XVI-XVII), con un dictamen.

- Títulos de propiedad de los Enríquez (XVIII).

1246 - Testamentos del Edo. de Villanueva de Duero (XVIII).

- Títulos de propiedad de la Abadía de Rueda (XV-XVI).

1247 - Papeles de las memorias de doña Alberta Barrales, de la administración de Burgos (XIX).

1248 - Cuentas de Almonacid (1758-84).

- Mayorazgo de los Enríquez (1693). Un libro.

- Otro mayorazgo de Enríquez (1641).

- Pagos por las obras hechas en Mazalquivir (1566) y otros documentos de los Portillo, emparentados con los Ramírez de Arellano (XVI-XVIII).

- Provisión de la Chancillería de Valladolid a favor de los de la Moneda (1779).

- Compraventas en Cabanillas (Guadalajara, XVI-XVII).

- Mayorazgos de los Pérez, en Guadalajara (XVI-XVII).

1249 - Mayorazgos de los Enríquez (XVI-XVII).

- Documentos varios de Burgos y del Edo. de Villariezo (XVIII).

- Testamentos mezclados de Mercado, Carvajal, León, Quiñones, etc. y otros en Talavera y Sevilla (XVI).

- Posesiones de mayorazgos por Bornos y Murillo (XVIII-XIX): en 1780 el conde de Murillo toma posesión de los mayorazgos de su tía Vicenta Antonia de la Moneda y Temiño. 
1250 - Mayorazgos de los Enríquez (1522).

- Pleitos en Gamonal y otros lugares de Burgos, sacados del Archivo de Simancas (XVII).

- Árbol genealógico de los Ramírez de Guzmán y Meneses.

- Testamentos de los Tello, en Arévalo (XV-XVII).

- Censos a favor de Bornos (XVIII-XIX): uno de 1751, de Joaquín Olivares, marqués de Villacastel, contra el marqués de Ariza en sus Edos. de Santa Eufemia y La Guardia, con dictámenes.

- Índice del antiguo legajo 27 de los Ramírez, sobre censos en Motril (XVXVIII).

1251 - Matrimonios del Edo. de Villanueva de Duero (XVI-XIX): en 1814 el marqués de Villanueva para casar a su hija María Asunción Belvís de Moncada y Rojas, condesa de Viliamarciel, con José Ramírez de Haro y Ramírez de Arellano, conde de Bornos.

- Bautismos y confirmaciones del Edo. de Villanueva de Duero (XVIII).

- Censos en contra del Edo. de Villanueva de Duero (1781-1840). Sin el documento.

- Posesiones y apeos de los Ramírez (XV-XVI).

1252 - Indice del antiguo legajo 20 de los Ramírez, sobre tomas de posesión; incluye los documentos del legajo anterior y algunos más en éste, aunque falta documento de 1475 .

- Méritos y servicios de los Ramírez y Adsor.

- Censos en contra del Edo. de Villanueva de Duero, en Medina del Campo, Segovia y Talavera (XVI-XVIII).

1253 - Correspondencia moderna suelta (XIX).

- Bautismos y confirmaciones del Edo. de Villanueva de Duero (XVII-XVIII), con índice del antiguo legajo 1 de Villanueva de Duero.

- Censos de la encomienda de Fuente de Cantos (1781).

- Documentos de las Salinas de Trafalcací (1492-1861).

1254 - Correspondencia de Talavera (1733-97).

1255 - Correspondencia de Talavera (1798).

- Correspondencia del Conde de Bornos (1871-93).

1256 - Cuentas de cabañas (1793-99).

- Cuentas del mayorazgo de los Losada (1590 y 1705-1802).

1257 - Correspondencia diversa: del Tomilloso, Tordesillas, Toledo, cabañas, etc., mezclada (XIX).

1258 - Correspondencia de cabañas y del Tomilloso (XIX).

- Rentas de los Ramírez (1530-34).

1259 - Recados y recibos de los Tello, en Ávila (XVII-XVIII).

- Justificantes de caja (1925 y 1929).

1260 - Correspondencia de las dehesas del Valle de Alcudia, Edo. de Villanueva de Duero (XIX).

- Correspondencia, cuentas e invitaciones a la boda del Conde de Bornos y Murillo, hermano del Conde de Villamarciel, con Juana Caamaño Pardo de Figueroa, primogénita de los Condes de Maceda y Fefiñanes (181926). Otras bodas contemporáneas. 
1261 - Cuentas de las casas de Madrid (1813-18).

- Órdenes y decretos de Bornos para sus empleados en contaduría y secretaría (1802-27).

1262 - Cuentas de Ávila, de la capellanía de Pedro Dávila (1835-80).

1263 - Correspondencia de Arévalo (1865-90).

- Cuentas de Loja, del Edo. de Villariezo (1802-13).

1264 - Cuentas de la memoria de don Antonio Meneses, en Talavera (1869-81).

1265 - Cuentas de la memoria de don Antonio Meneses, en Talavera (1850-68).

1266 - Cuentas de Logroño (1883-1902).

1267 - Correspondencia del Conde de Bornos con don Cayetano Montes, desde Aranjuez, El Escorial y San lidefonso (1805-07).

1268 - Correspondencia del Conde de Bornos con don Cayetano Montes, desde Aranjuez, El Escorial y San lldefonso (1803-05).

1269 - Correspondencia de Toledo y Lavadero de Rojas (1821-40).

1270 - Correspondencia de Toledo y Lavadero de Rojas (1841-50).

1271 - Correspondencia desde Santiago y La Coruña (1710-19 y 1795).

- Correspondencia de distintas administraciones (Olmedo, Motril, Lavadero, etc.) $(X X)$.

1272 - Correspondencia de la Huerta de Atocha (1819-40).

- Cuentas de esquileo (1882).

- Cuentas de fincas urbanas (1920).

- Correspondencia mezclada de varias administraciones (XIX).

1273 - Cuentas y correspondencia mezcladas (esquileo, Lavadero de Rojas, fincas urbanas en Madrid, préstamos, etc.) (XIX-XX).

1274 - Cuentas de fincas urbanas en Madrid (1889-92).

1275 - Cuentas de fincas urbanas en Madrid (1887-91).

1276 - Compraventas de la Abadía de Rueda (XVI).

- Concordia entre el Conde de Murillo y el lugar de Campo, confirmada por la Chancilleria de Valladolid (1774).

1277 - Cuentas contra el mayorazgo de los de la Torre, en Torrelobatón (XVII$X(X)$.

- Pleitos del Edo. de Villanueva de Duero (XVII).

- Permutas entre el Condestable y Francisco Sarmiento (XV-XVI).

- Censos a favor de la Abadía de Rueda (XV-XVI)

- Censos a favor de los de la Torre (XVI-XVII).

- Posesiones de los Andino-Torre (XVII).

1278 - Fundaciones de mayorazgos, de Butrón, Velasco, etc. (XV).

- Apeos de los de la Torre (XVI).

- Redenciones de censos de los de la Torre (XV|-XVII), en Medina del Campo, Torrelobatón y Valladolid.

- Certificados de los Condes de Peñarrubia (XVII-XVIII).

- Dos bulas a favor de los Téllez Girón (XVI). Falta una.

- Dictámenes de letrados de los Guevara (XVII-XIX).

- Pleito del Conde de Murillo (1780).

- Papeles genealógicos del mayorazgo de Velasco y Butrón (XVIII), con una pequeña historia del mismo. 
1279 - Compraventas de fincas rústicas y urbanas en Talavera, por los Ledesma (XVI-XVII), del Edo. de Murillo.

1280 - Cuentas del Lavadero de Rojas (1842-50).

1281 - Cuentas del Lavadero de Rojas (1835-41).

1282 - Cuentas de Tordesilias (1730-86).

1283 - Cuentas de Tordesillas (1616-1729).

1284 - Pleito entre el marqués de Villanueva de Duero con el marqués de Castrillo (Burgos, 1790-91).

- Ejecutoria a favor del Conde de Villariezo contra el conde de Villafranca de Gaytán (Madrid, 1788).

- Cuentas de Granada (de la casa de la c/. Reñidero de Gallos, de la Condesa de Bornos) (1825-78).

1285 - Libro-registro de los censos y sus detentadores de Bornos en Motril (1591-1730).

- Censos de los Ramírez en Motril (XVI).

1286 - Cuentas del Hospital de la Latina (1827).

- Correspondencia sobre Mariano Negrete (Madrid, 1843-60)

- Toma de posesión de casas en Talavera, del mayorazgo de Pedro Suárez de Meneses (1777), con plano coloreado y tabla explicativa.

- Documentos judiciales del Edo. de Villariezo sobre bienes en Talavera (XVI y XVIII), con varios dictámenes del XVIII.

- Pleito del Conde de Villariezo Antonio José Riaño Osorio Carvajal Toledo y Meneses con el Monasterio de las Huelgas sobre los diezmos de Tardajos (Burgos, 1787).

1287 - Cuentas del Hospital de la Latina (1824-25).

- Asuntos judiciales del Edo. de Villariezo (XVIII).

- Patronatos y capellanías, y cartas de pago de los Ramírez (XVI-XIX).

- Índice del antiguo legajo 19 de los Ramírez, sobre patronatos y capellanías.

1288 - Documentos judiciales del Edo. de Villariezo (XVI-XVIII).

- Censos y otros documentos de los Portillo de Valladolid (XV1).

- Cuentas de Segovia (1825).

- Fundaciones de mayorazgo de los Ramírez (XV-XVI). Faltan los originales.

1289 - Patronates y bulas de los Ramírez (XV-XIX).

- Indice del antiguo legajo 2 del Edo. de Murillo, sobre el mayorazgo de Quevedo (XVI-XVIII).

- Documentos judiciales del Edo. de Villaverde (XV-XVIII).

1290 - Censos redimidos de los Quevedo (XVI-XVII).

- Apeo de bienes en Reinosa (1881).

- Documentos judiciales del Edo. de Villaverde (XVIII).

- Documentos del Hospital de la Latina (XV-XIX).

1291 - Cartas de pago de los Portillo (XVI-XVII).

- Papeles de las memorias de Antonio Meneses, en Talavera (XVI-XIX).

- Poderes de los Portillo (XVI) y demás documentación familiar de ese linaje en Valladolid (XVI-XVII).

- Índice del antiguo legajo 6 del Edo. de Villaverde (XV-XVIII).

- Dictamenes (XVIII).

- Poderes de los Rojas Contreras (XVIII). 
1292 - Cuentas de Logroño (1781-1814).

1293 - Cuentas de Logroño (1616-1780).

1294 - Cuentas de Motril (1758-63).

1295 - Cuentas de Valdenarros (capellanía del Burgo de Osma) (1850-1901).

- Correspondencia de Villarrrubio (XVIII).

- Testamentarías (1848-54).

1296 - Papeles de los Tello (XV-XVII).

- Inventarios de documentos de los Salcedo y marqueses de Villacastel (XVIII).

- Relaciones de fincas de los Salcedo (XVIII-XIX).

- Índice del antiguo legajo 25 de los Ramírez, sobre arrendamientos en Cambil y Madrid (XVI-XIX).

- Algunos de los arrendamientos de los Ramírez (XIX).

- Poderes de los Salcedo (XVIII).

- Apeos del Edo. de Villariezo (XIX).

1297 - Testamentos de los Olivares y Herrera (XVII-XVIII).

- Testamento de María Pilar Teresa Olivares y Cepeda, condesa viuda de Murillo y marquesa de Villacastel (1800) y otras diligencias.

- Pleito de los Losada (1589).

- Capitulaciones matrimoniales de los Tello (XV-XVIII).

1298 - Informaciones judiciales de los de la Torre, en Medina del Campo (XVIXVII).

- Requerimientos de los de la Torre (XV-XVIII).

- Apeos en Torrelobatón y otros pueblos (1787).

- Pleito de Losada (1580-83).

- Fundaciones del Edo. de Villariezo (1713).

- Arrendamientos de los Olivares (XVIII).

- Pleito de Alonso de Ávila (1573).

- Cuentas de tutela y embargo de los Tapia, de Arévalo (1573-78).

- Apeos de fincas rústicas y urbanas en Cañizar (Guadalajara) del mayorazgo de Sanz del Barranco (XVIII-XIX); planos de todas ellas, por Pedro Vidal en 1881.

- Vinculos de los Moneda (XVI-XVIII).

- Árboles genealógicos de los Coronel.

1299 - Índice del antiguo legajo 38 del Edo. de Villariezo, sobre resguardos y cartas de pago (XVI-XVIII). Siguen las copias de los documentos.

- Censos en contra en Ávila, del Edo. de Villariezo (XVI).

1300 - Documentos judiciales de Alcanadre, señorio de los Ramírez de Arellano, condes de Murillo (XVI-XIX). [un traslado de carta del Rey de Navarra de 1392].

- Documentos judiciales sobre Cambil, Motril y otros (XVI-XIX), según el índice incluido en el legajo moderno 1301.

- Documentos judiciales de los Ramírez sobre diversos lugares (XVI-XIX).

1301 - Índice del antiguo legajo 35 (éste en cuestión).

- Documentos judiciales de Bornos (XV|-X|X). Incluye buen número de dictámenes de letrados, sobre todo del XIX. 
1302 - Escrituras y documentos judiciales de los Ramírez de Arellano, señores de Murillo (XV-XVIII).

1303 - Documentos de la administración de Segovia (1887).

- Cuentas de Motril (1755-1757).

1304 - Cuentas de Motril (1745-1754).

1305 - Cuentas de pagaduría (1883).

- Correspondencia sobre el Lavadero de Rojas (1835).

1306 - Cuentas de Tordesillas (1844-1869).

1307 - Cuentas de Tordesillas (1797-1843).

1308 - Cuentas varias (Ávila, XIX), Lavadero de Rojas y fincas urbanas de Madrid (XX).

1309 - Testamentaria y correspondencia de Ávila (XIX).

- Cuentas del esquileo de ganado en Lavadero de Rojas (XIX).

- Correspondencia de Zamora (XIX).

1310 - Correspondencia de Pueblanueva (1723-1816).

1311 - Correspondencia de Pueblanueva (1817-1854).

1312 - Cuentas de Cintruénigo (1817-1857).

1313 - Cuentas de Cintruénigo (1816).

- Cuentas de esquileo (XIX).

1314 - Cuentas y correspondencia de ganadería (1854-57).

1315 - Testamentaría de doña María Asunción Belvís de Moncada y Rojas, marquesa de Villanueva de Duero y condesa de Villariezo y Villaverde, fallecida el 23 de marzo de 1847, a las 6 menos cuarto de la mañana.

- Cuentas de Olmedo (1891).

- Correspondencia de Santander (1776-1818): restauración de la Capilla del Cristo de la Catedral.

1316 - Copias de documentos muy diversos del Edo. de Murillo, clasificados por secciones (XI-XVIII).

1317 - Correspndencia desde Aranjuez (1758-95).

- Correspondencia desde El Escorial (1796-98).

1318 - Correspondencia de Ausejo (1792-99).

- Cuentas de cabañas (1823-33).

1319 - Correspondencia de Jaén, del Edo. de Villanueva de Duero (1800-28): noticias de interés sobre los franceses y la degollina de Jaén.

1320 - Testamentarías y particiones de los Ramírez (XVI-XIX).

- Cuentas de la reparación del Hospital de la Latina, bajo la dirección de Herrera de la Calle (1856-57). Sin planos.

- Cuentas del hospital de la Latina (1857-58).

1321 - Arrendamientos en Tordesillas, de Villanueva de Duero (XVII-XIX).

- Papeles del patronato de Santa Catalina de los Dorados y la Capilla de San Jerónimo en Madrid, del mayorazgo de Trasmiera (XVI-XVII).

- Testamentaría de doña María Asunción Belvís de Moncada (1847).

- Poderes de los Tapia, de Ávila (XVI-XVII).

1322 - Cartas de pago del arrendamiento de las hierbas del Valle de Alcudia, por el marqués de Villanueva de Duero (1786-1808).

- Ejecutorias del Edo. de Murillo (XVI-XVIII). 
1323 - Testamentarías de los Ramírez (XVI-XIX).

- Partidas de bautismo, de casamiento, de confirmación y matrimonio del Edo. de Murillo (XVI-XVIII).

- Papeles y genealogías de los Trasmiera (XVII).

- Memorias de los Mercado (XVII).

- Fundaciones del Edo. de Villariezo, en Aranda de Duero (XVII-XVIII), con índice.

1324 - Papeles varios de Villariezo (XVI-XVII).

- Cuentas del Hospital de la Latina (1845).

- Papeles de Bernardo de Rojas como regidor de Toledo (XVIII).

- Papeles de los Tello (XVI-XVIII).

- Documentos sevillanos de Pedro de Mata (1495-1500).

1325 - Pleitos de los Ramirez (XVIII).

- Pleitos, donaciones y otros documentos de los Olivares (XVII).

- Papeles de la Compañía de Comercio de Toledo (XVIII).

1326 - Cuentas de Cambil (1892-97).

1327 - Cuentas de Cambil (1899).

- Correspondencia de Juan Gabriel Fombellida con el Conde de Bornos (1823).

- Correspondencia con el Rector del Hospital de la Latina (1822).

1328 - Expedientes conclusos de Villanueva de Duero (1831).

- Correspondencia con el Rector del Hospital de la Latina (1820-22).

- Correspondencia con Fombellida (1823).

- Correspondencia del Conde de Bornos, desde Santiago de Compostela (1821).

1329 - Cuentas de Medina del Campo (1802-20).

- Alimentos de la marquesa de Villanueva de Duero (marzo de 1798), fallecida entre los días 12 y 13.

- Alimentos por el conde de Villariezo, su hijo, hasta marzo de 1799 (17991805).

1330 - Cuentas de Medina del Campo (1644, 1777-78 y 1785-1816).

- Cuentas del maestro de coches (1827-32).

1331 - Cuentas de caja de Bornos (1872).

- Documentos muy diversos: correspondencia de Cádiz, Córdoba, Sevilla, Gibraltar, Toledo, etc., muchos documentos privados de los Vélez de Guevara, con boceto del Castillo de Guevara y pequeña historia genealógica de los Guevara (XVIII-XIX).

1332 - Cuentas del agente de la Casa de Bornos (1801-55).

- Cuentas de escribanos de Bornos (1823-50).

- Correspondencia de las memorias de Mencía Suárez y Antonio Meneses (1902).

1333 - Correspondencia de Toledo, del Edo. de Villanueva de Duero (1781-89).

1334 - Correspondencia de Toledo (1751-85).

1335 - Cuentas del Villanueva de Duero (1817-61).

1336 - Cuentas de Talavera (1861-65).

- Cuentas de Bornos (1892).

- Cuentas de ganadería yeguar (1862). 
1337 - Cuentas de Bornos (1896).

- Cuentas de Villaverde, Villanueva de Duero y Condesa de Alcudia (17931805).

- Cuentas de la Huerta de Atocha (1775-94).

1338 - Cuentas de las obras en la casa de la c/. El Escorial, n 15, de Madrid, dirigidas por Gaviña (1856-60). Sin planos.

- Cuentas de la Huerta de Atocha (1790-99).

1339 - Correspondencia y cuentas mezcladas del Tomilloso, Sevilla, Lavadero de Rojas, Cambil y cuentas de Bornos (XIX). Notas de 1893 del Hospital de la Latina.

1340 - Cuentas de las casas de Bornos en Madrid (1838-59).

- Cuentas de misas en el Monasterio de Carmelitas descalzos de las Batuecas (X|X).

- Correspondencia del Tomilloso (XIX).

1341 - Correspondencia de Logroño (1721-66).

1342 - Correspondencia de Molina de Aragón (1709-40).

- Cuentas de casas en Madrid (1817-25).

1343 - Cuentas y correspondencia mezcladas, de justificantes de caja (1913), de la administración de Zamora (1806), de casas en Madrid (1906), de esquileo (1881-83), cuentas e inquilinos del Hospital de la Latina (XIX), fincas rústicas (1917), etc. Dos grabados religiosos.

1344 - Correspondencia y cuentas de Zamora (1912-14).

- Cuentas de rabadanes (1789).

- Correspondencia y cuentas (1821-29).

- Cuentas de casas en Madrid (1877).

1345 - Cuentas de Cabeza de Buey (1924).

- Gacetas de Madrid (1844-60).

- Cuentas de Bornos (1834-35).

- Correspondencia del Lavadero de Rojas (1825 y 1900-01).

- Cuentas de mayordomo (1864-68).

- Cuentas de caja (1874).

1346 - Tomas de posesión del Edo. de Villanueva de Duero (XVIII).

- Memorias de censos y rentas, con inventarios, de los Pérez y de la Moneda (XVIII-XIX).

1347 - Censos redimidos de los Enríquez (XVIII-XIX).

- Capitulaciones matrimoniales de los Enriquez (1638).

- Arrendamientos de los Enríquez (XVIII-XIX).

1348 - Compraventas y apeos de los Riaño, condes de Villariezo, en Rabé de las Calzadas (XVII-XVIII).

- Documentos señoriales del conde de Murillo (XIII-XVII).

- Tomas de posesión del Edo. de Villanueva de Duero (XVIII).

1349 - Asuntos judiciales del Edo. de Villanueva de Duero (XVIII), con inventario.

- Títulos de propiedad del Edo. de Villanueva de Duero (XVII).

- Patronatos del Edo. de Murillo (XVII).

- Patronatos del Edo. de Villariezo (XVII), con genealogía.

- Asuntos judiciales de Murillo y Villariezo (XVII). 
1350 - Memorial ajustado del pleito entre José Arias del Hierro y Bernardo de Rojas y Contreras, como esposo de María Josefa del Hierro, sobre el mayorazgo de segundogénito fundado por Diego Moreno, Antonio del Hierro y Jerónima Millán (1754). Varios ejemplares impresos.

- Inventario de documentos de los Sellán, Herrera, Rueda, etc. (XVI-XVII).

- Inventario de documentos del condado de Peñarrubia, de apellido Guevara (XV|-XVIII). Edo. incorporado en 1713 al de Murillo por falta de sucesión del duque de Sotomayor, conde de Peñarrubia.

- Inventario de papeles de los de la Torre y Andino (XV-XVIII).

- Inventario de papeles del mayorazgo de Ausejo (XIV-XVII).

- Privilegios reales de los Ramírez de Arellano (XIV-XV). Copias.

- Títulos de los oficiales de Alcanadre, Murillo y Ausejo (XVIII).

- Documentos de jurisdicción del Edo. de Murilio (XIX).

- Asuntos judiciales del Edo. de Villanueva de Duero (XVIII).

1351 - Asuntos judiciales del Edo. de Villanueva de Duero (XVIII).

- Inventario de papeles de los mayorazgos de los Zuazo, incorporados por los Rueda-Herrera (Logroño, XVI-XVII).

- Asuntos judiciales del Edo. de Murillo (XVIII).

- Residencias tomadas en Ausejo (XVIII).

1352 - Patronatos del Edo. de Murillo (XVII).

- Memorial del conde de Murillo en pleito contra las villas de su jurisdicción (XVIII).

- Cartas de pago del Edo. de Villanueva de Duero (1713-53).

- Memoriales del Edo. de Murillo (XVII-XVIII).

- Cartas del pago del Edo. de Villanueva de Duero (1597 y 1599).

- Cuentas del Hospital de la Latina (1763 y 1808-10).

1353 - Documentos judiciales, en Cáceres, del Edo. de Villariezo (mediados del XIX).

- Cartas de pago de Villanueva de Duero (1701-12).

- Memoriales del Edo. de Murillo (XVIII-XIX). Gran número de documentos judiciales mezclados.

1354 - Patronatos del Edo. de Murillo (XVII).

- Capelianía de Pedro Miguel en Alcanadre (1638-1754).

- Documentos genealógicos de los mayorazgos de Coscojales y Castejón (XVIII).

- Libro de entrada de enfermos en el hospital de la Latina (1745-68).

1355 - Juro de Herbias (1700).

- Papeles varios (Ávila y Valladolid, XVII-XVIII).

- Títulos de propiedad de los Tello (Ávila, XVII).

- Censos en Toledo, del Edo. de Villanueva de Duero (XVIII).

- Capitulaciones matrimoniales y dotes de los Tello (XVI-XVII).

- Censos y juros de Villariezo (XVI-XVII).

- Inventarios de los Tello (XVI-XVII).

1356 - Censos en Cintruénigo, del Edo. de Murillo (XVIII-XIX).

1357 - Documentos de jurisdicción de Murillo (XVIII).

- Índice del antiguo legajo 3 del Edo. de Murillo, sobre documentos de jurisdicción y ser̃iorío (XIII-XVIII). 
- Documentos judiciales de los Quevedo de Reinosa (XVI-XVIII).

- Pleitos de los Quevedo (XVII).

- Índice del antiguo legajo 34 de los Ramírez, sobre asuntos judiciales (XIX).

1358 - Pleitos de Ramírez (XIX).

- Papeles de filiación de los Losada (XVI-XVII).

- Partición de bienes de Fernán Álvarez de Mencía (Talavera, XV).

1359 - Documentos y genealogías diversas, entre ellos de los Meneses (XVII-XIX).

- Libro de los bienes en Montamarta (Zamora, 1880).

- Pleitos de los Ramírez (XVI-XIX).

1360 - inventario de documentos de los mayorazgos asimilados por Villariezo (Toledo, Meneses, Carvajal y otros) (1735), con documentación desde el siglo XV.

- Censos en Toledo, del Edo. de Villanueva de Duero (XVIII).

- Inventario de documentos del Conde de Villariezo (1764), desde el siglo XVI.

- Documentos sueltos de Meneses y Riaño (XVIII).

- Relación de bienes en Montamarta (XIX).

- Relaciones de bienes en distintas administraciones (XIX).

1361 - Testamentos de los Rueda-Herrera, del Edo. de Murillo (XV-XVII).

- Mediciones de los Losada (XVII-XIX). Un plano coloreado de finca en Montamarta (Zamora).

- Documentos matrimoniales del Edo. de Villanueva de Duero (XVIII).

- Documentos reales de los Tello (XV-XVII).

- Libro con documentos reales a los Tello, cosidos (XVI).

- Índice del antiguo legajo 1 del mayorazgo de Barrasa, del Edo. de Murillo

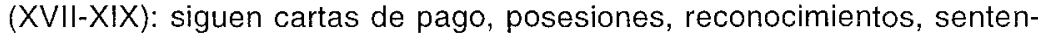
cias, etc. de ese mayorazgo.

1362 - Compraventas de fincas rústicas y urbanas en Torrelobatón (1412-1504). En gran número.

- Papeles genealógicos, árboles y escudos de varios linajes, entre otros de los Salcedo.

- Informaciones de limpieza de sangre de los de la Torre (1610).

- Fundaciones de mayorazgos de los de la Torre (XVI).

- Posesiones de los Losada (X/II-XIX,).

- Relaciones de fincas de Bornos en Alava (1830).

- Papeles de los diezmos del Abad de Rueda (XVI-XIX).

- Apeo de Motril (s.a.), sólo el certificado.

1363 - Amojonamiento de la Pradera de San Isidro (1869). Plano coloreado de Pedro Vidal.

- Posesiones de los Losada (1740).

- Reales cartas de sucesión en títulos, a los condes de Bornos (XVIII-XIX).

- Deslinde de la Pradera de San Isidro (1911) por los arquitectos Pablo Sánchez, Alonso Gasco y Alberto Albiñana y Chicote.

- Planos coloreados en gran número sobre la Pradera en la segunda mitad del XIX.

- Documentos matrimoniales del Edo. de Villanueva de Duero (XVIII). 
- Apeo en Motril, Salobreña, Restábal y otros sitios, de los Ramírez (1580), con un traslado posterior.

- Títulos de propiedad en Tordesillas del Edo. de Villanueva de Duero (XVIII).

- Patronatos de los Murillo en Alcanadre (XVI-XVII).

- Índice del antiguo legajo 2 de los Ramírez, sobre títulos y cartas reales.

1364 - Compraventas en Torrelobatón (XVI). En gran número.

- Papeles de los Guevara y Ramírez de Arellano (XVII-XIX).

1365 - Correspondencia de los condes de Bornos (1790-1877).

1366 - Correspondencia de Medina del Campo (1909).

- Cuentas de fincas urbanas en Madrid (1874-75).

1367 - Cuentas de la casa de la c/. Red de San Luis, del Edo. de Villariezo (1816-21).

1368 - Cuentas de la casa de la c/. Red de San Luis, del Edo. de Villariezo (1800-15), por Alejandro Madinaveitia.

1369 - Cuentas de Burgos, del Edo. de Villariezo (1789-1812).

1370 - Cuentas de Torrelobatón (1865-1902).

1371 - Cuentas de Torrelobatón (1839-65).

1372 - Cuentas de pagaduría (1876).

1373 - Cuentas de la Pradera de San Isidro (1803-08).

1374 - Cuentas de fincas urbanas (1918).

- Cuentas varias de Bornos y Guevara (fines del XIX y comienzos del XX).

1375 - Correspondencia del Tomilloso (1831).

- Cuentas y correspondencia de Jaén y Cambil (1905).

- Papeles de los Mercado (XVII-XVIII).

1376 - Cuentas de Burgos (1905).

- Cuentas del Hospital de la Latina (1776-79).

1377 - Cuentas del hospital de la Latina (1780).

- Papeles en blanco y cabeceras de antiguos legajos.

1378 - Cuentas de Zamora (1600-1852).

1379 - Cuentas de mayordomía de Madrid y El Escorial (1862).

1380 - Cuentas de Cambil (1900-02).

1381 - Cuentas de la Pradera de San Isidro (1786).

- Pleito por desperfectos en el mayorazgo de Murillo (Valladolid, 1778).

- Cuentas de Bornos (1890).

1382 - Correspondencia y cuentas mezcladas (XVII-XVIII). Destacan: correspondencia de Gaspar Fernando Varela con el marqués de Camarasa (1795) y del marqués de Villanueva de Duero participando el trato para el casamiento de doña María de las Mercedes Rojas y Tello, condesa de Villamarciel, su hija, con Valentin Belvís de Moncada y Pizarro, hijo del marqués de Bélgida (1795).

1383 - Cuentas de Motril (1784).

- Cargas de la dehesa de Villaverde, del Edo. de Villaverde (1847).

- Cartas de pago y cuentas variadas (XVI-XVII).

1384 - Justificantes de caja (1914).

- Regestas de documentos de los Ramírez. 
1385 - Cuentas de las memorias de Meneses (1866-79).

- Correspondencia de Villanueva de Duero, Bornos y Villariezo (1835-36).

1386 - Cuentas y correspondencia de cabañas (1848-50).

1387 - Cuentas de ganado cabíio (1893-94).

- Correspondencia del conde de Villariezo (1867).

- Cuentas del pleito contra el marqués de Paredes (Cáceres, 1867-68).

1388 - Correspondencia de Ausejo (1740-76).

1389 - Cuentas del Hospital de la Latina (1791-94) y cuentas de las comidas para los pobres de la cárcel (1790).

1390 - Cuentas de Talavera (1856-60).

1391 - Cuentas de Bornos (1897).

1392 - Cuentas de Toledo (1780-1808).

1393 - Cuentas de Toledo (1714-90).

1394 - Correspondencia de Motril (1767-75).

1395 - Correspondencia de Motril (1762-71).

1396 - Cuentas de fincas rústicas (1911).

- Impresos para gastos de obras de Villariezo y Bornos (185. y 186.).

- Correspondencia entre el conde de Villariezo y el vizconde de Palazuelos (1805-39).

1397 - Justificantes de caja (1922).

- Cuentas de Bornos (1874).

- Contratos de inquilinos en Madrid (1889).

1398 - Censos contrá Bornos y a favor de otras casas (Urquijo, Mondéjar, etc.) (XVIII-XIX). Con una consulta al nuncio (1884).

1399 - Censos contra Bornos (XVIII-XIX). Con un libro de asientos de censos a favor y en contra de la casa (1800-22).

1400 - Varios Índices de documentos, entre otros el del hospital de la Latina (XV$X I X)$.

- Escrituras de bienes en Talavera de la Reina (XIX).

- Apeo de bienes de Motril (1604).

- Capitulaciones matrimoniales (XVI-XVII).

- Apeos de bienes de los Losada (1604-1605).

1401 - Índice del antiguo legajo 13 de los Ramírez, sobre propiedades en Talavera tras 1836.

- Documentos de los Ramírez de Arellano (XVI).

- Documentos judiciales, Madrid (XIX).

- Apeo de bienes en San Cebrián, de los Losada (1738).

- Papeles del mayorazgo de Perea (XVII).

- Cuentas de fincas rústicas y urbanas (1932).

1402 - Apeo de las tierras de San Cebrián (XVII).

- Mayorazgo de Sebastián Antonio de Contreras (1633).

- Pleito por los bienes de San Cebrián de Castrotorafe (XVIII).

- Apeo de los bienes del mayorazgo de Losada en Montamarta (1738).

1403 - Papeles diversos (1857) y apeo de bienes en Peñarrubia (XVIII).

- Cuentas de las casas de Madrid (1883). 
- Documentos del Edo. de Murillo (XVIII-XIX).

- Venta judicial de casas en Madrid por el marqués de Bélgida a don Francisco Javier de Rojas Yerro y Contreras, marqués de Villanueva de Duero (1786).

1404 - Dotes del Edo. de Villanueva de Duero (XV-XVII).

- Títulos de propiedad en Burgos, del Edo. de Villariezo (XVIII).

- Títulos de compras en Viliacomparada (Burgos) (XVI).

- Nombramientos de los Guevara (XVII) y papeles de calificación y nobleza.

- Fundación de mayorazgos y documentos familiares de los Guevara (XVIXVII).

- Cuentas de casas en Madrid (1881).

1405 - Documentos mezclados de Villariezo (un plano, planta, corte y alzado de un molino) con otros de Murillo (XV-XVIII).

1406 - Memorial impreso de los derechos de doña María Isabel de Contreras Ramírez de Arellano al señorío de Villanueva de Duero con una adición impresa (XVII).

- Venta judicial de casas de la c/. del Pez de Madrid, propiedad de la marquesa de Bélgida (XVIII). Libro encuadernado.

1407 - Papeles del mayorazgo de Moreno, en Guadalajara (XVI-XVIII).

- Documentos judiciales del Edo. de Villanueva de Duero (XVIII).

- Planos de la casa de la c/. del Pez en Madrid (1833).

- Documentos de la casa de la Cc del Pez (XIX), incluye exención real de aposentos en 1623, en pergamino.

- Papeles del Edo. de Bornos sobre derecho a aguas del Canal de Isabel II $(\mathrm{XIX})$. Faltan las láminas.

- Venta judicial de la casa de la c/. del Pez, n. 18 (1854).

1408 - Documentos judiciales del Edo. de Villanueva de Duero (XVIII).

- Indice del legajo antiguo 2 del Edo. de Murillo, sobre títulos de propiedad de fincas (XIV-XVIII).

- Documentos del pleito de tanteo de Villanueva de Duero (XVII).

- Títulos de propiedad de los Ramírez de Arellano (XIV-XIX).

- Memorial impreso y documentos sobre méritos y servicios de los Ramírez de Arellano (XVII-XIX).

1409 - Correspondencia y cuentas varias mezcladas (XIX).

- Documentos de Villariezo; entre ellos, donación de las monjas del Monasterio de Gracia en Ávila al contador real Pedro Dávila de su capilla mayor (1530). Original.

1410 - Cuentas y correspondencia varias mezcladas (XIX).

- Cuenta de los tutores de don Diego Ramírez de Haro (1580).

- Cuentas de Motril y Salobreña (1565 y 1594-1599).

1411 - Documentos del Conde de Montenuevo, mayorazgo de los Enríquez. Reales cédulas (XVII-XIX).

- Censos con el Edo. de Murillo (XVII-XVIII).

- Cuentas (1910).

- Documentos de poderes de los Enríquez (XVII-XVIII).

- Información de hidalguía de Alonso de Lorca, en Madrid (1567). 
1412 - Documentos diversos sobre nobleza y genealogia de muy varios linajes (XVI-XVII) [linaje de los Molina de Úbeda y Arellano de Navarra, con escudo coloreado de éstos].

1413 - Documentos de los Tello (XVI).

- Pleitos y poderes de los Tello, de Valladolid (XVII-XVIII).

1414 - Cuentas de Cambil (1778 y 1791).

- Expediente para el derribo y nueva construcción de la casa de la Plazuela de la Cebada, $\mathrm{n}^{\circ}$ 10, en Madrid, con vuelta a Cava Alta (1867). Sin planos.

- Correspondencia de las administraciones de Arguedas y Ávila (XIX).

1415 - Cuentas de Medina del Campo (1871-1902).

1416 - Recibos de contribución (1882-1883).

- Correspondencia de don Diego Mora Ochoa (Toledo, 1852).

- Cuentas del Lavadero de Rojas (XX).

- Papeles de bulas y cofradías (XVIII-XIX), con grabados pequeños y escapularios.

1417 - Justificantes de caja (1923).

- Correspondencia con Tejerina (1828).

- Documentos de la quiebra de la Sociedad Unión Comercial (1845).

- Correspondencia sobre el derribo del Hospital de la Latina (1902).

1418 - Cuentas de la Casa de Bornos (1900).

- Cuentas de Guadalajara (1891).

1419 - Correspondencia del Conde de Bornos (1766-1824).

- Cuentas de la Casa de Bornos (1898).

1420 - Cuentas de Zamora (1860).

- Cuentas y correspondencia varia (XVIII-XIX).

- Testamentaría de la marquesa de Villanueva de Duero y condesa de Villariezo y Villaverde (1801).

1421 - Cuentas de Zamora (1803-1840).

1422 - Cuentas de fincas urbanas en Madrid (1901)

1423 - Cuentas de fincas urbanas en Madrid (1900)

- Cuentas de mayordomía (1858).

1424 - Cuentas de Medina del Campo (1860-1870).

- Cuentas de Madrid (1878).

1425 - Cuentas de Medina del Campo (1845-1859).

1426 - Cuentas de esquileo (1882-1883).

- Correspondencia y cuentas del Lavadero de Rojas (1872 y 1898).

- Correspondencia de la administración de Madrid (1867-1868).

- Correspondencia de Loja (1800).

1427 - Cuentas de esquileo (1878).

- Cuentas de la casa de la c/. Escorial 18, en Madrid (XIX).

- Correspondencia con procuradores (1870).

- Papeles de la Junta de patronos del Hospital de la Latina (1875 y 18801881).

1428 - Cuentas de varias administraciones $(X \mid X-X X)$, en muy mal estado.

1429 - Cuentas de Talavera, del Edo. de Villariezo (1843-1853). 
1430 - Correspondencia de los Contreras de Jaén (1655-1666).

- Cuentas de Talavera (1831-1836).

1431 - Índice antiguo de papeles del mayorazgo de Losada (desde 1590).

- Indice antiguo de papeles del mayorazgo de Enríquez (desde 1522).

1432 - Papeles muy diversos de fines del siglo XVIII y comienzos del XIX.

1433 - Correspondencia sobre Motril (1786).

- Memorias de misas fundadas por Sebastián de Borja, en Madrid, misas de los Contreras en el monasterio de Calatrava, cuentas de contaduría de Bornos en 1884 relativos a misas, y papeles de la capellanía en el Burgo de Osma, fundada en 1572 (1850).

1434 - Correspondencia de don Toribio Tarríus, arrendatario de las Huertas de Atocha y Pradera de San Isiaro (1835-1855).

- Papeles antiguos (XV-XVII).

- Documentos de ganado (XIX).

- Papeles de la dehesa de Tomilloso (1839-1841).

- Correspondencia de Toledo (1860).

- Correspondencia de la Puebla de Alcocer (1829).

- Cuentas de Motril (1724).

- Cuentas de las rentas de los Ramírez (XVI).

- Papeles sobre expropiación forzosa de la Huerta de Atocha para el ferrocarril de Aranjuez (1855-1857).

- Correspondencia con don Gregorio Ortega (1820-1823).

- Correspondencia con los arquitectos de la Casa, don Wenceslao Gaviña, don Félix María Gómez y don Carlos Colubí (1860-1862).

- Correspondencia de Tordesillas (1830).

- Mucha otra correspondencia suelta (XIX).

1435 - Cuentas de la Casa de Bornos (1901).

- Correspondencia de Canarias (1755-1774).

- Cuentas de mayordomía de Madrid (1844).

1436 - Correspondencia de Villanueva de Duero (1658-1792).

1437 - Correspondencia de Villanueva de Duero (1778-1816).

1438 - Correspondencia de Villanueva de Duero (1664-1777).

1439 - Cuentas de Toledo, del Edo. de Villariezo (1837-1860).

1440 - Cuentas de Motril (1764-1765).

- Libro de salarios de trabajadores del trapiche de Motril (1764).

1441 - Cuentas y correspondencia de ganado (1867-1869).

- Cuentas del Edo. de Bornos (1895).

1442 - Cuentas de esquileo (1868-1871).

1443 - Documentos sobre préstamos y empréstitos nacionales (1856-1873).

1444 - Cuentas de cabañas (1743-1787).

1445 - Cuentas de Villanueva de Duero (1722 y 1725-1726).

- Cuentas de cabañas (1802-1803).

- Cuentas de Villanueva de Duero (1719-1743).

1446 - Correspondencia del conde desde Aranjuez (1826).

- Cuentas de administraciones diversas (XIX-XX). 
1447 - Testamentarías en Medina del Campo (XVIII).

- Memorias de misas en Tudela de Duero y Olmedo, de los Salcedo (XVIII).

- Inventario de los Salcedo, en Tudela de Duero (XVII).

- Particiones de bienes de los Salcedo, emparentados con los Olivares, marqueses de Villacastel (XVI-XVII).

- Documentos sobre oficio de alcaide de Cambil y Alhabar con regimiento perpetuo anejo (XVII). [nombramiento de alcaide a don Mendo de Contreras, por muerte de Juan de Quesada, en Cuenca, 1 de junio de 1642].

- Documentos del oficio de notario mayor perpetuo del Reino de Granada, a los Contreras (XVII), del Edo. de Villanueva de Duero.

- Documentos del oficio de escribano del número y ayuntamiento de Cambil y Alhabar a los Contreras (XVII).

- Arrendamientos en Tudela de Duero, de los Salcedo (XVII-XIX).

- Documentos del oficio de veinticuatro perpetuo de Jaén, a los Contreras (XVII-XVIII).

1448 - Pleitos de los Enríquez (XVII-XIX) [uno sobre la construcción de la casa en la Plaza de la Cebada].

- Venta de una casa en Madrid, de los Ramírez (1823).

- Índice de los documentos de los Castro, en Madrid (1478-1719).

- Testamentos de los Guevara (XVII).

- Papeles de los Guevara y el Monasterio de San Agustín de Segovia (XVII), donde tenían su enterramiento familiar. Plano de bóveda y entierros de los Guevara.

- Papeles del mayorazgo de los Ramírez de Arellano, en Talavera (desde 1525), del Edo. de Villariezo.

1449 - Papeles de los Guevara y el Monasterio de San Agustín de Segovia (XVIIXVIII).

- Planos del palacio del Conde de Bornos, para su reforma, del arquitecto Joaquín Rodríguez, neoclásicos, en c/. Autores y Arco de Palacio.

1450 - Documentos mezclados de Villariezo y Villanueva de Duero.

- Carpetas de documentos diversos (vacías).

1451 - Documentos sobre compraventas de casas en Madrid (XVIII).

- Cuentas de la administración de Motril (1824).

- Testamentarías diversas (1568, 1600 y 1735).

- Descargos y pago de deudas de los Ramírez (XVI).

1452 - Tutelas y curadurías de los Ramírez (XVII-XVIII).

- Índices de los antiguos legajos 35 de Villanueva de Duero y 40 de los Ramírez (éste se corresponde).

- Documentos judiciales de Segovia, del Edo. de Villanueva de Duero (XVI).

- Papeles de capellanías de los Enríquez (XVI-XVIII).

- Documentos de los Ramírez, según índice anterior.

1453 - Papeles del mayorazgo de los Meneses (XVII-XVIII).

- Aniversarios y memoriales en Medina del Campo y Torrelobatón (XVI-XVII).

- Censos de solares en el Humilladero, junto a la Puerta de Moros, en Madrid (1568).

- Compraventas de los Enríquez (XV|-XVII), con índices. 
- Papeles diversos de los Enríquez (desde XVII) [entre otros, dictámenes de letrados].

1454 - Censo de casas en c/. Zaragoza, en Madrid (1851).

- Alegaciones impresas del pleito de los condes de Montenuevo con el marqués de Astorga (XVIII).

- Memorial del pleito entre Alonso Manrique e Inés de Solís con Juan de Solís (1510).

- Patronatos y capellanías de los Losada (XVI-XVII).

- Partidas de bautismo y casamiento de Losada (XVII).

- Cédulas y provisiones reales de Losada (XVI-XVIII).

- Cuenta de los maravedíes entregados para el pago de los criados del Príncipe don Juan (1512).

- Escrituras de declaración, etc., de los Losada (XVI-XIX).

1455 - Cuentas de la administración de Córdoba (XX).

- Cuentas de la administración de Reinosa (XX).

1456 - Matrimonios del Edo. de Villariezo (XVI-XVIII).

- Bautismos y confirmaciones del Edo. de Villariezo (XVI-XVIII).

- Particiones y tutelas (XVIII).

- Inventarios de los Cepeda en Talavera (XVIII).

- Patronato de Alcanadre del Edo. de Murillo (1675).

1457 - Patronato y aniversarios de la iglesia de Alcanadre, del Edo. de Villanueva de Duero (XVII). [dos dictámenes de letrados en 1690].

- Capellanías en la misma parroquia (XVIII).

- Partición de bienes del padre de la condesa de Heredia-Spínola (1892).

- Censos redimidos de los Ramírez de Haro (XVII-XIX).

1458 - Cuentas de gastos del hospital de la Latina (1809-1811).

- Recibos de alimentos y viudedades del Edo. de Villanueva de Duero (XVII-XVIII).

- Patrones de bordado del Journal des demoiselles (1884).

- Índice del antiguo legajo 28 de los Ramírez, sobre censos en Motril (XVII$X I X)$. [se corresponde en parte].

- Censos de los Ramirez en Motril (XVII-XVIII).

1459 - Cuentas de mayordomía (1857).

- Cuentas de Zamora (1913), Lavadero de Rojas (1871) y otros muchos mezclados.

1460 - Correspondencia con don Carlos Probo, en Zamora (1789).

- Cuentas de casas en c/. Escorial 15, en Madrid (1866-1871).

- Correspondencia de Ávila (1849).

- Documentos de ganado (XIX).

- Cuentas de fincas rústicas (1922).

- Correspondencia con el Sr. Urrutia (1856-57).

- Minuta de oficios (1867-69).

1461 - Vínculos de Villariezo, con Índice antiguo (XV-XVII).

- Memorial impreso del pleito entre el Conde de Murillo y Peñarrubia, marqués de Villacastel, con el marqués de Sardeñola, por el mayorazgo de Butrón, fundado en 1449 (1780). Varios ejemplares. 
- Índice impreso de sentencias del Tribunal Supremo (1874).

- Varias Gacetas de Madrid de 1887.

- Varios documentos sueltos (XVII).

1462 - Censo contra el Edo. de Murillo (XVII-XIX).

- Papeles sobre Tudela de Duero (XVII).

- Fundaciones del Edo. de Murillo (XVI-XVII).

1463 - Papeles de bienes de Pedro Salcedo y Salazar (XVII-XVIII). Libro con los documentos cosidos.

- Árbol genealógico impreso del conde de Villariezo. Varios ejemplares.

- Partición de bienes de Álvaro de Mercado (1612).

1464 - Dictámenes de letrados (XVI-XVIII).

- Inventarios varios (XVII-XVIII).

- Papeles del mayorazgo de Valmaseda, fundado por Butrón en 1449, con índices antiguos (XVII-XVIII), del Edo. de Murillo.

- Documentos varios y árbol genealógico de los Ramírez de Guzmán y los Cervantes (XV-XVII).

- Juros del mayorazgo de Borja (XVI).

- Cuentas del Hospital de la Latina (1844).

- Papeles genealógicos de muchos linajes.

- Registro de bautizos (XVI-XVII).

1465 - Pleitos de los Tello, de Olmedo (XVII-XIX).

- Capellanías en Burgo de Osma y Aranda de Duero, del Edo. de Villariezo (XVI-XIX).

1466 - Papeles genealógicos (Meneses, Mercado, Robles, etc.).

- Censos sobre casas en Madrid (XVII-XVIII).

- Capellanía del contador Dávila en Ávila (1550).

- Títulos de caballeros de Santiago a los Fernández de Lorca y García de Trasmiera (XVII).

1467 - Libro-registro de la administración de Bornos (1854).

- Papeles de los terrenos de Bornos junto a la futura estación de ferrocarril de Atocha (un plano), en el arroyo de las Yeserías (1860).

- Correspondencia de Archivo (1858).

- Papeles de bordados.

- Documentos varios (XVII-XIX).

1468 - Informe de obras necesarias en palacio y en la capilla mayor de Medina del Campo (1914), arquitecto Mauricio Patrón.

- Capellanías de doña Alberta de Barrada (XVIII).

- Certificados y planos sobre edificios afectados por la estación de Atocha, por el arquitecto de Bornos, don Federico Aparici (1884).

- Un plano de retablo de altar mayor en Monasterio de San Francisco de Miranda de Ebro.

- Títulos y planos sobre la estación de Atocha (XIX).

1469 - Informes de Archivo de 1856.

- Bienes matrimoniales del Edo. de Villanueva de Duero (XVII-XIX).

- Censos redimidos de los Ramírez (1866). 
- Certificación del mayorazgo de Recalde Castejón y Coscojales (1849).

- Pleito de Bornos en Castuera (1874).

- Apeo de terrenos en Motril (1893 y otros del XIX).

- Papeles de ganadería (XIX).

- Pleito de la Inquisición (1754).

- Informes de Archivo en 1863.

1470 - Cuentas de fincas urbanas (1919 y 1928).

- Correspondencia de Molina de Aragón (1786-87).

- Cuentas de mayordomía (1857).

- Papeles de dehesas en Plasencia (XVIII).

- Correspondencia de Ojos Negros (1800-21).

- Correspondencia de Molina de Aragón y Ojos Negros (1795).

- Cuentas de fincas urbanas (1913-1914).

- Testamento en Motril (1867).

1471 - Escrituras de reconocimiento de censos en Motril (XVII-XIX).

1472 - Correspondencia de Ojos Negros (1824-26).

- Justificantes de caja (1916).

- Peticiones de inquilinos a los testamentarios de la condesa de Bornos (1915).

1473 - Correspondencia de Molina de Aragón (1777-1785).

- Correspondencia de las minas de Ojos Negros (1828-1857).

1474 - Cuentas de las casas de Madrid (1860-1863).

1475 - Correspondencia de Madrid y Tordesillas (XIX).

- Cuentas de Motril (1597-1693).

- Cuentas de fincas rústicas (1867-1871).

- Papeles de censos y recibos pendientes de fincas rústicas, en la Puerta de Atocha (1870-73).

1476 - Cuentas de Motril (1697-1729).

- Correspondencia suelta de Madrid (XVIII-XIX).

- Correspondencia con don Gregorio Ortega (1826-1829).

- Correspondencia de los Losada (XIX).

- Rentas de los Ramírez (XVI).

- Relación de rentas en Granada (XVI).

- Ropa donada al Hospital de la Latina (s.f.).

- Deudas de Mosén Juan, rector del Hospital (s.f.).

1477 - Pleito sobre bienes en Motril (1700).

- Testamentos de los Enríquez (1758).

- Testamento de la duquesa viuda de Arco, condesa de Montenuevo (1758). Original y protocolizado.

- Papeles de Cintruénigo (XVII-XIX).

- Correspondencia de Motril (1788).

- Justificantes de caja (1923).

1478 - Pleitos sobre Motril (1598, 1599, 1600 y 1700).

- Compraventas de bienes del Edo. de Villariezo (1487-1648), sobre todo en Villariezo, también en Burgos, Arcos y Medina de Pomar.

- Índice antiguo del legajo 33, 141 registros sobre compraventas en Toledo y Talavera (1493-1632). 
1479 - Testamento de la condesa de Montenuevo (1761).

- Documentos muy mezclados del Edo. de Villariezo y sobre Talavera (XVXX). [Tres documentos de censos en Talavera en 1474].

- Índice del antiguo legajo 35 de Villariezo, sobre censos en Talavera.

1480 - Inventarios y particiones de los Moneda (XVI-XVIII).

- Sentencias de los Ramírez de Haro (XV-XIX).

- Reales provisiones del Edo. de Murillo (XVIII).

1481 - Índice del mayorazgo del capitán Navarro, del Edo. de Murillo (XVII-XIX).

- Inventario antiguo de papeles de Cintruénigo y del capitán Navarro en Cintruénigo (XVII-XVIII).

- Documentos reales a los Ramírez de Arellano (XVI-XVIII), incluido un pasaporte del Rey de Francia (XVIII).

- Inventarios de los Enríquez (XVIII).

- Testamentarias de los Enríquez (XVIII-XIX).

- Particiones e hijuelas de los Enríquez (XVI-XVII).

- Títulos de propiedad del Edo. de Villariezo (XVII), incluyendo venta en 1499 en San Martín de Valdeiglesias.

- Capitulaciones y dotes de los Águila, en Ávila (XVI-XVII).

- Títulos de propiedad en Cintruénigo (XVIII).

- Testamentarías del Condado de Bornos (1827 y 1849).

1482 - Censos en Zamora, del Edo. de Villariezo (1502-1626).

- Mercedes y peticiones de los Ramírez de Arellano (XVIII).

- Juros sobre reritas reales (XVI).

1483 - Testamentos de los Enríquez (1534).

- Reales provisiones de los Ramírez de Arellano (XVII-XVIII).

- Capellanías, aniversarios, memorias y obras pías de los Moneda (XVI-XVIII).

1484 - Reales cédulas de los Ramírez de Arellano (XVI-XVIII).

- Borrador de los censos de Talavera y otros lugares.

- Censos del Edo. de Villanueva de Duero en Valladolid (XVII).

- Testamentos de los Enríquez (XVI-XVIII).

- Arrendamientos de casas en Burgos (XVII-XVIII).

- Posesiones de los Moneda (XVI-XVIII).

- Apeos de los Moneda (XVII-XIX).

1485 - Documentos de la Casa de Rivas (XVII-XVIII).

- Índice del antiguo legajo 4 de los Ramírez (1438-1884) (sigue la documentación original).

1486 - Índice del antiguo legajo 3 de Murillo (mayorazgos de Moneda y Lerma) (XVI-XIX).

- Índice del antiguo legajo 36 de los Ramírez de Haro (XV-XIX).

- Sentencias de los Ramírez de Haro (XVII-XIX).

- Censos de los Enríquez (XVIII).

- Testamentos del Edo. de Villanueva de Duero (XVII).

1487 - Dos inventarios antiguos del Edo. de Murillo (XV-XVIII).

- Inventario antiguo de bienes vinculados en Madrid (XVII-XVIII).

- Censos del Edo. de Villariezo, en Salamanca (XVI). 
- Índice del antiguo legajo 11 del Edo. de Villanueva de Duero, sobre herencias (XVI-XVIII) y dos de estos testamentos (XVIII).

- Censos redimidos de los Tello (XVII-XVIII).

1488 - Herencias del Edo. de Villanueva de Duero (1727).

- Censos redimidos de los Tello, en Olmedo (XVII-XVIII).

- Inventario y partición de los Mercado (1635).

- Genealogias varias (Dávila, de Ávila; Quiñones; Tellos, de Arévalo; Núñez Vela, de Ávila, etc. Otros del Edo. de Villanueva de Duero), algunos árboles genealógicos.

- Ejecutoria de la Chancillería de Granada de los señores de San Román (1521).

- Testamentos del Edo. de Murillo (XVII-XIX).

1489 - Índice del Edo. de Murillo, mayorazgo de Olivares, antiguo legajo 2.

- Compraventas en Villariezo (1527).

- Papeles de la nobleza de los Salazar (XVII).

- Fundación del mayorazgo de los Salazar (1733).

- Árbol genealógico de los López de Porres.

- Capellanías del Edo. de Murillo, de los de la Torre. Fundación de una en el monasterio de Sta. María de Gracia, de agustinos, en Medina del Campo (XVI-XVIII).

- Fundación del mayorazgo de Martín García de Medina (1532).

- Reconocimientos de tierras en Madrid y Motril (XVIII). Dos de Ventura Rodríguez, arquitecto calificador sobre obras en el camino del Prado, con un plano acuarelado y firmado (1770). Siguen tasaciones de obras (entre ellas, unas hechas en la Huerta de Atocha en 1785 por los arquitectos Juan Fernando Ocaña y Pablo Morales Ramírez de Arellano). Otro por obras del ensanche del camino que va desde la ermita de San Isidro hasta el puente de Toledo, en 1855 del arquitecto Antonio Herrera. Otro del mismo arquitecto en 1846 de los edificios y demás existencias en la Huerta de Atocha.

- Fundaciones del Edo. de Villariezo (XVII).

- Tutelas y cuaraderías del Edo. de Murillo (XVIII).

- Certificaciones no judiciales (XVII-XVIII).

- Consignación de alimentos del marqués de Villanueva de Duero a los condos de Villamarciel (1795).

- Ventas de fincas a extraños (XVII-XVIII).

1490 - Documentos de diezmos y primicias del Edo. de Villanueva de Duero (XVI y XVII y XIX). Un dictamen.

- Compraventas de casas en Villariezo (1531).

- Inventario antiguo de documentos de Peñarrubia (XIV-XVIII).

- Testamento de Fernández y Salcedo (XVI-XVII).

- Pleitos de Villanueva de Duero (XV-XVIII).

- Papeles de los Salcedo (XVI-XVII).

1491 - Inventario antiguo de documentos del mayorazgo de Pérez Temiño, en Guadalajara, y de los Moneda (doña Vicenta, sucedida por su hija María Teresa del Pilar Olivares, Cepeda y Moneda, condesa de Murillo y marquesa de Villacastel) (XVI-XVIII). 
- Obra pía en Arévalo (1775).

- Censo en Olmedo (1478-1879), del Edo. de Villariezo.

- Papeles del mayorazgo de Petronila de Somoza, en Encinillas (XVII).

- Papeles de censo de los Salcedo, en Tudela de Duero (XVII-XIX).

- Papeles sueltos de los Yáñez de Pineda, Rojas y del Edo. de Villariezo (XVI-XVIII).

- Inventarios antiguos de documentos de Peñarrubia, los Moneda y mayorazgo de Butrón (XV-XVIII).

1492 - Títulos de los Salcedo, en Tudela de Duero (XVI-XVII).

- Inventario antiguo de los documentos de la Abadía de Alcanadre (XIXVIII).

- Inventario antiguo de papeles de Portillos (XV|-XVIII).

- Testamentaría de don Joaquín de Riaño, conde de Villariezo (1790).

- Índice antiguo del legajo 12 de Villariezo, de herencias (XVII-XIX).

- Papeles de los Menchaca (XVI-XVII).

- Testamentaría de doña Javiera de Riaño y Osorio (1789).

- Compraventas del Edo. de Villariezo (1527-38).

- Capitulaciones matrimoniales del Diego de Herrera (1623).

- Papeles de la Abadía de Rueda (1434-1584).

- Inventario antiguo de papeles de la Abadía de Rueda (XV-XVI).

1493 - Fundación pia de Villariezo (1663).

- Árbol genealógico de Villariezo (1769).

- Correspondericia del conde de Torrejón (XVIII).

- Papeles y árboles genealógicos del Edo. de Villaverde, de apellido Ramírez de Guzmán (desde 1490).

- Inventario de Peñarrubia (XVI).

- Pleito del Edo. de Villaverde con el conde de Valparaíso, con inventario de documentos (XIV-XVI).

- Pleito del conde de Torrejón con el marqués de Mondéjar (XVIII). Un dictamen.

- Inventario de documentos para el pleito (desde 1490).

- Papeles del Edo. de Villaverde (XVIII).

- Testamento de los Mercado (XVIII).

1494 - Arrendamientos en Motril (1822-70).

- Cuentas del Hospital de la Latina (1856).

- Arrendamientos del Edo. de Villanueva de Duero, en Segovia y en Burgos (XVII-XIX).

- Dictámenes de letrados, del Edo. de Ramírez de Haro (XVII-XIX).

1495 - Fundaciones pías del Edo. de Villariezo (XVI-XVII).

- Patronatos y capellanías del Edo. de Murillo (1505-1816).

1496 - Cuentas del Hospital de la Latina (1641).

- Papeles del socorro de guerra a pueblos de Toledo y La Mancha (1756).

- Reales provisiones de los Salcedo (1773).

- Cuentas del Hospital de la Latina (1858-1859).

- Fundaciones del mayorazgo del Edo. de Murillo (XVI-XVIII). 
- Documentos del señorío de Cameros, al que pudieran tener derecho los condes de Murillo (1718-1856). Un dictamen.

1497 - Títulos y dignidades de los Rojas (XVII-XVIII).

- Cartas de pago de censos del Edo. de Villanueva de Duero (XVIII-XIX).

- Fundaciones pías del Edo. de Villariezo (XVI-XVIII).

1498 - Justificantes de caja (1911-1918).

- Papeles de los Rojas-Contreras (XVII-XVIII), alguno de Jaén; documentos inquisitoriales.

- Bula de Urbano Il, al Edo. de Murillo (1095).

- Fundaciones pías de Villariezo (XVI-XIX).

1499 - Cuentas cabañiles (1911-1912).

- Liquidaciones (1825-26).

- Censos y préstamos (XIX).

- Correspondencia de Tordesillas (1843).

- Papeles de la dehesa de Tomilloso (1816).

- Correspondencia de Tordesillas (1849).

- Correspondencia de Madrid (1869).

- Copias de poderes y escrituras para pago de censos (XIX).

1500 - Testamentaría de la condesa de Bornos, con relación de fincas e ingresos $(\mathrm{XX})$.

- Cuentas del Hospital de la Latina (XIX).

- Correspondencia varia.

1501 - Cuentas de mayordomia de Madrid (1840).

- Índice de varios mayorazgos del Edo. de Murillo (XVI-XIX).

- Recurso de casación con sentencia sobre la nulidad del testamento de la condesa de Bornos (1919). Folleto impreso.

1502 - Datos genealógicos de los Ramirez de Madrid.

- Breves pontificios (XVI-XVII).

- Partidas de bautismo, matrimonio y defunción de los Enríquez (XVI-XVII).

- Inventarios de los Enríquez (XVI-XIX).

- Papeles de los Enríquez (XV|-XIX).

- Documentos judiciales, Castuera (XIX).

- Indice del mayorazgo de Pérez, del Edo. de Murillo (XVI-XIX).

- Fundaciones de varios mayorazgos del Edo. de Villariezo (1489-1523).

- Fragmento de escritura otorgada en Sevilla por la que los diputados de los acreedores y fiadores del banco de Jácome Mortedo y Cía., vendieron a Fernando de Torres del Salto un juro de 500 ducados de renta anual situados sobre las alcabalas reales de Sevilla (1602).

1503 - Documentos genealógicos de los Dávila, de Cuéllar (XVIII).

- Árboles genealógicos (en gran número) de los Ramírez de Madrid, ascendientes y descendientes, y otras casas colaterales.

- Papeles sobre los escudos de armas de los condes de Bornos (XIX).

- Probanzas del linaje de los Jaques (XVI).

- Biografía de Beatriz Galindo, por el presbítero Cristóbal Gómez de Vega (1721). 
- Documentos genealógicos de los Ramírez de Haro y otras casas emparentadas (XVIII).

- Expllcación de escudo de armas del Conde de Bornos (escudo coloreado sobre tabla).

- Mayorazgo de Suárez de Toledo, de la Casa de Villariezo (1483).

- Dictámenes (1754).

1504 - Juros, privilegios y cartas de pago del marqués de Villanueva de Duero (XVII-XVIII).

- Documentos de Motril (XVIII).

- Pleito del Edo. de Villanueva de Duero (XIX).

- Información de los Dávila de Ávila (XVII).

- Correspondencia y cuentas de Madrid (XIX).

- Documentos varios mezclados (entre ellos, una carta particular del siglo XV).

- Cuentas de las casas de Villariezo y Bornos (XIX).

1505 - Apeos de bienes en Medina del Campo (XVI-XVII).

- Documentos judiciales del linaje de Losada (XVI-XVIII).

- Censos del mayorazgo de Luis Pérez, en Guadalajara (XVI). Un libro.

1506 - Papeles de los Herrera y Bande de Santander (XVII).

- Genealogía de los Ramírez de Guzmán, señores de Villaverde (desde 1490).

- Mayorazgo de los Pineda, de Palencia (s. XVII).

- Documentos de Medina del Campo y Torrelobatón (XVII).

- Papeles familiares de los Olivares (XVII-XVIII).

- Pleito y documentos varios sobre las fábricas de Liérganes y La Cavada (XVII-XIX).

- Inventarios de los documentos de la administración de Torrelobatón y Medina del Campo (XVII-XIX).

- Documentos de concesión de Grandeza al conde de Villaverde por Carlos IV (1794). Pintura sobre pergamino en la portada, muy interesante.

- Documentos sueltos de Villanueva de Duero (XVIII).

1507 - Poderes del Edo. de Villanueva de Duero (XVI-XIX).

- Títulos de propiedad de una encomienda por el Edo. de Bornos (XIX).

- Escrituras varias (algunas sobre los Britos de Santander y Liérganes) (XVII-XVIII).

1508 - Documentos judiciales del Edo. de Murillo, principalmente de Alcanadre (XVI-XVII).

1509 - Arrendamientos en Castilla la Vieja (XVI-XVHI).

- Título de alguacil mayor de Tordesillas, del Edo. de Villanueva de Duero (XVIII).

- Documentos del alcaide de la Real Casa y Bosque de Brahojos (plano de estilo escurialense, XVII).

1510 - Arrendamientos rústicos en Castilla la Vieja (XVI-XVII).

- Papeles del Edo. de Villaverde, de los mayorazgos de Ygares y Silva (XVIII).

- Arrendamientos de la dehesa del Torriquillo (1642-1820).

- Otros arrendamientos (XVIII-XIX). 
1511 - Índice antiguo de los papeles del mayorazgo de Calcheta (XVII).

- Papeles del Priorato de Arguedas (Navarra) (XVIII-XIX).

- Papeles de los Ramírez de Guzmán (XV-XVI).

- Índice antiguo del legajo 10, sobre los Ramirez de Guzmán (XVI-XVIII).

- Índices del mayorazgo de Arguedas, fundado en Navarra por los Calchetas (XVIII).

- Papeles de familias y genealogías vinculadas al título de Bélgida (XVIXVIII).

- Ejecutoria a favor del Edo. de Villaverde, sobre la dehesa de Noalos (XVII). Libro encuadernado.

1512 - Papeles muy variados del Edo. de Villaverde (XVII-XVIII).

- Arrendamientos de casas en Talavera (1574-1789).

- Arrendamientos de la Huerta del Prado, en Talavera (1764-18..).

- Arrendamientos de tierras en Villariezo (1528-1774).

- Arrendamientos de tierras en Almenara (1627-18..).

- Arrendamientos de tierras en Burgos y Gamonal (XVII-XIX).

1513 - Memoriales de varios linajes (Arellanos, etc.).

- Certificaciones de pertenencias a Ordenes Militares de los Rojas y Contreras, de Jaén (XVII-XVIII). Con árbol genealógico.

- Petición de Grandeza de don Francisco Javier de Rojas y Hierro, marqués de Villanueva de Duero (1783). Folleto impreso, varios ejemplares.

1514 - Documentos diversos (XVIII-XIX). Plano de la Mina de Monte Corbo, en Aragón, coloreado por el arquitecto Herrera de la Calle.

1515 - Documentos judiciales (XVIII).

- Censos contra Edo. de Murillo (XVII-XVIII).

- Señoríos y alcabalas del Edo. de Villanueva de Duero (XVII-XVIII).

- Padrón de vecinos y sus haciendas de Villanueva de Duero (1727).

- Certificado del arquitecto Wenceslao Gaviña (23-XII-1869, en Madrid) de tasación de casas en el antiguo camino de los Yeseros, fuera de Atocha.

- Planos del arquitecto Carlos Colubí (1866) en casas de c/. Atocha.

- Censos y títulos de fincas en Madrid (XIX).

- Plano de Gaviña, Gómez y Colubi (1861) sobre deslinde de terrenos en Atocha.

- Apeos de fincas en Madrid (XIX).

- Dictamenes (XIX).

1516 - Documentos de los Cepeda (XVII-XVIII).

- Índice del antiguo legajo de Cepeda, del Edo. de Murillo (XVI-XVII).

- Papeles de la encomienda de Fuente de Cantos (XVIII).

- Papeles de los Rojas-Contreras (XVII).

1517 - Defunciones del Edo. de Murillo (1433-XIX).

- Testamentarlas del Edo, de Murillo (XVIII).

- Testamentos de los Cepeda (XVIII).

- Papeles de la capellania del capitán Perea (XVI-XIX). Incluye la expropiación de sus tierras para el ferrocarril y estación de Atocha, con muchos planos. 
1518 - Censos de los Herrera (XVI-XVIII).

- Capitulaciones matrimoniales de los Herrera (XVI-XVIII).

- Señoríos y alcabalas del Edo. de Villanueva de Duero (XVII-XVIII).

1519 - Partidas de bautismo, matrimonio y defunción de los Salcedo-de la Torre (XVII-XVIII).

- Informaciones judiciales y requerimientos de los Salcedo (XVI-XVIII).

- Testamentos y censos de los Salcedo (XV-XVIII).

- Apeos de los Ramírez en Motril (1666-1777).

- Índice del antiguo legajo 28 del Edo. de Villanueva de Duero sobre bienes matrimoniales (XV-XIX).

- Cuentas de varios linajes (Mercado, Riaño, Orovio) (XVII-XVIII).

- Pleitos y particiones de los Herrera-Rueda (XVII).

- Memoriales de los Losada.

- Cuentas y relaciones de fincas de las Salinas de Duernas, Cádiz, Badajoz y Segovia $(X I X-X X)$, con algunos documentos protocolizados. Un plano sencillo, planta y alzado, con presupuesto de construcción de un toril en el Tomilloso.

1520 - Inventario de bienes de Beatriz Fernández de Salinas, en Medina de Pomar (1540).

- Censos de Mercado (XVIII).

- Títulos de propiedad del Edo. de Villariezo en Arévalo (XVII).

- Cuentas y partición del Diego de Rueda y Herrera, en Arévalo (XVII).

- Bienes matrimoniales del Edo. de Villanueva de Duero (XVIII).

- Capitulaciones matrimoniales entre marqueses de Villanueva de Duero, condes de Villariezo y marqueses de Bélgida, con la condesa de Villamarciel (1795) y dote (1796).

- Índice del antiguo legajo 1 de Ramírez de Arellano (XIV-XVIII).

- Papeles de la capellanía del capitán Perea (XVII-XVIII).

- Indice antiguo del cajón 36 de Villariezo, con sus documentos (XVI-XVII).

1521 - Cuentas del Hospital de la Latina (1561-63).

- Libro-índice de dotes del Edo. de Villariezo.

- Bienes matrimoniales del Edo. de Villanueva de Duero (XIX).

- Herencias de Medina de Pomar (XVI).

- Papeles del abad de Rueda (i_ogroño, 1694).

- Cuentas de cabañas (XX).

- Cuentas de Logroño (XX).

- Cuentas de Motril (1923).

- Inventario del Archivo de don Manuel Fulgencio Ramírez de Arellano, conde de Murillo y Peñarrubia, marqués de Villacastel (1764). Libro encuadernado (desde XIV).

1522 - Particiones de Olivares y colaterales (Britos, Herrera, etc.) (XVII-XVIII).

- Índice del antiguo legajo 3, del mayorazgo de Olivares, del Edo. de Murillo (XVII-XVIII).

- Inventarios de bienes de los Ramírez (XVII-XVIII).

- Poderes de los Losada (XVII-XVIII).

- Cartas de pago de los Ramírez (1754) y Losada (XV-XVIII). 
- Inventarios de bienes de los Losada (XVII-XVIII).

- Papeles de los Enríquez (1774 y 1861).

- Papeles de los Mercado (XVII).

1523 - Recursos de casación y sentencias contencioso-administrativas del Tribunal Supremo (1871-75). Impresos.

- Dos documentos de servicios de Pedro de Mazuelo (1586) y Diego de Riaño (1595).

1524 - Papeles de los Mercado (XVI-XVII).

- Documentos militares del Conde de Villariezo (comienzos del XIX).

- Adjudicación al Edo. de Bornos de la capellanía de Juan Fernández de Tresala (1882). Protocolo.

- Papeles de los Carvajal de Cáceres (XVII-XVIII).

1525 - Certificados a favor del Conde de Villariezo: dos de ingreso en la Orden de San Juan (1607-08). Con sellos de placa del Maestre, notables.

- Nombramiento de Catedrático de Decretales a favor de Pedro Manzano en la Universidad de Alcalá de Henares (1666).

- Arrendamientos del Edo. de Villanueva de Duero en Toledo para su cabaña (XVIII-XIX).

1526 - Censos de Olmedo, del Edo. de Villariezo (XVIII).

- Renuncia a regiduría de Arévalo (1633).

- Tutelas del Edo. de Murillo (XVI y XVIII).

- Arrendamientos en Toledo, del Edo. de Villanueva de Duero (XVIII-XIX).

- Apeos de Segovia, del Edo. de Villanueva de Duero (XVIII-XIX).

- Cuentas del Hospital de la Latina (1840 y 1861-63).

- Apeo de bienes en Encinillas, del mayorazgo de Moreno (Segovia, 1818).

- Inventario de documentos del Conde de Murillo, señor de Alcanadre, Ausejo y Alerre, y poseedor de los mayorazgos de Zuazo, Herrera, Rueda, Andino, Torre, Torme, Lozares y otros (1750). Recoge documentación desde 1351.

1527 - Inventarios y memorias del Edo. de Murillo (XVI-XVIII).

- Cuentas del Edo. de Viliariezo (1849-65).

- Requerimientos del Edo. de Murillo (XVI-XVIII).

- Memorias de bienes del Edo. de Murillo (XVIII-XIX).

- Apeos y tasaciones del Edo. de Vilianueva de Duero en Jaén, Segovia y Toledo. Faltan los planos.

- Planos de rejas y edificios en Burgos, Tordesillas, Toledo, Lavadero y Villanueva de Duero. Planos del puente de hierro, colocado en 1888 sobre el río Adeja, término de Villanueva de Duero, construido en Valladolid por Talleres Gabilondo Hnos.

1528 - Fundaciones pías en Talavera, del Edo. de Villariezo (XV-XVIII).

- Partidas de bautismo de los Ramírez (XV-XIX).

- Genealogías de los Ramírez y linajes afines (Adsor, Jaques, etc.). Con el índice del antiguo legajo 1 de Ramirez, sobre esto.

- Planos y certificados de arquitectos de varios edificios.

- Papeles de la casa de c/. Jesús y María, de Madrid, perteneciente al mayorazgo de Enríquez (XIX). 
1529 - Fundaciones pías en Zamora del Edo. de Villariezo (XVI-XVII).

- Arrendamientos de casas y tierras (XVII-XIX).

1530 - Poderes del Edo. de Murillo (XVII-XVIII).

- Títulos de propiedad de fincas en Toledo, del Edo. de Villanueva de Duero (XVII-XVIII).

- Cartas de pago del Edo. de Murillo (XVII-XVIII).

1531 - Pleitos de Bornos (1851-56).

- Pleitos de los Losada (XVI-XIX).

- Inventarios de documentos del Edo. de Vllaverde y mayorazgo de Trasmiera (XIV-XVIII).

- Inventario de documentos dados al conde de Villariezo (1853), incluyendo desde 1430.

- Otros inventarios y muchos papeles sueltos.

- Títulos de propiedad de fincas en Toledo, del Edo. de Villanueva de Duero (XVI-XIX).

- Construcción de casa en Villaverde (1818), con planos.

1532 - Pleito de los Losada (1599-1601).

- Dos índices de documentos de Bornos y Villariezo (1895 y 1888). Muy parciales, con datos de siglos XVI-XVIII.

- Índice del antiguo legajo 14 del Edo. de Villariezo, sobre títulos de propiedad (XVII-XIX).

- Fundaciones pías del Edo. de Villariezo en Toledo (1541), en vitela, y Valladolid (1661).

- Papeles de la regiduria de los Borja en Madrid (XVIII-XIX).

1533 - Genealogías diversas.

- Inventario de documentos del mayorazgo de Trasmiera, cedidos por el marqués de Castrillo al de Villanueva de Duero (1792). Con documentación de siglos XVI-XVIII.

- Posesiones de Villarrubia (XVII-XVIII).

- Inventario de bienes de María Montenegro (1601).

- Papeles del mayorazgo de Trasmiera (XVII-XVIII).

- Fundación de memoria por Francisco Pignón en el Monasterio de la Victoria de Madrid (1598).

- Bula de Clemente XI a Francisco José López del Castillo, canónigo de Palencia (1715). Vitela.

- Testimonio de nobleza de los Lorca (Madrid, 1628), sacado del libro de Alonso de Toledo Linajes de Castilla y Galicia de 1464. Pergamino, escudo coloreado.

1534 - Inventario de documentos de los mayorazgos de Lorca y Trasmiera (XVIIXVIII). Libro.

- Convenios, cartas de pago y posesiones del mayorazgo de Trasmiera (XVII-XVIII).

- Hijuelas de los Carvajal (1602).

- Índice del antiguo legajo 1 de Trasmiera (XV-XVIII). El único documento del siglo XV es el testamento de Pedro Fernández de Lorca, fundador del colegio de Santa Catalina de los Donados, de Madrid (1460, mayo 23. Madrid). 
1535 - Índice del antiguo legajo 1 del mayorazgo de Ledesma, Edo. de Murillo $(X V \|-X \mid X)$.

- Arrendamientos, créditos contra el Estado, testamentos, inventarios (falta), papeles de nobleza (con árbol), cartas de pago, posesiones y fundaciones y agregaciones al mayorazgo de Ledesma (XVII-XIX).

1536 - Inventario de documentos de Talavera (XVII-XVIII). En poca cantidad.

- Dos inventarios de documentos de Talavera (XV-XVIII).

- Poder del conde de Bornos (1829).

- Capellanía de Ledesma en Talavera (XVII-XIX).

- Censos de los Ledesma (Talavera, XVII-XVIII).

1537 - Cuentas de bienes del Edo. de Murillo (1799).

- Índices de los antiguos legajos 12 y 29 de Ramírez.

- Índice del antiguo legajo 32 del Edo. de Villanueva de Duero, sobre censos en contra (XVII-XVIII).

- Pleito con Filomena Sáenz (1917).

- Papeles del testamento de la última condesa, impresos y mecanografiados (comienzos del XX).

- Juros de los Ramírez (XV-XVIII).

1538 - Fes sacramentales del Edo. de Villanueva de Duero (XVII-XVIII).

- Cuentas de bienes del Edo. de Murillo (1797-1800).

- Créditos y cuentas de acreedores del Edo. de Bornos (1790-1834).

1539 - Pleito entre el conde de Villariezo y el de Guevara por la sucesión del Edo. de Bornos; actas del proceso desde el juzgado municipal hasta el Tribunal Supremo, con dictámenes de Melquiades Álvarez, Manuel García Prieto, Gabino Bagallall y Araujo, Niceto Alcalá-Zamora, y Augusto González Besada (1915-17). Mecanografiado.

1540 - Papeles genealógicos de los Enríquez.

- Reales autorizaciones al Edo. de Villanueva de Duero (XVI-XVII).

- Fes de defunción del Edo. de Villanueva de Duero (XVII-XIX).

- Cuatro censos del Edo. de Villariezo (XVI-XIX).

1541 - Papeles de los administradores del Edo. de Bornos (1817-27).

- Títulos de propiedad y fundaciones de mayorazgo de los Portillo (XVIXVII).

- Particiones de los Quevedo (Reinosa, XVII).

1542 - Cuentas de caudales del Edo. de Bornos (1828-34).

- Revocaciones de mayorazgos (Tapia, Dávila, etc.) (XVI-XVII).

- Censos de los Portillo (XVI-XVII).

- Mayorazgo de Pedro Portocarrero (1495). Impreso.

- Mayorazgos de los Enríquez (XVIII-XIX).

- Cuentas de Sajambre (XVIII).

1543 - Curadurias, inventarios y particiones de bienes y testamentos de los Dávila (XV|-XVII).

- Derechos pagados en puertos de montaña por los ganados de Villanueva de Duero (XVIII).

- Papeles sueltos de Villariezo (XIX). 
- Transacciones de los Quevedo (XVI-XVII).

- Redención del censo de Mazuelo (1657).

- Censo contra el concejo de Mazuelo (1462-1500).

1544 - Pleitos de los Ramírez (XVII).

- Papeles varios de Quevedo (XVII).

- Venta de viña de los Tello (1530).

- Papeles de nobleza de los Enríquez (XVII).

- Índice del antiguo legajo único del mayorazgo de Portillo y Calderón, Edo. de Murillo (XVI-XVIII).

- Memorias pías, poderes, partidas de bautismo y matrimonio, ventas, memorias de bienes e inventarios de documentos de los Quevedo (XVII-XIX).

1545 - Testamentaría de la marquesa de Villanueva de Duero (1847).

- Censos con el marqués de Perales (XIX), con una alegación impresa (1805).

- Títulos de propiedad del Edo. de Villanueva de Duero en Segovia (XVI).

- Testamentarias de los Ramírez (XIX).

- Pleitos de los Ramírez (XVII).

- Tres mayorazgos de los Mariscales de Castilla, de apellido Rivadeneira (XV). Libro con traslados.

1546 - Índice del antiguo legajo 31 de Ramírez.

- Pleitos de los Ramirez (XVI).

- Títulos de propiedad de fincas en Segovia, del Edo. de Villanueva de Duero (XVI-XIX).

- Papeles de las dehesas de Bornos en Toledo, con un plano de Pedro Vidal de la dehesa de Realejo (1869).

- Papeles de las obras pías de Mencía Suárez (XVII).

1547 - Poderes de los Ramírez (XVI-XIX).

1548 - Documentos del portazgo de Madrid, de los Ramírez (XVII-XIX).

- Títulos de propiedad de fincas vinculadas de los Ramírez (XVIII).

1549 - Títulos de propiedad de fincas libres y vinculadas de los Ramírez (XVI-XIX).

- Índice del antiguo legajo 30 de los Ramirez, de poderes.

- Fianzas de los Ramírez (XVI-XIX).

1550 - Testamentos de los Pérez (XVII).

- Inventarios y particiones de los Pérez (XVI-XVIII).

- Pleitos de los Ramírez (XVII).

- Papeles de nobleza de los Losada.

- Tomas de posesión del Edo. de Villanueva de Duero (XVI-XVII).

- Capitulaciones matrimoniales de los Pérez (XVII).

1551 - Índice del antiguo legajo de los Pérez, Edo. de Murillo (XV-XIX).

- Cuentas tomadas al mayordomo de las memorias de Antonio Meneses (1688-1744). Libro.

- Títulos de propiedad del Edo. de Villariezo en Zamora (XVI).

- Inventario de documentos de los Pérez (XVIII-XIX).

- Mayorazgos del Edo. de Villanueva de Duero (1524-83).

- Posesiones de los Ramírez (XVII-XVIII). 
1552 - Pleitos de los Ramirez (XVII-XVIII).

- Títulos de propiedad de los Edos. de Villariezo en Zamora y Valladolid (XVI).

- Papeles de nobleza de los Losada (XVII).

- Posesiones de los Ramírez (XVII-XIX).

1553 - Toma de posesión de bienes en Logroño por el conde de Murillo (1764). Libro.

- Arrendamientos en Logroño (XVI-XIX).

- Tres documentos de nobleza de los Brito (XVII).

- Venta de una heredad en Talavera (1631).

- Índice del antiguo legajo 1 del mayorazgo de Olivares, del Edo. de Murillo (XVI-XVIII). Parte.

- Información de nobleza de Juan Osvaldo de Brito (1623). Libro.

- Censos a favor de los Enríquez (1765).

1554 - Herencias del Edo. de Villanueva de Duero (XVIII).

- Noticias genealógicas de los Dávila.

- Cuentas de cabañas (1821-26).

- Papeles de los Pérez y los Moneda (XVI-XVII).

- Índice del antiguo legajo 1 de los Olivares. Parte.

1555 - Herencias del Edo. de Villanueva de Duero (1798).

- Censos a favor de los Enríquez (1758).

1556 - Testamentos, cartas de pago, informaciones y sentencias de los HerreraZuazo (XVI-XVIII).

- Testamentos (XVI), apeos y arrendamientos de los Pérez (XVI-XIX). Con planos de las fincas.

- Toma de posesión por el conde de Bornos del mayorazgo de Trillo (1802).

- Censos a favor de los Enríquez (1703 y 1763).

1557 - Pleito de las hermanas Sanguinetti con Bornos por el Lavadero de Rojas (1873-81).

- Dictámenes a los Contreras (XVII).

- Pleito con Bornos por servidumbre de paso en Toledo (1877).

- Informaciones diversas (XVI-XIX).

- Papeles de los Guevara (XVI-XIX).

- Memoriales de pleitos manuscritos (XVIII).

- Pleito por las minas de hierro de Molina (1842).

- Ejecutoria de mil y quinientas a favor del Edo. de Murillo (1777).

- Ejecutoria del Consejo de Hacienda contra los Guevara (1527).

- Índice del antiguo legajo 1 del mayorazgo de Butrón, del Edo. de Murillo (XV-XVIII).

- Ejecutoria de la Chancillería de Valladolid contra el Edo. de Murillo por embargo de censo (1565).

- Cuentas de viaje y nóminas (1810-13).

1558 - Compraventas en Tudela de Duero (XV-XVI).

- Papeles de las capellanías de los Rueda en la iglesia de San Bartolomé de Logroño (1720-1814).

- Papeles de la Abadia de Rueda (XVIII-XIX). Incluye dos pleitos criminales y una Bula de 1452 a Juan Il de Castilla (original y dos traducciones). 
1559 - Hijuelas y particiones de los Herrera, Barrasa y Trasmiera (XVI-XVII).

- Redenciones de censos en contra de los Zuazo (XVII).

- Memorias de fincas y relaciones de papeles de los Zuazo (XVIII-XIX).

1560 - Memorial impreso del pleito por el Edo. de Villaverde (1803). Varios ejemplares.

- Compraventas en Tudela de Duero de fincas rústicas (XVI) y urbanas (XVI-XVII).

1561 - Censos en Medina del Campo (XVII).

- Censos, posesiones y apeos de los Enríquez (XVII-XIX). Un plano de casa en Motril.

- Herencias del Edo. de Villanueva de Duero (XVIII).

- Índice de documentos del mayorazgo de Coscojales (XVI-XVIII).

- Inventarios de documentos de los Edos. de Villariezo y Murillo (XIV$X \mid X)$.

1562 - Censos redimidos de los Salazar (XVI-XIX).

- Obra pía de los Salazar en Medina del Campo (XVII-XIX).

- Capitulaciones matrimoniales de los Salazar (XVI-XVII).

- Títulos de propiedad de los Salazar en Brahojos (XVI).

- Juros (XIX) y dotes (XVI-XVII) de los Salazar.

- Derechos de diezmos del Edo. de Murillo (XVI).

- Cuentas de caja (1888).

1563 - Derechos de diezmos del Edo. de Murillo (XVI-XVIII).

- Facturas en blanco.

- Cuentas de caja (1886-1905).

1564 - Mayorazgo y testamento de Juan de Salazar (1634). Dos ejemplares.

- Derechos de diezmos del Edo. de Murillo (1708). Libro.

- Fascículos sueltos de la Gaceta de Madrid y Boletín Oficial del Estado (1916-22).

1565 - Testamentos del Edo. de Villanueva de Duero (XVIII).

- Inventarios y particiones del Edo. de Murillo (XVI-XVIII).

- Inventario de documentos del Edo. de Murillo en Medina del Campo (XVXVII).

- Arrendamientos de los Ramírez en Salobreña y Motril (XVIII-XIX).

- Compraventas de tierras y solares en Medina del Campo, Edo. de Murillo (XVI).

- Cuentas de los Tello (1641 y 1643).

- Juros y posesiones de los Dávila (XVII-XVIII).

1566 - Papeles de la casa c/. Jesús y María, de Madrid (XIX). Noticias de la guerra de la Independencia y certificados de arquitectos.

- Herencia del Edo. de Villanueva de Duero (1701).

- Cuentas de los Mercado (XVI-XVII).

- Juros de los de la Torre (XVI y XIX).

- Testamentaría del Edo. de Villanueva de Duero (1883).

- Inventario de documentos de los de la Torre (XV-XVIII).

- Ejecutoria de la Chancillería de Valladolid a favor de la marquesa de Villacastel y condesa viuda de Villanueva de Duero, contra el conde de Valparaíso por tierras en Medina del Campo (1799). 
- Papeles de la casa c/. de la Madera Alta, de Madrid (XVII-XVIII).

- Papeles de la casa c/. Jesús del Valle, de Madrid (XVIII).

- Arboles genealógicos (Beizanas y otros).

1567 - Cuatro escrituras protocolizadas de compras de tierras (XIX).

- Compraventas y permutas de tierras en Medina del Campo, del mayorazgo de la Torre (XVI-XVIII).

- Compraventas de casas de los de la Torre en Medina del Campo (1516-64).

- Tres herencias del Edo. de Villariezo (XVII).

- Testamentaria de Martín Fernández de Salazar (1595).

- Arrendamientos de los Ramírez en Motril (1763-1815).

1568 - Recibos de caja (1912).

- Títulos de propiedad de fincas de los Ramírez en El Escorial (1857).

- Certificados del Edo. de Villaverde (XV y XVII-XVIII).

- Mayorazgos del Edo. de Villariezo (XVIII-XIX).

1569 - Censo de unas gallinas sobre una casa en Madrid, del mayorazgo de Trasmiera (XVII-XIX).

- Testamentos, memorias de misas, juros y estados de fincas del mayorazgo de Trasmiera (XVII-XIX). Plano de casa.

1570 - Mayorazgo del Edo. de Villaverde (1490). Tres ejemplares.

- Títulos de propiedad en Olmedo del Edo. de Villariezo (XV-XIX).

1571 - Papeles de los Ramírez sobre la Pradera de San Isidro (XVII-XIX).

- Títulos de propiedad de fincas vinculadas por los Ramírez (XV-XVIII).

- Dictámenes a los Enríquez (XVIII-XIX).

- Partidas de confirmación y defunciones del Edo. de Murillo (XIX).

- Autos de los Moneda (XVIII).

- Instrumentos del Edo. de Villaverde (1742).

- Índice del antiguo legajo 1 del mayorazgo de Calchetas, del Edo. de Murillo (XVI-XIX).

- Escritura de declaración de inmediato sucesor de María Javiera de Riaño y Orovio, viuda de Juan Pedro Tello y Mercado, a favor de su hija segunda María Eusebia Telio y Riaño (1764).

1572 - Documentos del Edo. de Villaverde (XV-XVIII).

- Árboles genealógicos de los Ramírez de Arellano y de los Calchetas.

- Mayorazgo y otros documentos de los Calchetas (XVI).

- Índice del antiguo iegajo 1 del Edo. de Villaverde (XIV-XVIII).

- Censos contra el Edo. de Villariezo en Burgos (XV|I-XVIII).

1573 - Censos en contra del Edo. de Villariezo en Aranda de Duero (XVI-XVII), Arévalo (XVI-XVIII) y Burgos (XVII-XIX).

- Capitulaciones matrimoniales y dotes de los Ramírez (XV-XVIII).

1574 - Títulos de propiedad del Edo. de Villariezo en Olmedo (XVI-XIX).

- Documentos de los Calchetas (XVI-XIX).

1575 - Documentos del Edo. de Villaverde (1429-XVII), algunos en pergamino; con dos índices antiguos.

- Capitulaciones matrimoniales y dotes de los Ramírez (XVIII-XIX).

- Censos del Edo. de Villariezo (XVI-XVII).

- Tomas de posesión del Edo. de Villariezo (1486-1520). 
1576 - Documentos del Edo. de Villaverde (XVIII-XIX).

- Residencias tomadas a los oficiales de Villanueva de Duero (1732-57).

- Fundaciones de capellanías de los Dávila en Ávila (XVI-XVIII).

1577 - Memorias de fincas de los Ramírez, especialmente en Motril (XVI-XVIII).

- Residencias tomadas a los oficiales en Villanueva de Duero (1628-1722).

1578 - Inventarios y memorias de los Ramírez (XVII-XIX). Con índice del antiguo legajo 31 de los Ramírez.

- Documentos de los Ramírez en Motril (XVII-XIX).

1579 - Títulos de propiedad de fincas rústicas y urbanas de los Quevedo (XVIXVIII). En gran número.

- Título del oficio de contador de cuentas y particiones de Reinosa (16371715).

- Título de la escribanía del ayuntamiento de Reinosa (1523-1624).

1580 - Fundación de patronato en convento de San Agustín de Segovia (XVI). Libro; y otros documentos sobre 10 mismo, del Edo. de Peñarrubia (1600).

- Vínculos de los Quevedo (XVII-XVIII).

- Censos de los Quevedo (XVII-XIX).

- Posesiones del Edo. de Murillo (XVIII).

- Documentos de los Carvajal de Cáceres (XV-XVIII).

- Memorias de bienes de los Ramírez (XVI-XVII).

1581 - Testamentos de los Losada (XV-XVIII).

- Compraventas, transacciones y requerimientos de los Guevara (XVI-XVII).

- Correspondencia de los Rueda-Herrera (XVIII). Una carta familiar del Conde de Murillo a sus hijos con consejos de comportamiento.

- Documentos de los Ramírez en Motril (1691-93).

- Compraventas de los Quevedo (XVIII-XIX).

- Inventario de documentos de los Quevedo en Reinosa (1854), con documentación de los siglos XVII-XVIII.

1582 - Papeles de los Dávila (XVI-1624).

- Censo contra Bornos (1784). Libro.

- Papeles y cuentas del Lavadero de Rojas (XX).

- Documentos del Edo. de Villariezo (XVII-XVIII).

1583 - Papeles de la encomienda de la Fuente del Maestre (XVIII-XIX).

- Traslados de mayorazgos de Villariezo (1500), con índice antiguo.

- Redención de un censo de Bornos (1886). Protocolizado.

- Privilegio del Edo. de Villariezo contra la Mesta (1654).

- Títulos de propiedad del Edo. de Villanueva de Duero en Tordesillas (XVIII).

- Papeles de las Salinas de Duernas (XVII-XVIII).

1584 - Censos contra los Ramírez (XVIII-XIX).

- Árboles genealógicos de los Tello, Dávila y otros muchos linajes.

- Papeles genealógicos de los Dávila.

- Plano de las Salinas de Duernas, por Esteban Moyano (1879).

1585 - Cuentas del Hospital de la Latina (1809 y 1812). 
- Cartas de pago por hierbas de dehesas a los Rojas en Toledo (1616-1700 y 1754-85).

- Pleito de Alcanadre (1794).

1586 - Papeles de las Salinas de Duernas (XVI-XVIII).

- Documentos de jurisdicción del Edo. de Murillo (XVIII).

- Títulos de propiedad del Edo. de Villanueva de Duero en Tordesillas (XVII).

1587 - Papeles de las Salinas de Duernas (XVII-XIX).

- Títulos de propiedad del Edo. de Villanueva de Duero en Tordesillas (1635).

- Documentos del Edo. de Villariezo, de los Mercado y de otros linajes (XVIXVII).

- Ejecutoria a favor de Sebastián Antonio de Contreras contra la Mesta (1652).

- Papeles varios (XVII-XVIII).

1588 - Inventario general de documentos del Edo. de Villaverde (XIV-XVIII). Libro con una estampa inicial.

- Índice del antiguo legajo 16 de los Ramírez, sobre apeos y planos (XV-XIX).

- Índice de documentos del Edo. de Villariezo (XVIII).

- Apeo de bienes en Motril (1580). Libro.

- Apeos y títulos de propiedad de los Ramírez (XVI-XIX).

- Curadurías de los Tello (XVI-XVII).

- Patronatos del Edo. de Murillo (XVI-XVIII).

1589 - Títulos de propiedad del Edo. de Villanueva de Duero en Tordesillas (1633). Libro.

- Censo contra el mayorazgo de Quevedo (1763). Libro.

- Papeles de los Ahumada (XVI).

- Patronatos del Edo. de Murillo (1622). Libro.

- Herencias del Edo. de Villariezo (1788-1826).

1590 - Cuentas de las rentas del Hospital de la Latina (1536-57). Libro.

- Inventario y traslado de documentos del Edo. de Villariezo, de obras pías de los Meneses (XVII).

- Patronatos del Edo. de Murillo (XVIII).

- Papeles de los Perea (XIX).

- Inventario de censos de los Ramírez (XVI-XIX).

1591 - Testamentos de los Ramírez (XVII).

- Mayorazgo de Sebastián Antonio de Contreras (1633). Original en pergamino y copia.

- Cuentas de misas del Hospital de la Latina (1758).

- Capellanías de los Ahumadá (XVI-XIX). Árbol genealógico.

- Indices de los antiguos legajos 29 y 33 del Edo. de Villariezo (XIV-XVIII).

- Documentos de los Ahumada (XVI-XIX).

- Cuentas del Hospital de la Latina (1756-57 y 1761).

- Censos de los Edos. de Villariezo y Bornos (XVII-XIX).

1592 - Inventario de bienes de Antonio de Mercado y Tapia, y adjudicación a su viuda, Josefa María Tello Dávila y Guzmán (1749). 
- Inventario de bienes de Francisco Manzano (1666).

- Otros inventarios, testamentos y particiones de los Tello (XVII-XVIII).

- Arrendamientos de los Ramírez en Motril (1763-1869).

- Dictamen a Onofre Ramírez de Haro (XVIII).

- Censos contra el Edo. de Villariezo en Zamora (1513-63).

- Testamento del marqués de Falces (1777).

1593 - Compraventas de los Ramírez (XV-XVI).

- Inventarios de documentos del Edo. de Villanueva de Duero; entre ellos, uno de los Contreras de Jaén, con documentos sin fecha (XVII).

1594 - Censos del Edo. de Villaverde (XVIII).

- Arrendamientos y otros documentos del Edo. de Villaverde (XVIII).

- Dos memoriales del conde de Murillo, solicitando la Grandeza de España (1771). Manuscritos.

- Títulos de mercedes y empleos del Edo. de Murillo (XVII-XVIII).

1595 - Papeles de los Contreras (XV|I-XVIII). Planos de la casa principal de Tordesillas (1628-31).

- Dictámenes, sentencias, apeos, correspondencia, inventarios de bienes, etc. de los Contreras (XVIII-XIX). Una relación de bienes de la administración de Jaén (XVIII-XIX).

1596 - Genealogías de Manzolo y Moneda.

- Papeles genealógicos de los Moneda (XVII).

- Toma de posesión del mayorazgo de Velasco (1736).

- Índice del antigio legajo 27 de Villariezo, sobre tomas de posesión (XVXVIII). Sigue parte de la documentación.

- Índice del antiguo legajo 1, del mayorazgo de Moneda y Lerma, del Edo. de Murillo (XVI-XVIII).

- Dictámenes (XIX).

- Memoriales de varios pleitos (XVI-XVIII).

1597 - Testamento de los Moneda (1624).

- Memoriales de pleitos por los mayorazgos de Ramírez de Tovar y del marqués de Valdefuentes (XVIII).

- Tomas de posesión de los de la Torre, en Torrelobatón (XVI-XIX).

1598 - Genealogía de los Lerma.

- Obligaciones de los Moneda (XVII).

- Partidas de bautismo, casamiento y defunción de los Moneda (XVI-XVII).

- Otros documentos familiares de los Moneda (XVII-XVIII).

1599 - Capitulaciones matrimoniales y títulos de propiedad de los Ramírez, con índice de los antiguos legajos 11 y 22.

- Provisión a los de la Torre (1642).

- Papeles y árbol genealógico de los Moneda (XVIII).

- Reales provisiones para contraer matrimonio a los Ramírez (XVII-XIX).

1600 - Papeles del Monasterio franciscano de Scala Dei, en el despoblado de Brahojos, cerca de Valladolid (1627 y siguientes). Plano, corte y alzado.

- Fundación de varias misas cantadas en el Monasterio de Calatrava (XVIII).

- Redención de varios juros del conde de Villaverde (XVIII). 
- Inventario del antiguo legajo 3.

- Censo de la dehesa del Castañar (1528 y siguientes).

1601 - Documentos judiciales de la Rioja (XVI-XVIII).

- Fundaciones pías en varios lugares (XVIII-XIX).

1602 - Fundaciones de diversos vínculos y agregaciones del Edo. de Villanueva de Duero (XVIII).

- Fundaciones pías varias (XVIII).

- Documentos judiciales de Segovia (XVI).

- Documentos judiciales del Edo. de Villanueva de Duero (XV|II-XIX).

1603 - Fundación de vínculos y mayorazgos del Edo. de Villanueva de Duero (XVIII).

- Testamentarias de la zona de Segovia (XVI).

- Testamentarias varias (XVII-XIX).

1604 - Censos en Medina del Campo (XVI).

- Expediente de construcción de un edificio en la Plaza de la Audiencia de Burgos (1862). Con planos del arquitecto Antonio Herrera de la Calle.

- Idem de un molino en Burgos (1873). Con Planos.

- Papeles del mayorazgo de los Meneses (XVI-XVIII).

- Papeles de los Enríquez (XVIII-XIX).

- Documentos de los Olivares y las fábricas de Liérganes y La Cavada (XVII-XVIII).

- Cuentas del Hospital de la Latina (1854-1855).

1605 - Papeles del mayorazgo de Ahumada, de Medina del Campo (XVI-XVII).

- Índice del legajo antiguo sobre ese mayorazgo, perteneciente al conde de Murillo.

- Papeles de Molina y Beteta (XVII).

- Testamentos de los Ramirez de Haro (XV-XVIII).

- Índice de dichos testamentos.

- Censos de Villariezo en Sepúlveda (XVI-XVII).

1606 - Cuentas de rendimientos de propiedades de Bornos (XIX).

- Idem y testamentaría de doña María Asunción Belvís de Moncada y Rojas, marquesa de Villanueva de Duero y condesa de Villariezo y Villaverde (1849).

1607 - Herencias del Edo. de Villanueva de Duero (XVII).

1608 - Cuentas de fincas rústicas y urbanas (1930).

- Testamentos del Edo. de Murillo (XIV-XIX).

1609 - Servicios de los Olivares y Britos (XVI-XVil).

- Índice de documentos del mayorazgo de Olivares (XVII-XVIII).

- Arrendamiento de la Virgen, Motril (1764-1849).

- Fundaciones de los Villalpando, Sevilla (1513).

- Arrendamientos de Motril (XIX).

- Índice de los arrendamientos (XVIII-XIX).

1610 - Documentos mezclados de los Meneses y Talavera de la Reina (XVII).

- Indice del antiguo legajo 32 de los Ramírez de Haro sobre pleitos (XVII).

- Documentos judiciales referentes al índice y otros (XVII-XVIII).

- Documentos testamentarios del Edo. de Villanueva de Duero (XVII). [Copia de privilegio de Alfonso XI a Toledo en 1332]. 
1611 - Papeles de la casa de Santiago, en la plaza de ese nombre, en Madrid, perteneciente al mayorazgo de los Losada (XVI-XIX). Planta del edificio, construido en 1830-1831.

- Documentos sueltos de Zamora, Talavera, Cintruénigo (XVII-XIX).

- Documentos varios de los Ramírez de Haro y Losada (XVII).

- Cuentas de varias administraciones (XIX).

1612 - Cuentas de varias administraciones (XIX).

- Documentos de mayorazgos de los Losada (XIV-XVII). [uno de Juan I, donando la Puebla de Sanabria].

- Documentos sobre méritos y títulos de los Losada (XVII).

- Títulos de propiedad de Bornos en Castilla la Nueva (XIX).

- Cuentas y testamentarias (XIX).

1613 - Arrendamientos de casas en Madrid, de los Ramírez (XVI-XIX).

- Relaciones de papeles de los Losada (XVI-XIX).

- Censos en contra en Motril, de los Ramírez (XVIII).

- Censos a favor, de los Olivares (XVI-XVII).

1614 - Documentos de diferentes procedencias (Arévalo, Navarra, etc.) (XVIXVIII).

- Documentos de señorío del Edo. de Murillo (XVIII).

- Censos de los Losada (XVII).

- Inventarios y juros de los Ahumada (XVI-XVII).

- Papeles de rentas del Hospital de la Latina (XVIII).

1615 - Inventarios de los Ramírez (XVII).

- Testamentos de muchфs linajes, entre otros, los Tello (XV-XVI).

- Herencias del Edo. de/Villanueva de Duero (XVIII).

1616 - Facultades para fundar mayorazgos a los Ramírez (XV-XVI).

- Testamento de Peñalosa (1482).

- Censos a favor del Edo. de Villariezo, en Sepúlveda (XVI).

- Méritos y servicios de los Ramírez (XVII). Faltan todas las cuentas de Francisco Ramírez de Madrid (1497-1502). Sólo queda la carátula.

- Documentos del mayorazgo de Meneses (1608-1764). Documentos cosidos en un libro.

1617 - Índice del antiguo legajo 34 de Villariezo, de censos a favor (XVII-XVIII).

- Fundaciones de mayorazgo de los Ramírez.

- Indice del antiguo legajo 10 de Ramírez, sobre títulos de propiedad (XV$X I X)$.

- Índice del antiguo legajo 15 de Villanueva de Duero, sobre títulos de propiedad en Burgos (XVI-XVII).

- Juros y documentos de señorío de Murillo (XVII).

- Herencias de Villanueva de Duero (XVIII).

- Censos a favor, de Villariezo (Soria, XVII).

1618 - Compraventa de casa (Toledo, 1887).

- Cuentas de Villariezo (1847-58).

- Quinquenios de la administración de Villariezo (1837-50).

- Pleito de los Meneses (Talavera, 1623). 
- Compraventa de casa (Segovia, 1563).

- Compraventas de varias dehesas $(X \mid X)$. La de Realejo, en Toledo, contiene documentación del siglo XV.

- Visitas a las memorias de Meneses (Talavera, 1710).

1619 - Censos a favor de Villariezo, en Salamanca y Olmedo (XVI).

- Arrendamientos en Talavera (XVI-1872).

- Compraventas de tierras por Losada (1587).

- Reales autorizaciones a Villanueva de Duero (XVII).

- Papeles de las memorias de los Meneses (XVII-XIX).

- Testamento de los Enríquez (1633).

- Libro horadado de la contaduría real, sobre juros (XVI).

1620 - Testamentos de Vilianueva de Duero (XVII).

- Papeles de fincas en Montamarta (1740). Libro.

- Papeles de los Contreras (XVIII).

1621 - Préstamos, cuentas, correspondencia del Tomilloso, mezclados (XIX).

- Recibos del Hospital de la Latina (1892).

- Correspondencia de Jaén y Cambil (1906).

1622 - Préstamos (XIX).

- Correspondencia de Motril con el conde de Guevara (elección de alcaldes) $(X X)$.

- Informe reservado sobre el administrador de Cambil (1914).

1623 - Papeles de varias administraciones, en especial, de Cambil, Motril, Olmedo y Abadía de Rueda (fines del XIX y comienzos del $X X$ ).

1624 - Documentos de sumillería de Corps (1820-30).

- Documentos de la Diputación permanente de la Grandeza (1815-40 y 1851).

- Cuentas varias (central, Lavadero, etc.) (XX).

- Gacetas de Madrid, copiadas (1870-80).

- Correspondencia de Zamora (1803).

- Correspondencia con Víctor Martín, abogado de Toledo (1871-75).

- Correspondencia varia y recursos del Edo. de Villaverde (un dictamen de 1805).

- Documentos de distintas Sociedades Económicas de Amigos del País (XX).

- Papeles de la Real Maestranza de Sevilla (1851).

- Papeles de la Orden de Carlos III (1830-33).

- Papeles de la encomienda de Castellanos (1827).

- Recibos del Hospital de la Latina (1883).

- Correspondencia de Motrii y Tordesillas (XIX).

- Solicitudes de empleo (XX).

1625 - Correspondencia de escribanos de la casa (1850-70).

- Correspondencia con José María González de Castro (1838-55).

- Correspondencia de Ávila (1842-48).

- Correspondencia con Antonio Cabanilies, letrado de Bornos (1863-64).

- Correspondencia varia (XVIII-XIX).

- Asuntos modernos (XX). 


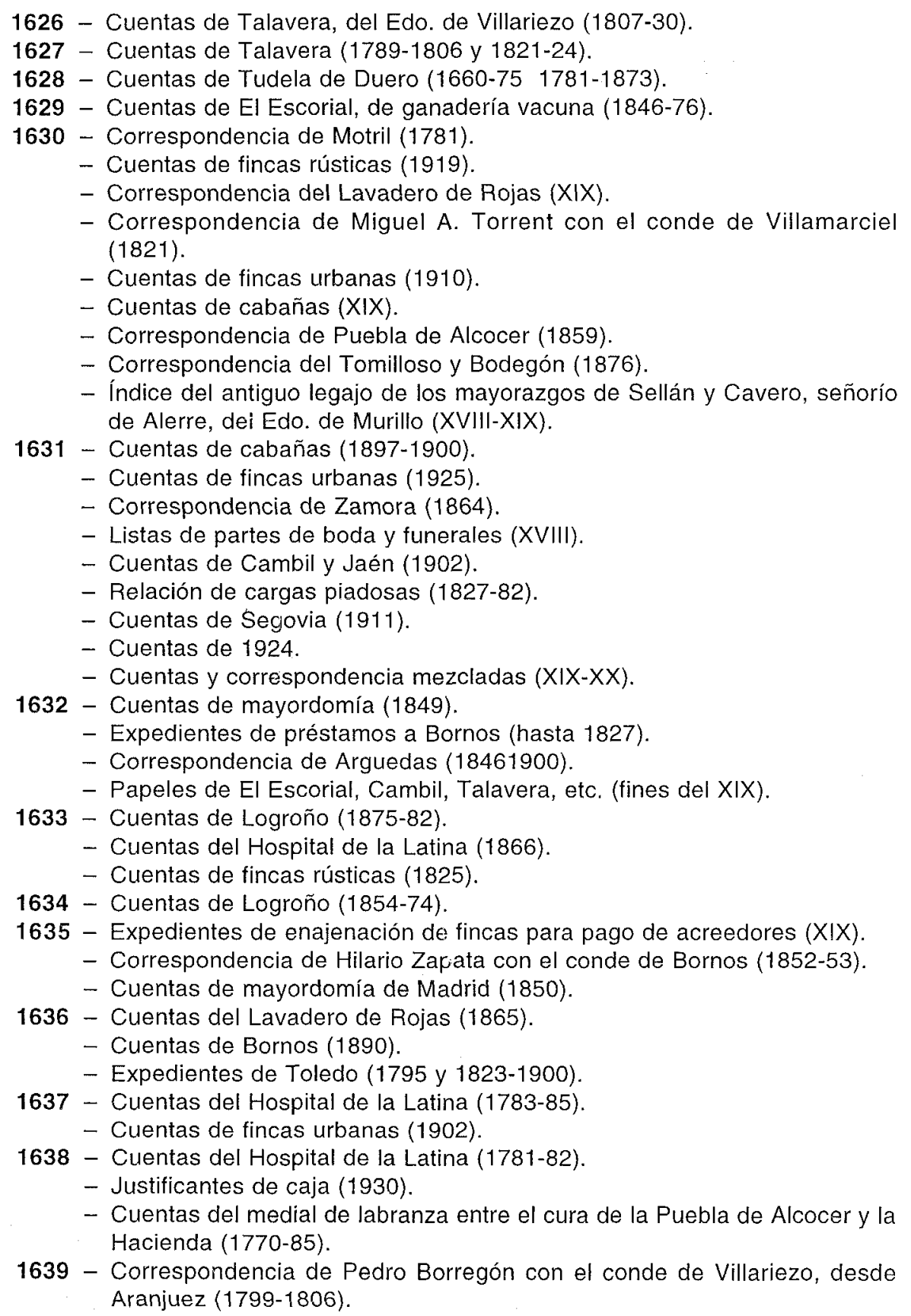


1640 - Cuentas de cabañas (1844-51).

- Relaciones presentadas a la comisión evaluadora de la contribución (1885-87).

- Cuentas de Bornos (1901).

1641 - Cuentas de cabañas (1816 y 1897).

- Cuentas de Olmedo (1908).

- Cuentas de fincas urbanas (1921).

- Recibos del ganado de Villanueva de Duero (1815).

1642 - Justificantes de caja (1929 y 1931).

- Presupuestos del Lavadero de Rojas (X|X).

- Correspondencia de Zamora, León, Soria y Segovia (comienzos del XIX).

1643 - Correspondencia de Murcia, Gerona, Ávila, Extremadura y Guadalajara (XIX).

1644 - Cuentas del Hospital de la Latina (1796-99).

1645 - Cuentas de Córdoba (Salinas de Duernas) (1889-1900).

1646 - Cuentas de Córdoba (1878-90).

1647 - Cuentas de Cambil (1880-91).

1648 - Papeles de rentas caducadas: salinas de Trafalcací y Duernas, fábrica de Liérganes y varias alcabalas (XIX).

- Cuentas de Cambil (1879).

- Dictámenes.

1649 - Cuentas y correspondencia de cabañas (1801-22).

1650 - Correspondencia de Guadalajara (1787-1892).

1651 - Correspondencia de Motril (1783).

- Correspondencia de Medina del Campo, Torrelobatón, Tordesillas y Villanueva de Duero (1902).

- Correspondencia de Medina del Campo (1870-84).

- Correspondencia de Valmaseda (1841-67).

1652 - Cuentas de Logroño y Alcanadre (1875).

- Expedientes de Logroño (1878-92).

- Cuentas de gastos de la marquesa de Villanueva de Duero (1822).

- Cuentas de Bornos (1904).

1653 - Cuentas de Córcioba (1822-60).

- Expedientes de la memoria de doña Mencía Suárez (Talavera, 1820-98).

1654 - Cuentas de Jaén y Cambil (1903).

- Cuentas del Hospital de la Latina (1805-08).

1655 - Justificantes de caja (1915).

- Testamentaría de la condesa de Bornos (1915).

- Cuentas del Lavadero de Rojas (1829-36).

1656 - Justificantes de caja (1920).

- Cuentas de las Salinas de Añana (1906-12).

- Correspondencia de Calzada de Calatrava (1855-84).

- Correspondencia de la condesa de Bornos desde el balneario de Santa Agueda (1861).

- Cuentas de cabañas (1890-91). 


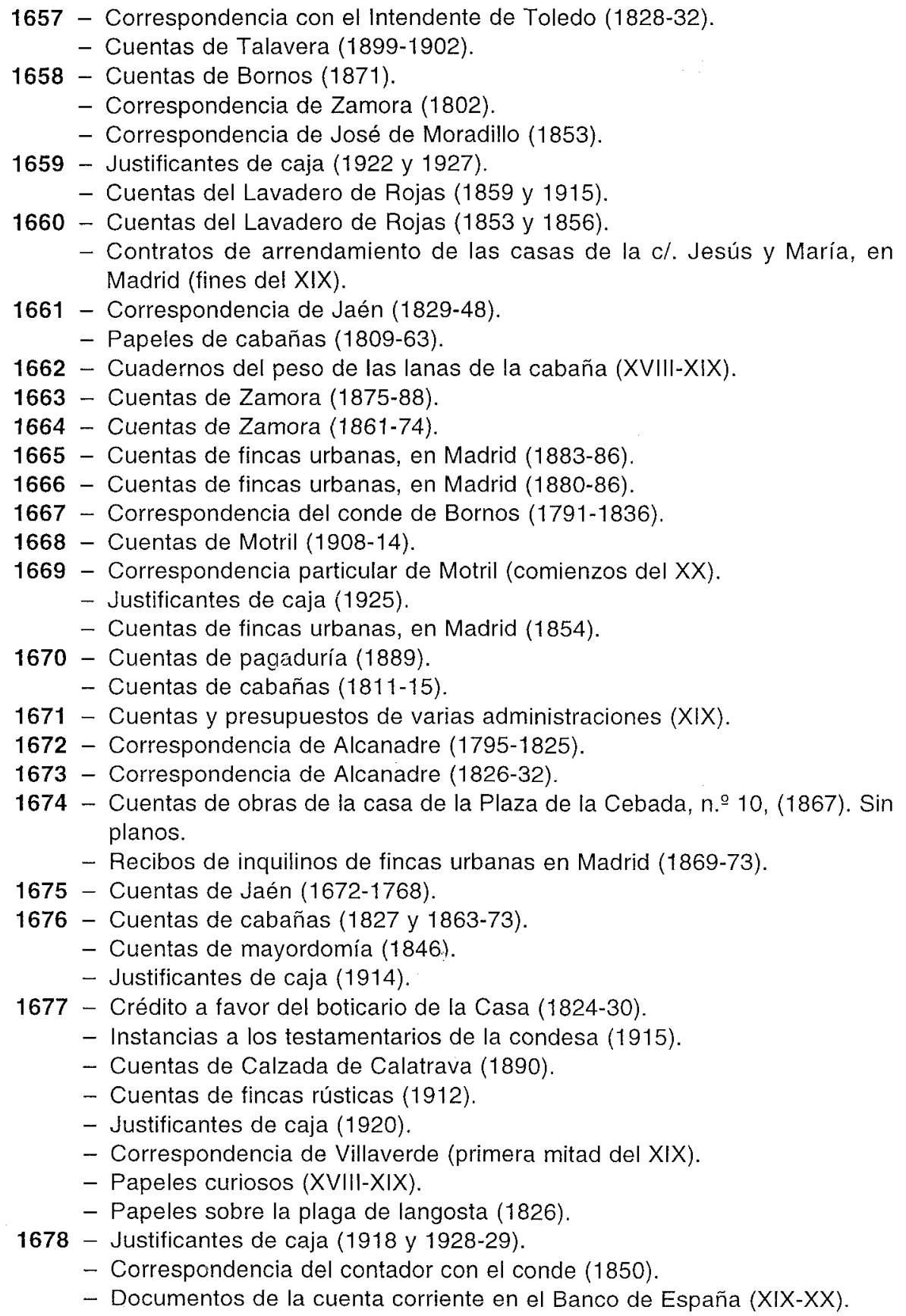




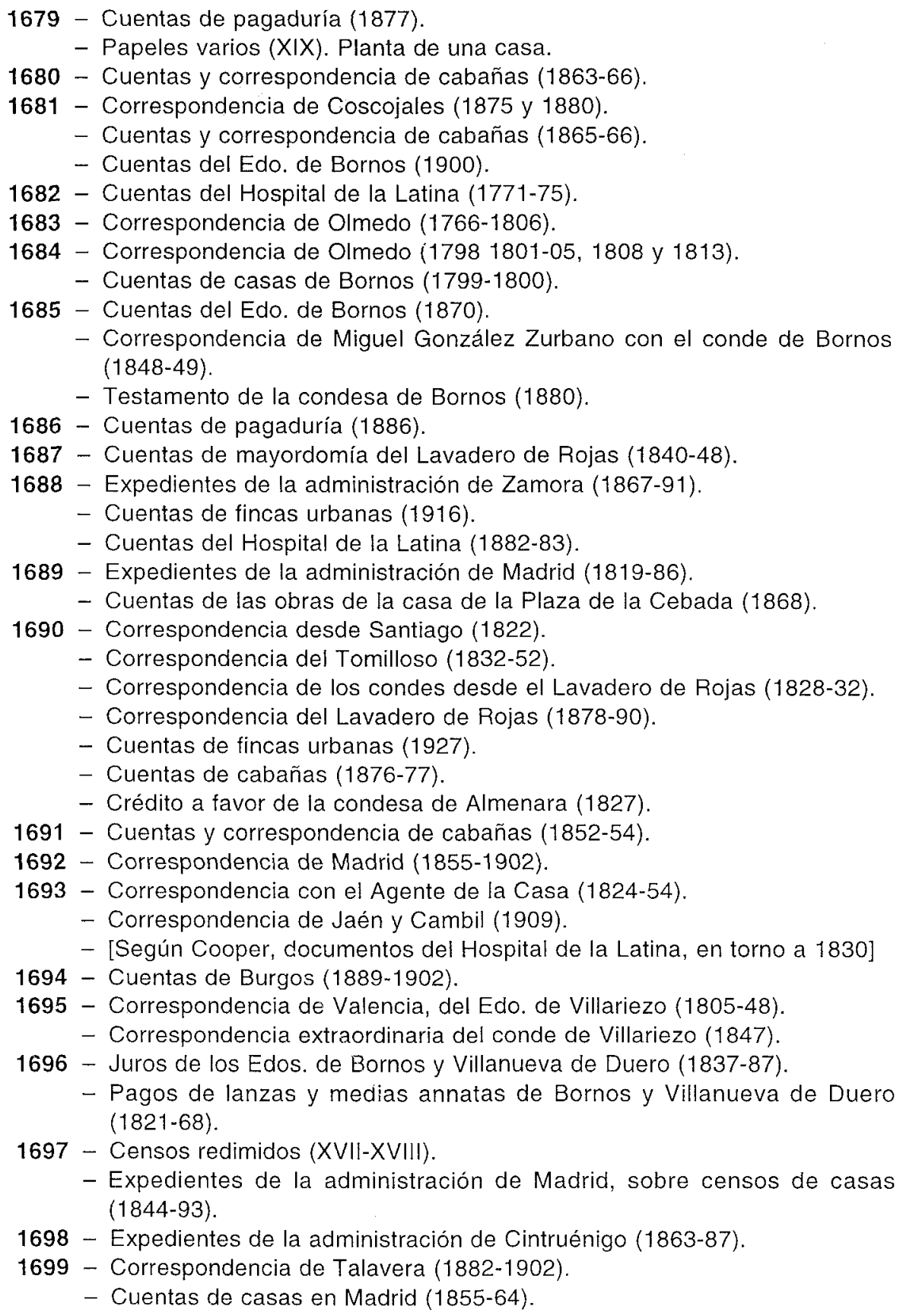


1700 - Administración de distintas posesiones de Bornos (XIX), con correspondencia con la duquesa de Frías y el marqués de Jabalquinto.

- Correspondencia del conde de Villariezo (XIX), entre otros temas, sobre grados militares y venta de la red de San Luis.

1701 - Documentos de Torrelobatón (1815).

- Testamentarías, funerales e impresos de participación del óbito del conde de Bornos, fallecido en el lavadero de Rojas, casa de campo extramuros de Toledo (1845).

- Cuentas de Torrelobatón (1818-1838).

1702 - Cuentas de Caballeriza (1827-1835).

- Cuentas de mayordomía de Madrid (1851).

- Relaciones de ganadería (XIX).

1703 - Cuentas de Cambil (1825-56).

1704 - Correspondencia mezclada de Zamora, Lavadero de Rojas, cabañas, Villariezo, etc. (fines del XVIII y comienzos del XIX).

- Cuentas de Cintruénigo (1908).

- Texto impreso de la sentencia de la Audiencia Territorial de Madrid en el pleito entre el conde de Villariezo y el de Guevara por la sucesión de la condesa de Bornos (1917, junio 27. Madrid). En mal estado.

1705 - Reglamento impreso de las Ordenes de San Fernando y San Hermenegildo (1815).

- Cuentas de la condesa de Alcudia (1809-22).

- Aprobación de la fundación de una capilla en el convento de Nuestra Señora de Gracia, en Salamanca, por el prior de la Orden (1531).

- Cuentas de la Pradera de San Isidro (1795-96 y 1798).

- Correspondencia de Tordesillas (1814-50).

- Correspondencia de Zamora (1791 y 1799-1800).

- Gravámenes de fundaciones piadosas (1843 y 1860).

- Correspondencia de Toledo (1859-60).

- Correspondencia de Calahorra (1778).

- Correspondencia de Ávila (1832-35).

- Correspondencia del marqués de Villanueva de Duero (fines del XVIII).

- Compraventas en Tordesillas y Valladolid (1554-55).

1706 - Cuentas de Jaén (1891-1902).

- Autos de la marquesa de Villanueva de Duero con Higinio Melere (183359).

1707 - Justiticantes de la administración del Lavadero de Rojas (1924).

1708 - Cuentas de Guadalajara (1781-1868).

1709 - Cuentas del Edo. de Bornos (1891).

- Cuentas y recibos del Tomilloso (1817-45).

1710 - Correspondencia del Conde de Villariezo (1800-13), noticias sobre la Guerra de la Independencia.

1711 - Correspondencia de Alcalá de Guadaira (1714-67).

- Correspondencia del conde de Villariezo desde Toledo y los Reales Sitios con su secretario Moya (1806-08). 
1712 - Correspondencia de Torrent con el Conde de Villariezo (1805-08).

- Testamento, mandas, cuentas, etc. de la marquesa de Castromonte, María Mercedes Belvís Mendoza y Pizarro, fallecida en 1837 (1824-38). Con correspondencia y cuentas de Jaén, como condesa de Garciez.

1713 - Correspondencia de Arévalo (1824-50).

1714 - Correspondencia de Arévalo (1791-1823).

1715 - Cuentas de la Huerta de Atocha (1804-08).

1716 - Cuentas del Lavadero de Rojas (1909-12).

- Ejemplar impreso de libro eclesiástico de Bienvenido Monzón (1864).

- Número del Memorial de Artillería (noviembre-1916).

- Contratos de arrendamiento de casas en Madrid (XIX).

- Correspondencia de Segovia (1911).

- Cuaderno con fotografías familiares (XIX).

- Correspondencia de Toledo (1857).

- Otros impresos.

1717 - Cuentas de la encomienda de Castellanos (1815-51).

1718 - Cuentas de Villanueva de Duero (1862-82).

- Justificantes de caja (1915).

1719 - Cuentas de la encomienda de Fuente de Cantos (1772-94).

- [Según Cooper, documentos particulares de Bernardino de Rojas y Contreras, consejero real (s.f.)]

1720 - Correspondencia de Motril (1782-83).

- Cuentas y recibos de Claudio de Cea (1794).

- Correspondencia diversa (XIX).

1721 - Cuentas de casas en Madrid (1784-87).

- Cuentas del Edo. de Bornos (1765-83).

- Cuentas de Villanueva de Duero (1883-1902).

- Cuentas de los Ramírez (1594 y 1603).

1722 - Cuentas de Talavera (1867-75).

1723 - Cuentas de Talavera (1874-81).

1724 - Cuentas del Tomilloso, Bodegón y Yuntar (1891-1901).

1725 - Cuentas del Tomilloso, Bodegón y Yuntar (1883-91).

1726 - Cuentas de Valencia, del Edo. de Villariezo (1806-49).

- Correspondencia de cabañas (1831-32).

1727 - Cuentas del Edo. de Bornos (1919).

- Cargas eclesiásticas del Edo. de Murillo (XIX).

1728 - Correspondencia de la condesa de Bomos (1866-69).

- Cuentas del Edo. de Borrios (1892).

1729 - Cuentas de almacén (1921).

- Cuentas de mayordomía (1852 y 1898).

1730 - Cuentas de Guadalajara (1779-1850).

- Cuentas de casas en Madrid (1897-98).

1731 - Cuentas de casas en Madrid (1894-97).

1732 - Cuentas de Tudela de Duero (1906).

- Cuentas de Segovia (1908) 
- Nombramientos de capellanes, alcaldes, médicos, oficiales, agentes, abogados, etc. y administradores de la Casa de Bornos (XVIII-XIX).

1733 - Cuentas del Edo. de Bornos (1903).

- Cuentas de Motril (1767).

1734 - Cuentas de Motril (1768).

- Cuentas de mayordomía (1845).

1735 - Correspondencia y cuentas varias (Tomilloso, Toledo, Ávila, cabañas, Hospital de la Latina (1812) (comienzos del XIX).

- Papeles de las Salinas de Duernas para la Exposición de Minería (1885).

- Correspondencia del conde de Villariezo (1839-40).

1736 - Recibos de la dehesa de Navaestena (1776-89).

- Recibos de arrendamiento del Prado de Almonacid (1766-68).

- Cuentas y correspondencia mezclados (XVIII-XIX).

- Correspondencia de Zamora (1791 y 1817-19).

- Testamentarías (1823).

- Correspondencia del Lavadero de Rojas (1834 y 1902).

- Correspondencia del Hospital de la Latina (1868).

- Cuentas de cabañas (1843).

- Cuentas de la casa de la c/. de la Parra (1829).

- Cuentas de casas en Madrid (1906).

1737 - Cuentas de Cintruénigo (1888-1901).

1738 - Cuentas de Cintruénigo (1882-87).

- Correspondencia de Valladolid (1829).

- Cuentas de arrendamiento de varias casas y tiendas en Madrid (1876-88).

1739 - Cuentas de Motril (1769-71).

1740 - Cuentas de Toledo, del Edo. de Villanueva de Duero (1830 y 1832).

- Cuentas de Segovia (1828-47).

1741 - Expedientes de contaduría, sobre redención de cargas eclesiásticas (1883).

- Correspondencia del mayordomo mayor del Infante don Carlos y papeles de la Diputación General de la Grandeza (1816-20).

- Cuentas de Coscojales (1872-80).

1742 - Cuentas de Tordesillas (1871-1902).

- Correspondencia de Tordesillas (1800-09).

1743 - Correspondencia de Valladolid (1780-98).

1744 - Correspondencia de la Abadía de Rueda (1915).

- Papeles de arrendamiento de dehesa en Almodóvar del Campo (1843-44).

- Correspondencia extraordinaria del conde de Bornos (1848).

- Arrendamientos de dehesas para ganado (1823-40).

- Expediente con el marqués de Bélgida sobre tierras en Trujillo (1826).

1745 - Correspondencia del conde desde el Lavadero de Rojas (1838-41).

- Correspondencia extraordinaria del conde (1842-43).

- Correspondencia de Jaén y Cambil (1911).

1746 - Justificantes de caja (1921).

- Correspondencia de los condes desde el Lavadero de Rojas (1859 y 1864). 
1747 - Justificantes de caja (1924).

- Cuentas del maestro de coches (1828).

- Cuentas y correspondencia del conde de Bornos (1815-23).

- Arrendamientos en Cifuentes (1840-49).

1748 - Cuentas de cabañas (1851).

- Correspondencia del Lavadero de Rojas (1879).

- Correspondencia de Zamora (1824 y 1827).

- Correspondencia de Madrid (1821).

- Cuentas de la Huerta de Atocha (1792-93).

- Cuentas de la Pradera de San Isidro (1794).

- Correspondencia mezclada de Madrid, Zamora, Lavadero de Rojas, Tomilloso, etc. (XVIII-XIX).

1749 - Correspondencia del Lavadero de Rojas (1820-34).

- Correspondencia del Tomilloso (1875-76).

- Correspondencia de Zamora (1792-96).

1750 - Expedientes de la administración de Burgos (1800-93).

1751 - Cuentas de las casas en Madrid del marqués de Villanueva de Duero (1772-99).

1752 - Cuentas y correspondencia de cabañas (1836-40).

1753 - Expediente de incidencias con el ferrocarril de Atocha (1852-82).

- Cuentas de fincas urbanas (1922).

1754 - Correspondencia de testamentaría (1848-53).

- Expedientes y correspondencia particular del conde de Bornos (XIX).

1755 - Cuentas de Jaén (1819-60).

1756 - Cuentas de Jaén (1768-1818).

1757 - Testamentos de los Meneses (XVI).

- Escrituras varias del Edo. de Villanueva de Duero: acuerdo con la Cartuja de Aniago (1743-45); copias de documentos de los Dávila, Rojas, Contreras (XVIII); documentos diversos de Valladolid y Segovia (157080 ), incluyendo un contrato de obras (Segovia. 1571).

1758 - Testamentos del Edo. de Villariezo (XVI).

- Escrituras varias del Edo. de Villanueva de Duero, algunos sobre los Contreras de Jaén (XVII-XVIII).

- Memorial del pleito de Migalvín (1492).

- Árbol genealógico de los Dávila.

- Índice del antiguo legajo de Villariezo sobre testamentos (1479-1600).

1759 - Traslado notarial del haber materno de la condesa de Bornos (1885). Libro voluminoso encuadernado.

1760 - Cuentas de Jaén (1861-87).

1761 - Cuentas de Jaén (1888-90).

- Correspondencia de Ronda, del Edo. de Villariezo (1819-50).

- Cuentas de casas en Madrid (1869-73).

1762 - Cuentas de Burgos (1842-54).

- Cuentas de obras en casas de Madrid (1801-08). Sin planos.

1763 - Correspondencia de Miajadas (1713-1822).

- Expedientes de la administración de Alcanadre (1797-1898). 
1764 - Correspondencia de Talavera, del Edo. de Villanueva de Duero (1813-49).

1765 - Correspondencia de Talavera, del Edo. de Murillo (1822-60).

- Papeles sobre la defunción del marqués de Villanueva de Duero (1824). Recibos de misas en Jaén y participaciones impresas, con pequeños grabados.

1766 - Correspondencia de Talavera, del Edo. de Murillo (1777-1812).

1767 - Cuentas de la Pradera de San Isidro (1809-12 y 1828-50).

1768 - Expedientes de esquileo (1828-34).

- Papeles sobre el embargo de los bienes de la condesa de Bornos y desembargo (1874-76).

1769 - Testamentarías varias (XVII).

- Inventarios y particiones de los Tello (XVII-XVIII).

- Censos de los Ramírez en Motril (XVII y XIX).

- Apeos en Guadalajara y Cabanillas (XVIII-XIX), con planos de fincas de Pedro Vidal.

- Arrendamientos en Guadalajara, del Edo, de Murillo (XVII-XIX).

- Capellanías del Edo. de Murillo (XVI). Faltan los documentos.

- Donaciones de los Pérez y los Moneda (XVI-XVII).

- Poderes, pleitos y partidas de bautismo de los Pérez-Temiño (XVI-XVIII).

- Tomas de posesión en Cintruénigo (XVIII).

1770 - Arrendamientos en Reinosa (XVII-XVIII).

- Testamentos de los Moneda (XVII-XVIII).

- Censos redimidos en Cintruénigo (XVII y XIX).

- Arrendamientos en Cintruénigo (XVIII-XIX).

1771 - Mayorazgo a favor de Luis Enríquez, conde de Montenuevo, con bienes de su hermano Juan (1695).

- Inventarios de bienes de los Quevedo (XVII-XVIII).

- Tomas de posesión de los Quevedo (XVIII).

- Testamentos de los Quevedo (XVI-XVIII).

1772 - Censos en contra de Cintruénigo (XVII-XVIII).

- Censo del conde de Montijo a favor del mayorazgo y memorias de Alberta Barrasa (1763). Libro.

- Otros censos a favor de dichas memorias en Badajoz, Zafra y Salamanca (XVIII).

- Testamentos varios, del Edo. de Villariezo (1511-22).

- Índice del antiguo legajo 23 del Edo. de Villariezo, de obras pías de los Meneses (XV|I-XVIII).

- Relación de fincas en Alcanadre (1880).

- Escrituras varias del Edo. de Villanueva de Duero (XIX).

- Préstamo al conde de Bornos (1821).

- Testamentaría de la condesa (1882-85).

1773 - Expedientes de Burgos, Cintruénigo, Olmedo, Medina del Campo y Guadalajara (fines del XIX).

- Lanzas y medias annatas de los Ramírez (XIX).

1774 - Lanzas y medias annatas de los Ramirez (XVIII-XIX). 
- Documentos de portazgo de los Ramírez (XIV-XIX).

- Papeles de la Compañía de Julián José Negrete y Simón Hernández y Moreno (1822-38).

- Herencias del Edo. de Villanueva de Duero (1752).

1775 - Ejecutoria de la Chancilleria de Valladolid a favor de los hijos de Francisco Lantadilla (1557). Libro encuadernado, conteniendo mucha otra documentación del Edo. de Villariezo (XV-XVI)

- Árbol genealógico de los Dávila, señores de Navamorcuende.

- Pleito de los Tello-Dávila (XVII), citándose documentación desde el siglo XIII, sobre la tenuta del señorío de Navamorcuende y Cardiel; dos alegaciones, con otros documentos.

- Varios árboles de los pretendientes a ese señorío.

- Papeles genealógicos de los Tello (XVIII).

1776 - Censos en contra del Edo. de Villanueva de Duero (Tordesillas, 1735).

- Censos del conde de Montijo (1610-26). Tres documentos.

- Censos a favor del Edo. de Villariezo (Ávila, XVI-XVIII).

1777 - Papeles genealógicos y memorial impreso del pleito por la sucesión del Edo. de Navamorcuende, fundado en 1294 (1755).

- Censos a favor del Edo. de Villanueva de Duero (Talavera, 1515-1701).

- [Según Cooper, testamento de Antonia Yera, mujer de Alonso de Bracamonte (1571) y mayorazgo de Tabladillo (1511)].

1778 - Papeles en gran número del mayorazgo de Navamorcuende (XV-XVII).

- Testamentos y mayorazgos de los Tello (XVI-XVII).

- Árbol genealógico de los Dávila.

- Papeles del mayorazgo de Tabladilla, con árbol (XVI).

- Mayorazgo de Migalvín (XV).

- Censos a favor de la Cartuja de Aniago (1745).

- Censos en contra del Edo. de Villanueva de Duero (Tordesillas, XVII).

1779 - Árboles genealógicos en gran número, de los Dávalos y otros.

- Cuentas del Hospital de la Latina (1832-34 y 1838).

1780 - Cartas de pago de los Ramírez (XVII).

- Papeles de la Compañía de Negrete y Hernández y Moreno (1839-42).

- Censos en contra del Edo. de Villanueva de Duero (Tordesillas, 16301755).

1781 - Herencias de varios linajes (Mercado, Lantadilla-Riaño, Villacorta, Mazuelo y Méndez de Carvajal) (fines del XVI).

- Cédula real confirmando el escudo de armas a los Brito (1630).

- Carátula anunciando herencias de los siglos XIV-XV (faltan todas).

- Arrendamientos de los Losada (XVII-XIX).

1782 - Documentos familiares del capitán Fernando de Prada (Zafra y Oropesa, segunda mitad del XVI).

- Papeles de la capellanía de Prada (XVII).

- Tres documentos de Popayán (1558-77).

- Dictámenes sobre el mayorazgo de Torres-Andino (XVIII).

- Testamentos y mayorazgos de varios linajes (Olea, Torres, Medina, Andino) con árboles (XV-XVI). 
- Papeles genealógicos de los Brito, en varios idiomas, con escudos en color (1624-64).

- Censos de los Enriquez (XVIII).

- Mayorazgo de Herrera Campuzano (1627).

- Relación de los juros del mayorazgo de Herrera Campuzano (XVIII).

- Mandamiento a los Moneda, como poseedores de ese mayorazgo (1749).

- Cartas de dote y arras de los de la Torre (1526-1644).

1783 - Venta judicial de casa de los Herrera (Logroño, 1588).

- Herencias de los Tello (XV1), en gran número.

- Pruebas de limpieza de sangre de Francisco Rodríguez de Valcárcel, obispo de Cartagena de Indias (1637).

- Inventarios de los bienes de Francisco de Meneses (1569) y de los Lantadilla (1565).

- Índice del antiguo legajo 11 del Edo. de Villariezo, sobre herencias (XIV-XVI).

- Papeles del capitán Fernando de Prada (XVI).

- Capitulaciones matrimoniales de los de la Torre (XVII).

- Mayorazgo de Torre-Andino (1384). Falta.

- Dictámenes.

- Disposiciones reales sobre capas y sombreros (XVIII).

- Papeles sueltos (XVII-XVIII).

1784 - Documentos de los Zuazo (XVI). Uno de ellos contiene varias hojas en pergamino, con obra en latín sobre derecho privado.

- Relación de pobres que han recibido limosna del conde de Villariezo (1765-1807).

- Arrendamientos en Talavera (1772).

- Partidas de bautismo de los de la Torre (XVII).

- Poderes de los Ramírez (XIX) y Torre (XVII-XVIII).

- Cartas de pago de los de la Torre (XVI-XVII).

- Herencias del Edo. de Villanueva de Duero (XVIII).

- Documentos judiciales de los de la Torre (1502-1801).

1785 - Herencias del Edo. de Villanueva de Duero (XVIII).

- Toma de posesión del mayorazgo de Zuazo y Rueda, por Juan Carlos Ramírez de Arellano (1739).

- Posesiones, apeos, compraventas, etc. de los Zuazo-Herrera (Logroño, XV-XIX).

- Particiones y mayorazgos de los de la Torre (Medina del Campo, 1528-1675).

1786 - Inventarios de bienes, testamentarías y tutelas de los de la Torre (XV-XVII).

- Cuentas de esquileo (1824-25).

- Censos de los Olivares-Brito (XVII-XVIII).

- Cuentas de ganado (1817-21).

1787 - Cuentas de cabañas (1808-16).

- Compraventas y censos de los de la Torre, en Medina del Campo y Torrelobatón (XV-XVIII).

1788 - Censos de los de la Torre (XV-XVII).

1789 - Testamentos de los Trasmiera y linajes afines, en Madrid y otros lugares (XV-XVII). Entre ellos, el de Pedro Fernández de Lorca, secretario de Juan II. 
- Mayorazgo de Bernardino García de Trasmiera y de la Flor y Estefanía Blanco de Salcedo y Monroy (1619).

- Aprobación real de la transacción por el mayorazgo de Sebastián Vicente (1687).

1790 - Ejecutorias de los Losada (1492, 1603 y 1664).

- Cuentas del Hospital de la Latina (1840 y 1842).

- Toma de posesión por el conde de Villariezo del Condado de Villaverde (1804).

- Dotes y capitulaciones matrimoniales de Trasmiera (Madrid, XVII).

1791 - Ejecutorias y dictámenes de los Losada (XVIII-XIX).

- Documentos de la toma de posesión por el conde de Villariezo del Condado de Villaverde (1804).

- Índice de los antiguos legajos 11 y 12 del Edo. de Villaverde, con esas tomas de posesión (1804-20).

- Árboles genealógicos de los señores de Villaverde.

- Documentos de cabañas (XVIII-XIX).

1792 - Testamentos de varios linajes (Espinosa, Molina, Maldonado, etc.) (XVI-XVII).

- Títulos y empleos de los Ramírez (1832).

- Fundaciones de mayorazgos del Edo. de Villanueva de Duero (1554-1625).

- Caudales del mayorazgo de Trasmiera (XVIII).

- Cuentas del Edo. de Bornos (1788-1819).

1793 - Dictámenes (XVIII).

- Papeles varios (XVI-XVIII).

- Mayorazgo de Diego Moreno de la Cueva, regidor de Segovia (1568).

- Documentos judiciales de Segovia (XVII).

- Cartas de pago variadas (Ávila, Oropesa, Extremadura, etc.) (XVI-XVII).

- Inventarios de documentos de los Dávila (XVI-XVII).

- Reales provisiones de varios linajes (XVI-XVII).

- Relación de los bienes recibidos en partición de los de Juan de Guevara (1580).

1794 - Títulos de propiedad de los Ramírez (XV-XVI).

- Permuta en San Martín de Valdeiglesias (1623).

- Títulos de propiedad en Cebolla (1748).

- Títulos de propiedad en Talavera, del Edo. de Villanueva de Duero (XIX).

- Índice del antiguo legajo 7 de Villanueva de Duero (1372-1789); sigue la documentación del siglo XVIII.

- Censos del Edo. de Villariezo (1527-1848). Faltan todos, menos los más recientes (una nota indica que han pasado a c/. Jorge Juan. n. 46).

1795 - Índice del antiguo legajo 3 de Ramírez, sobre títulos y cartas reales.

- Cuentas de la hacienda de Motril (XV-XVIII).

- Títulos y empleos de los Ramírez (XIX).

- Dos memoriales impresos a los hacendados de Motril (1867 y 1875).

- Títulos de propiedad de Villariezo (Salamanca, XV-XVII).

- Fundaciones de mayorazgos del Edo. de Villanueva de Duero (XV-XVII), con su índice del antiguo legajo 21.

1796 - Posesiones de la Abadía de Rueda (XVI-XVIII).

- Apeos de la Abadía de Rueda (XVI-XIX). 
- Incorporación de las fábricas de Liérganes y La Cavada a la Corona (1769). Libro con documentación anterior.

- Certificaciones de rentas de encomiendas de Órdenes Militares (1818-38).

1797 - Cuadernos de caja del Edo. de Bornos (1868-86).

- Documentos varios (1755-1870).

1798 - Cuadernos de caja (1868-84).

- Testamento de Juan José Ramírez de Arellano y Navarra, conde de Murillo y Peñarrubia, señor de Ausejo, Alcanadre, Alerre y Pompier, en Aragón, señor de las casas de Andino y Lozares, abad y señor de Rueda, vecino y regidor perpetuo de Logroño (1739). Libro encuadernado.

1799 - Posesiones del Edo. de Murillo (1764 y 1793). Del mayorazgo de la Abadía de Rueda, Andino y Torme por Joaquín Ramírez de Haro, conde de Bornos y Montenuevo, como marido de doña María Josefa Ramírez de Arellano, primogénita del conde de Murillo y Peñarrubia (1793).

- Alegaciones contra la incorporación a la Corona de las fábricas de Liérganes y La Cavada (1769). Libro.

- Índice del antiguo legajo 1 del mayorazgo de Olivares, sobre las fábricas de Liérganes y La Cavada (XVIII-XIX).

- Papeles diversos del Edo. de Villanueva de Duero (XVII-XVIII).

- Recibos de varias dehesas (XVIII-XIX).

1800 - Mayorazgos y otros documentos de los Ramírez de Arellano, señores de Murillo de Río Leza (XIV-XV).

- Documentos muy diversos (XVIII-XIX).

1801 - Haber perteneciente a doña María Francisca Crespí de Valldaura, condesa viuda de Bornos y Murillo (1860), viuda de don Manuel Jesús Ramírez de Haro Córdoba Belvís de Moncada. Un libro encuadernado.

1802 - Cuentas de fincas urbanas en Madrid (1876).

- Cuentas de fincas urbanas de Villariezo (1844).

1803 - Correspondencia de Toledo y Lavadero de Rojas (1807-20).

1804 - Correspondencia de Toledo (1790-1806).

1805 - Cuentas del Lavadero de Rojas (1857-63).

- Cuentas de escribanos de Villanueva de Duero (1774-1853).

1806 - Cuentas del Lavadero de Rojás (1850-57).

1807 - Cuentas y correspondencia de cabañas (1826-28).

1808 - Cuentas del Edo. de Bornos (1894).

- Cuentas del Hospital de la Latina (1803-04).

1809 - Cuentas de mayordomía (1853).

- Cuentas del Hospital de la Latina (1800-02).

1810 - Correspondencia de Córdoba (1911).

- Correspondencia de Jaén y Cambil (1907).

- Cuentas de Tudela de Navarra (1881).

- Cuentas de Arguedas (1902).

1811 - Cuentas del Edo. de Bornos (1897).

- Cuentas de fincas urbanas (1928).

- Correspondencia de Cambil (1904). 
1812 - Papeles del mayorazgo de Brizuela, adjudicado en 1791 a fray Esteban de Riaño y Orovio; con índice antiguo (XVII-XIX).

- Testamento de la marquesa viuda de San Gil (1783).

- Reconocimientos de censos, apeos y posesiones en Olmedo y Arévalo (XVII-XVIII). Un dictamen.

- Censos contra el duque de Osuna (XVI).

- Cartas de pago y despachos requisitorios de los de la Torre y Salcedo (XVI-XVIII).

- Testamentos del Edo. de Villanueva de Duero (XIX).

1813 - Ejecutoria de nobleza de Pedro de Ochoa y Orovio, de Ágreda (1494).

- Papeles sobre la nobleza de los Castrillo (XVI).

- Información de nobleza de Francisco Méndez de Carvajal y su mujer para entrar en la cofradía de San Bartolomé, en Talavera (1561).

- Testamentos del Edo. de Villanueva de Duero (XVIII-XIX), con índice del antiguo legajo 10.

- Testamento del conde de Villariezo, Valentin Belvís de Moncada (1799).

- Papeles de nobleza y escudos de armas de varios linajes (XV-XVI).

- Censos de Bornos y Murillo (1825).

- Apeos de Montamarta (1587 y 1604-05), de los Losada.

1814 - Títulos de propiedad en Olmedo, Arévalo, etc. (XV).

- Títulos de empleos y cargos de los Olivares (XVII-XVIII).

- Índice de documentos de los Olivares (Liérganes y La Cavada; marquesado de Villacastel; mayorazgos de Quevedo, Monedas, Guadalajara, Salcedo y Torre) (XIV-XVIII). Libro.

- Títulos de propiedad de los Olivares (XVII-XVIII).

1815 - Arrendamientos y pleitos de los Tello (XV-XVIII).

- Índice del antiguo legajo 15 de Ramírez, sobre títulos de propiedad tras la desvinculación (XIX).

- Documentos sobre pleitos de los Ramirez (XVIII-XIX).

- Documentos de los Tello (XV).

- Documentos eclesiásticos de Murillo (XVI-XVIII).

1816 - Sentencias de los Tello (XV).

- Censos en Olmedo (XVII-XVIII).

- Sentencias del Tribunal Supremo (1873-74). Impresas.

1817 - Cuentas de caja (1871).

- Justificantes de caja (1916).

- Expedientes de Hacienda (1834-50).

1818 - Cuentas del Hospital de la Latina (1828 y 1839).

- Cartas de pago de los Ramírez (XVI-XVIII), del antiguo legajo 20.

- [Según Cooper, documentos dé fincas de Salobreña (1546)].

1819 - Censo del Conde de Montijo (1636).

- Papeles de nobleza de los Losada (XVII).

- Papeles de varias administraciones de Villariezo (XVII-XVIII).

1820 - Inventario de documentos del Edo. de Villariezo en Talavera (XVII-XVIII).

- Cuentas del Hospital de la Latina (1829-30).

- Censos en contra del Conde de Montijo (XVII-XVIII). 
1821 - Documentos eclesiásticos de los Ramírez (XV-XIX).

- Censos diversos (XVII).

- [Según Cooper, documentos de Beatriz Galindo, de comienzos del siglo XVI].

1822 - Censos y otros documentos de la memoria de Alberta Barrasa (XVIIXVIII).

- Papeles de varias administraciones del Edo. de Villariezo (Ávila, Burgos, Arévalo, XVIII).

- Títulos de propiedad de los Ramírez (XIX).

1823 - Títulos de propiedad de los Ramírez tras la desvinculación (XIX).

- Papeles del portazgo de Madrid, de los Ramírez (XVIII-XIX).

1824 - Documentos sobre la casa de c/. de San Bernardo, n 18, de Madrid.

1825 - Compraventas del Edo. de Villariezo (comienzos del XVI).

- Libro-registro de documentos del Edo. de Villariezo (XVI-XVIII).

- Compraventas en Talavera (XV).

- Papeles de filiación de los señores de Villaverde (XV). Libro.

- Privilegios reales (XIV-XV). Copia.

- Impresos diversos (XVIII).

- Nombramiento de alcalde de los hidalgos en Reinosa a Nicolás J. de Olivares y Quevedo (1701). Con árbol genealógico.

- Apeos y censos diversos (XVI-XVIII).

1826 - Privilegio rodado de Enrique III donando las salinas de Duernas en Córdoba (1403). Copia.

- Pleitos por los diezmos de Alcanadre (1543). Libro.

- Compra de Villagonzalo, por el conde de Villariezo (1653). Libro.

- Herencias y apeos de Talavera (XVI-XVII).

- Censos (1774).

- Libro-registro de documentos del Edo. de Villariezo.

- Etiqueta de ceremonias de recepción de la Reina de María Cristina de Borbón. Impreso.

1827 - Libro-registro de documentos del Edo. de Villariezo.

- Particiones de los Riaño (1624). Libro.

- Ejecutoria a favor del marqués contra el concejo de Villanueva de Duero (1780). Libro.

- Compraventas y apeos en Medina de Pomar (XVI).

1828 - Censos a favor del Hospital de la Latina (XVIII-XIX). Libro.

- Pleito por el patronato de la iglesia de la Abadía de Rueda (1626). Libro.

- Censo en Burgos (1564).

- Alegación impresa en pleito por mayorazgo de Jerónimo Gutiérrez de Anaya (s.f.).

- Grabado con retrato de L. Pons y Gallarza.

- Alegación impresa en pleito por el mayorazgo de Navamorcuende (1788).

- Cuentas de la tutela de García de Toledo, del Edo. de Villaverde (1553). Libro.

- [Según Cooper, Bula de Urbano VIII, con sello de plomo (1625)]. 
1829 - Ejecutoria a favor de Pedro López de Rueda como propietario de la Abadía de Rueda. Libro con incípit iluminado, papel.

- Privilegio a Pedro de Luna de juro en las salinas de Duernas, en Córdoba (XV-XVI). Pergamino y papel.

- Nombramiento de Sancho de Losada como consejero de Cámara (1668). Pergamino, dos ejemplares.

- Escudos de armas coloreados.

- Fundaciones de vínculos del Edo. de Villariezo, con árboles.

- Árboles de los Losada, en gran número (Losada, Pimentel, Sarmiento, Caduérniga, Porras, Docampo, Luzón y Ludeña).

- Juro de Sebastián Antonio de Contreras (1647). Pergamino.

- Memorial genealógico del marqués de Villanueva de Duero (1783). Impreso, con árboles.

- Juros, títulos y otros documentos de los Edos. de Villariezo y Villanueva de Duero (XVII-XVIII).

- Índices de documentos del conde de Foncalada (XV-XVII).

- Árboles genealógicos.

1830 - Historia del Condado de Murillo. Libro manuscrito.

- Dote de la condesa de Villamarciel (1814). Libro.

- Censos en Candemuño (1524). Pergamino.

- Privilegio de Enrique III de las salinas de Córdoba (1401). Original y copia.

- Bula de 1541 y sentencia de la Rota de 1678 , con sello de plomo.

1831 - Bula de fundación del Convento de la Concepción Francisca o de la Latina (1504). Pergamino.

- Libro de actas de la Junta de patronos del Hospital de la Latina (1703-1801).

- Libro de linajes (1597). Manuscrito.

- Información de testigos sobre la santidad de la Madre Mariana de Jesús, de la Merced descalza (1627).

1832 - Cuentas de casas en Madrid (1889-91).

- Cuentas de las memorias de Alberta de Barrasa (XVII-XVIII).

1833 - Cuentas de casas en Madrid (1884-91).

- Compra de casa en Burgos a favor del mayorazgo de Mazuelo (1761).

- Papeles de la casa de cuatro torres en Burgos, con cuaderno sobre incidencias con el ayuntamiento por el derribo de la casa para alineamiento de la calle.

- Dictámenes, nombramientos de curadores y capellanías de los Tello (XVIXVII).

- [Según Cooper, presenta un contenido distinto:

- Obras pias en Castañares (1665).

- Documentos referentes a los gremios de Madrid (1777), Priego (1776), Orden de San Francisco en Italia (1571), Inquisición (1493), suministro de bizcocho a los barcos de Colón (1493), fincas de Migalvín (1550), Burgos (1761) y Villariezo (modernos).

- Historia del señorío de Navamorcuende (XVIII), con documentos relevantes, incluyendo codicilo del testamento del arzobispo de Sevilla, Diego de Deza (1513)]. 
1834 - Cuentas del Hospital de la Latina (1849-50).

- Capitulaciones matrimoniales, dotes y testamentos del Edo. de Murillo (XVI-XVII).

- Reales provisiones de los Tello (XVI).

- Cartas de pago del marqués de Bélgida por la venta de la casa de c/. del Pez, del concurso de Jacobo de Flon (1751).

- Informes de archivo (1859). Dictamen.

1835 - Genealogías y árboles de varios linajes (Manzano, Olmedo, Benavente, Salamanca, Falconi, Tello, Coca, Meneses, Oviedo, Mesa).

- Fundación pía del conde de Villariezo en Burgos (1724).

- Poderes de los Ramírez (XVII-XIX).

- Cartas de pago del Edo. de Murillo (XVI-XVIII).

- [Según Cooper, documentos de fincas en Madrid (1565)].

1836 - Documentos de los Salcedo (XVI-XVII).

- Documentos de los Manzano (XVII). Tres cartas en italiano.

- Testamentos de los Tello (XVII-XVIII).

- Índice del antiguo legajo 10 del Edo. de Villariezo, sobre testamentos posteriores a 1601.

- Cartas de pago a favor del conde de Bornos (Toledo, 1905).

1837 - Apeos del Edo. de Murillo (Segovia, Ojos Negros, Fresneda, Peñarrubia y Carboneras, XVI-XIX).

- Testamentos de los Guevara, condes de Peñarrubia (XVI-XIX).

1838 - Correspondencia muy mezclada (XIX-XX).

- Justificantes del Hospital de la Latina (1789).

- Cuentas de casas en Madrid (1868).

- Cuentas del Lavadero de Rojas (1912).

- Cuentas de cabañas (1894-95 y 1900-01).

- Cuentas de caja (1871).

- Correspondencia con Antonio Gali y Cía., de Tarrasa (1877).

1839 - Correspondencia diversa (XIX-XX).

- Justificantes de fincas urbanas (1923).

- Correspondencia de Almodóvar (1877).

- Correspondencia de Zamora (1908-11).

- Correspondencia con el letrado Francisco de Paula Lobo (1858-77).

- Cuentas de gastos en casa de c/. de El Escorial, no 15 (1881-85).

- Cuentas de fincas urbanas (1923).

- Cuentas de esquileo (1860-61).

1840 - Hijuela de María Josefa Ramírez de Arellano, condesa de Murillo y Peñarrubia, mujer de Joaquín Ramirez de Haro, conde de Bornos, e hija de María del Pilar Teresa Olivares y Cepeda, marquesa de Villacastel y condesa viuda de Murillo (1806). Libro.

- Apeo de bienes de Villariezo, de Antonio José Benito de Riaño y Gaceta, conde de Villariezo y vizconde de Villagonzalo (1719). Libro.

- Arrendamiento de salinas (1508-11 y 1700) y permuta de tierras en Villariezo (1544). 
- Apeo de la Abadía de Rueda (1765). Libro.

- Cuentas del Hospital de la Latina (1638-40). Libro.

- Testimonio de la venta de la jurisdicción de Vilamarciel (1657).

- Alegación impresa del conde de Murillo (s.f.).

1841 - Memorial impreso del pleito entre los condes de Colomera y Murillo, por la testamentaría de doña Teresa Cepeda (1791).

- Alegación impresa del conde de Murillo contra sus villas por su jurisdicción (1769).

- Memorial impreso del pleito por el condado de Fuensalida, con árboles (1782-83). Libro.

- Relación de fincas de los Moneda y Lerma, del Edo. de Murillo.

- Inventario de documentos del Edo. de Murillo, desde 1342 (1764).

1842 - Compra de la dehesa de Salinas (Talavera, XV). Pergamino.

- Venta de Villamarciel por Felipe IV a Antonio de Contreras, comendador de Fuente el Maestre, del Consejo y contador mayor de Hacienda (1659). Libro en pergamino.

- Ejecutoria del término de San Andrés de Pedernales, vendido por el rey a Diego de Riaño y Gamboa (1656). Libro.

- Censo contra el mayorazgo de Orejón (1719). Libro.

- Cuentas de cabañas (1815-18). Libro.

- Ejecutoria a favor del conde de Murillo por una mina en Beteta (1633). Libro.

- Memorial impreso del conde de Murillo contra los acreedores de su padre (1719).

- Servicios de los Ramírez (1705).

1843 - Fundación de capellanía en la parroquia del Salvador de Madrid, por el capitán Alonso Alvarez de Perea (1590). Libro.

- Memorial del pleito de la Puebla del Maestre (1754). Libro impreso.

- Otros memoriales impresos.

- Libro de acuerdos de la Cía. de Minas de Guadalcanal (1736).

- Documentos de las salinas de Duernas (Córdoba), pertenecientes a Juan de Guevara (1578).

1844 - Testamentos en Guadalajara (XVI-XVIII). En gran número.

- Dotes y particiones en Guadalajara (XV-XVI).

1845 - Compraventas de tierras, apeos, padrones, etc. del Edo. de Villariezo (XVXVIII).

- Desglose de casa de c/. del Pez, por don Jacobo de Flon (1720). Libro.

- Memorial impreso incompleto del pleito de la Puebla del Maestre (s.f.).

- Pleito sobre la jurisdicción de Murillo, favorable al conde (1705). Libro.

1846 - Pleito por los derechos de la Abadía de Alcanadre (1643). Libro.

- Compraventas, censos y pleitos del Edo. de Villariezo (XVI-XVIII).

- Ejecutoria de hidalguía de la Chancillería de Valladolid a favor de Miguel de la Moneda (1732).

- Pleito del conde de Murillo por los derechos de Alcanadre (1537). Una alegación posterior impresa.

- Mayorazgo y testamento del Lcdo. Diego Dávila (1580). 
1847 - Cuatro libros-registro de documentos del Edo. de Villariezo.

- Tres memoriales de pleitos impresos.

- Arrendamientos y compraventas de tierras y casas en Villariezo (XVI-XVIII).

1848 - Apeo de bienes en Torrelobatón, del Edo. de Murillo (1787). Libro.

- Cuentas del Hospital de la Latina (1685-92). Libro.

- Arrendamientos, herencias, particiones y compraventas del Edo. de Villariezo (XVI-XVIII).

1849 - Cuentas del Hospital de la Latina (1693-1701). Libro.

- Memorial del pleito por la Puebla del Maestre (1754). Libro

1850 - Ejecutoria del mayorazgo de Villoslada, primer tomo (1720); incluye documentos fundacionales desde 1489. Libro encuadernado.

1851 - Reales cédulas impresas (1780-1805).

- Memoriales de pleitos impresos (uno con grabado de la Virgen de las Angustias de Granada y otro en segunda suplicación).

- Papeles de jurisdicción de Villariezo (XVII).

- Dos documentos del mayorazgo del capitán Perea (XVII).

- Ejecutoria de hidaiguía de Lorenzo Olivares Gijón, vecino de Zamora (1550).

1852 - Censos a favor de la marquesa de Villacastel (1765). Libro.

- Ejecutoria a favor del Lcdo. Diego Fernández Vilorado, presbítero de Villacastín (1698). Libro.

- Fundación de misa en la iglesia de San Isidro, en Madrid, por Perea (1662). Libro.

- Memoriales impiesos de pleitos.

- Compraventa de viña en Medina del Campo, del Edo. de Murillo (1538).

- Tres nombramientos reales a los Losada (XVII).

- Censo en Alcanadre (1537).

- Dos compraventas de tierra en Talavera (1493-98).

1853 - Memoriales impresos de pleitos.

- Censos y compraventas de Villariezo (XVII).

- Cuentas de la cabaña de Rojas (1749-1809). Libro.

- Cesión de censo a la marquesa de Villacastel (1765). Libro.

- Testamento de Diego de Rojas y Ortega (1731). Libro.

1854 - Memoriales impresos de pleitos, muchos de ellos con árboles genealógicos.

- Mayorazgo de Guevara y agregaciones, con documentación desde el siglo XIV (1588). Libro.

- Compra de tierras por lldefonsa Dávalos (1803). Libro.

- Permuta de fincas de Villariezo (1544).

- Inventario de bienes de Nicolás Javier de Olivares (1737). Libro.

- Cuentas de cabañas (1821-63).

1855 - Memoriales impresos de pleitos.

- Venta de casas en c/. de Jesús y María, por los herederos del Conde el Real a Luis Enríquez, conde de Montenuevo (1681). Libro voluminoso.

1856 - Bula de Urbano VIII aprobando la fundación del patronato del Carmen calzado en Medina del Campo por Juan de Salazar (1623). Libro en pergamino con sello de plomo. 
- Información de propiedad de diezmos y tercias de Alcanadre (1539). Libro.

- Provisión sobre el encabezamiento de alcabalas en Villariezo (1657). Libro.

- Memorial impreso del pleito sobre el mayorazgo de Ludeña (1757).

- Títulos de propiedad de la casa de c/. del Pez, de Jacobo de Flon (1714). Libro.

1857 - Provisión de Carlos II facultando a Lorenza de Cárdenas y Portugal, mujer de Luis Enriquez, para titularse condesa de Montenuevo, por los muchos servicios de sus antepasados, en especial, su padre, que había enajenado buena parte de sus bienes en servicio suyo (Madrid, 23-noviembre1692). Libro en pergamino iluminado.

- Ejecutoria de hidalguía de la Chancillería de Valladolid a favor de los Trasmiera, vecinos de San Sebastián de los Reyes (Madrid) (1617). Dos ejemplares en pergamino, iluminados con escudo de armas a colores.

- Censos a favor del convento de San Juan en Burgos (1440-1638). Libro voluminoso.

1858 - Pleito por un censo sobre Mazuelo (Burgos, 1529-1645). Libro muy voluminoso.

1859 - Ejecutoria de hidalguía de Juan de Rojas, vecino de Antequera (1578). Libro en pergamino. Falta la primera hoja.

- Ejecutoria de hidalguía de Benito Salcedo, vecino de Tudela de Duero (1612). Traslado en papel, iluminado.

- Mayorazgo de Pedro de Contreras, santiaguista, del Consejo de Indias, de la Junta de Guerra, secretario de la Cámara y Estado de Castilla y de la Justicia, y de Despacho universal de las consultas (1621). Libro en pergamino iluminado.

- Felipe $V$ concede a Pedro José de Rojas y Contreras el título de marqués de Villanueva de Duero (1740). Libro en pergamino.

- Transacción entre el conde de Murillo y José de Salazar sobre los censos de Alcanadre con aprobación real (1731). Libro.

1860 - Cuentas de la memoria de Antonio Meneses (Talavera, 1688-1819). Libro.

- Pleito por el mayorazgo de Losada, fundado por Rodrigo de Losada en 1506 (1671). Libro.

- Papeles de servicios de Gregorio, Alonso y José de Mercado (XVII-XVIII). Libro sin coser, con documentos reales.

- Memoriales impresos de pleitos.

- Cuentas del mayorazgo de Alcanadre (1645-50). Libro.

1861 - Papeles varios, de Peñarrubia (XVIII).

- Compraventa en Medina del Campo (1536).

- Concordia de Guevara (1599).

- Ventas de fincas a extraños (comienzos del XIX).

- Compraventa de Guevara (1609).

- Inventario de documentos del mayorazgo de Guevara (XIV-XVIII).

- Testimonios, renuncias, cesiones y fianzas de los Guevara (XVIII-XIX).

- Índice del antiguo legajo 37 del Edo. de Villariezo, sobre asuntos judiciales (XV y comienzos deI XVI). 
- Pleito de Salazar con el Carmen calzado de Medina del Campo (1640).

- Cuaderno de caudales (1824-27).

1862 - Compraventas en Medina del Campo y Torrelobatón (XVI-XVIII). En gran número.

- Pleito de Salazar con el Carmen calzado de Medina del Campo (1640).

1863 - Títulos de propiedad de Torrelobatón (XVII y XIX).

- Títulos de propiedad de la casa c/. de la Madera, en Madrid, con dos privilegios de exención de huéspedes en pergamino (1739). Libro con documentación descle el siglo XVII.

1864 - Títulos de empleos de los Ramírez (XV y XVIII).

- Mayorazgo de Bernardo de Rojas y Contreras a favor de Francisco Javier de Rojas y Hierro, sobre bienes en Toledo (1763). Libro en pergamino.

- Títulos de propiedad de casa c/. de la Madera, en Madrid (1683). Libro.

- Títulos de propiedad del Edo. de Villanueva de Duero en Segovia (XVI) y Medina del Campo (XV|I).

- Censo a favor del mayorazgo del coronel Arizcun (1793). Libro.

1865 - Documentos de Enrique IV sobre las salinas de Córdoba (1462 y 1468). Originales en pergamino.

- Capitulaciones matrimoniales de Rodrigo de Contreras y María de Peñalosa, hija de Pedro Arias Dávila (1523).

- Papeles de los Tello, con escudos y genealogías (XVIII).

- Mayorazgo de Sebastián de Contreras y Mitarte y Luisa de Castrillo y Guzmán (1623). Libro en pergamino, iluminado.

- Títulos de empleos de los Ramírez (XVIII-XIX). Con documentos reales y eclesiásticos, uno con sello de cera intacto.

- Información de hidalguía de Diego Ordóñez, vecino de Tordesillas (1502). Pergamino iluminado.

1866 - Mayorazgo de García de Tormes, obispo de Burgos (1384). Original en pergamino, también copia.

- Ejecutoria de hidalguía a favor de Juan y Pedro Flores, vecinos de Valdepeñas (1498). Pergamino iluminado.

- Pedro Orense, regidor de Burgos, vende censos a García Martínez de Mazuelo (1499). Pergamino iluminado.

- Papeles genealógicos de los Ortega, de Loja.

- Cartas de la villa de Arechavaleta (XVIII). Con árboles.

- Pleito por el mayorazgo de Cristóbal Colón, impreso, con árboles (s.f.).

- Escudos de armas coloreados de Villariezo y Villanueva de Duero.

- Merced al marqués de Villanueva de Duero de la jurisdicción de Villamarciel (1755). Pergamino.

- Privilegio rodado de Enrique III de las Salinas de Córdoba a Juan Carrillo (1401). Original en pergamino.

- Genealogía de los Tello de Arévalo (1631), con escudo y árbol. Libro. 
- Varios documentos reales y particulares sobre las salinas de Córdoba (XV-XVI).

- Cartas y certificaciones de la nobleza de los Brito y de los Olivares, con escudos coloreados (XVII).

- Pleito del mayorazgo de Cristóbal Colón, impreso (s.t.).

- Capitulaciones matrimoniales de Sebastián Antonio de Contreras y Mitarte con Luisa de Castrillo (1617).

- Concesión de Grandeza de España al marqués de Villanueva de Duero (1790). Libro en pergamino, iluminado.

1867 - Pleito del mayorazgo de Cristóbal Colón.

- Memorial genealógicó de los señores del mayorazgo de Villoria (1660). Impreso.

- Memorial genealógico del conde de las Torres y marqués de Cullera (sobre señoríos de Villanueva de Barcarrota, Navamorcuende, Montalvo, Villoria, Santiuste y la Vega) (1722). Libro impreso, con un grabado mitológico.

- Privilegio de Felipe IV a Juan Osvaldo Brito, con escudo de armas coloreado (1630). Pergamino.

- Memorial genealógico de los Tello de Meneses (XVIII). Libro.

- Capitulaciones matrimoniales entre Martín Ruiz de Mitarte y su mujer Antonia Ordóñez, para casar a Pedro de Contreras con María Vázquez de Mitarte (1585).

- Capitulaciones matrimoniales de Diego de Contreras y María de Contreras y Guzmán (1639).

- Capitulaciones matrimoniales de Sebastián de Contreras y Luisa de Castrillo (1623).

- Ejecutoria del nuncio en pleito de Alonso Girón (1615). Con bulas originales, pergamino.

- Documentos de los Reyes Católicos a Juan de Cuéllar, su copero mayor y su contador de rentas en Asturias (1477-1526). En cierto número.

- Títulos honoríficos a los Quevedo (XVI-XVII).

1868 - Concurso de acreedores, con intervención del fiscal de la Inquisición, sobre los bienes de Juan de Franquis, vecino de Granada y Motril (1696). Libro voluminoso.

- Consentimiento de las principales ciudades del Reino para enajenar la villa de Villanueva de Duero (1632).

- Libro relativo a la Huerta de Atocha (XIX).

1869 - Cuentas del Hospital de la Latina (1712, 1721, 1731-43 y 1762).

1870 - Cuentas del Hospital de la Latina (1755-57).

- Ejecutoria de hidalguía de Pedro Ramírez de Arellano e hijos (1599). Con muchos escudos coloreados. Libro en pergamino grande, iluminado.

- Ejecutoria de hidalguía de Juan Vizcaíno, vecino de Medina del Campo (1565). Pergamino iluminado, con una miniatura de Felipe II sentado con los atributos del poder. Sello de plomo.

1871 - Memoriales impresos de pleitos (uno de ellos en segunda suplicación).

- Reales cédulas (XVIII-XIX). 
- Ejecutorias contra el Edo. de Murillo (1644). Libro.

- Facturas del Lavadero de Rojas (1919).

- Compraventas de tierras y molinos en Burgos, del Edo. de Villariezo (1487-1523).

- Transacción entre Carlos Ramírez de Arellano y los patronos de la parroquia de Murillo (1671). Libro.

1872 - Memoriales impresos de pleitos.

- Venta de regiduría en Talavera (1613).

- Cuentas del Hospital de la Latina (1751-52).

- Libro de servicios de Diego de Castrillo y Guzmán (XVII). Con cartas reales originales.

- Cuentas de fincas rústicas (1923).

- Libro-registro de documentos del Edo. de Villariezo.

1873 - Hijuela de María Cristina Fernández de Córdoba, marquesa de Griñón y condesa viuda de Villariezo (1897). Libro.

- Corona poética a los Reyes (1851). Grabados reales y de los poetas.

- Ejecutoria de nobleza de Lorenzo Olivares Gijón, vecino de Zamora (1550). Pergamino iluminado, con escudos.

- Ejecutoria de hidalguía a favor de Fernando y Pedro de Contreras, veinticuatros de Jaén ambos, y sus hermanos, vecinos de Jaén (1550). Pergamino.

- Información de nobleza de los Perea (1625). Dos ejemplares.

- Ejecutoria de ia Chancillería de Valladolid atribuyendo la propiedad de la Abadía y mayorazgo de Rueda a Pedro López de Rueda Herrera, vecino de Logroño (1591). Pergamino.

1874 - Cuentas de la administración de Córdoba (1905-22). Libro.

- Ejecutoria de hidalguía de Ruy Gómez, vecino de Horcajo de las Torres (Arévalo) (1550). Pergamino iluminado.

- Ejecutoria de hidalguia de Francisco de Benavente, vecino de Medina del Campo (1572). Libro en pergamino, iluminado, miniatura.

- Ejecutoria de hidalguía de Sebastián Antonio de Contreras y Mitarte (1616). Libro en pergamino, iluminado, miniatura.

- Plano de Navarra (1902).

1875 - Libro de accionistas de la Cía. de la Mina de Guadalcanal (desde 1725).

1876 - Cuentas del Edo. de Bornos (1871, 1876 y 1903).

- Licencias reales y pasaportes del Capitán General (1824).

1877 - Cuentas de Bornos (1876 y 1918).

- Expedientes de contaduría (1769-1880).

- Juros y capellanías (XIX).

- Correspondencia con la casa Gibbs de Londres (1875-1902).

- Correspondencia con la casa Abaroa y Goguel de París (XIX).

- [Según Cooper, cuentas de la fábrica de artillería de Liérganes (1769-1880)].

1878 - Gastos del funeral de la Condesa de Bornos (1753).

- Cuentas de Bornos (1898, 1905 y 1920).

- Cartas sin interés (XX). 


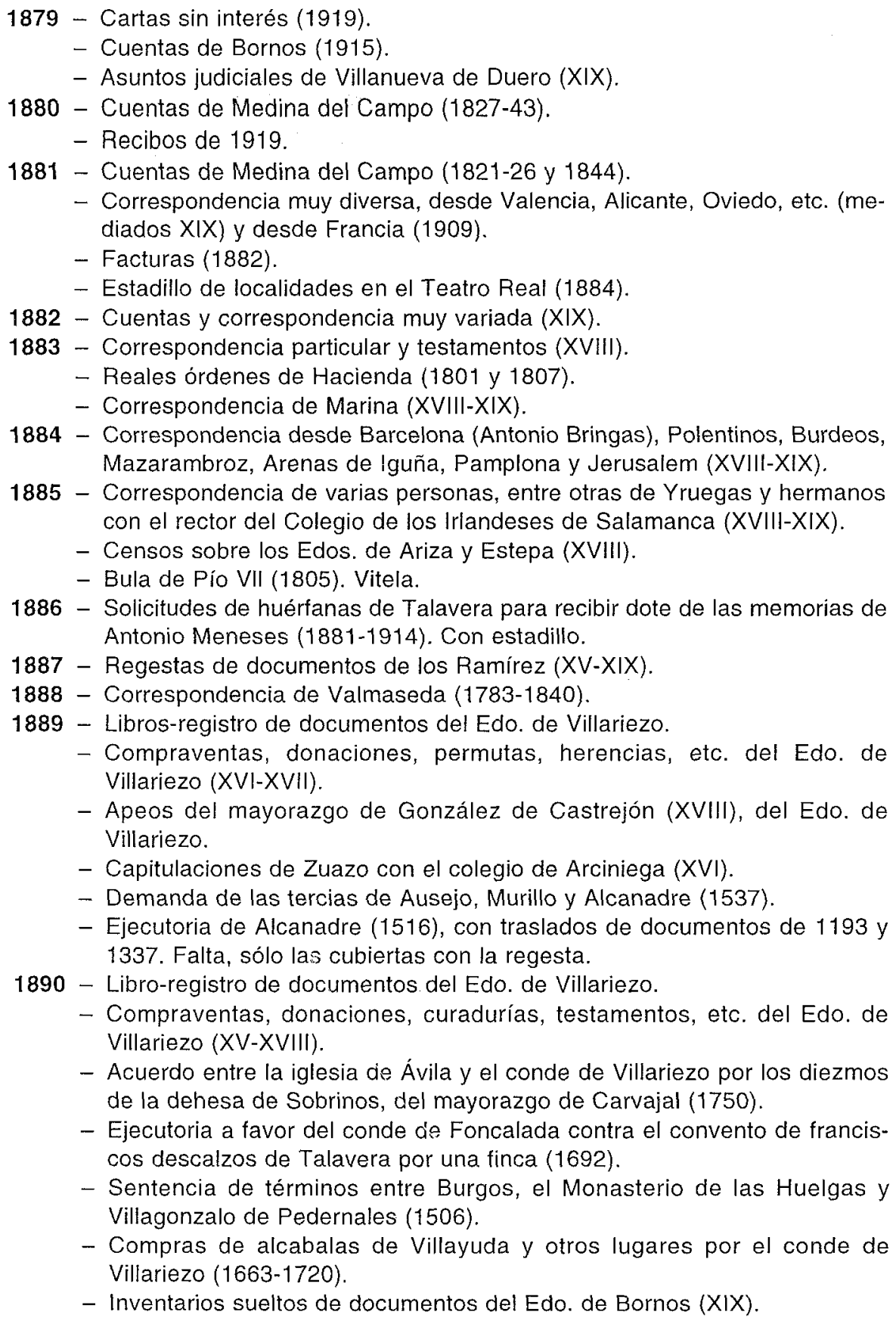


- Venta de una viña en Medina del Campo, de los de la Torre (1543), del Edo. de Murillo.

1891 - Libro-registro de documentos del Edo. de Villariezo.

- Compraventas y documentos familiares del Edo. de Villariezo (XVI-XVII).

- Inventarios de documentos de los Moneda y otros linajes de Burgos (XVIII-XIX).

- Informe de linaje de los Quevedo (1625).

- Padrón de moneda forera de San Martín de Iguña (1592), donde constan como hidalgos los Quevedo.

- Papeles de servicios de Pedro de Contreras y Mitarte (XVII). Dos ejemplares.

- Sentencia de la Chancillería de Valladolid sobre propiedad de unas casas en el Humilladero de San Francisco, en Madrid (1656).

- Elección de capellán de Alcanadre (1561).

1892 - Dos libros-registro de documentos del Edo. de Villariezo.

- Compraventas de casas, tierras y regiduría, testamentos, etc. del Edo. de Villariezo (XV-XVII).

- Testamento y memorias de Mariana Enríquez, condesa de Montenuevo y duquesa viuda del Arco (1762). Libro.

- Hijuela de Cándida Rosa de Robles y Gorbalán, mujer de Bernardo de Rojas y Contreras (1720). Libro.

- Hijuela de Rodrigo de Cepeda (1722). Libro.

- Testamento de Diego de Riaño y Gamboa (1764). Libro.

- Ejecutoria del pleito entre Carlos de Arellano y su villa de Alcanadre por el cumplimiento de una concordia efectuada en 1645 (1675). Libro.

- Capitulaciones matrimoniales de José de Rojas y Contreras y su sobrina, María Teresa de Rojas y Robles, señora de Villamiel (1738). Con dote de la misma fecha.

1893 - Mayorazgo de la marquesa viuda de San Gil (1787). Libro.

- Títulos de propiedad de 3 casas en Chillarón (Toledo) (1691). Libro.

- Alegación impresa por la encomienda de la Fuente de Cantos (1735). Libro.

- Certificación de reclutamiento en Valladolid en descargo de Diego de Riaño y Gamboa (1656).

- Recibos de gastos secretos de orden del secretario Pedro de Contreras (1623-28). Libro.

1894 - Protocolo notarial de Madrid (1522-27). Libro.

- Inventario testamentario de la difunta Marla Isabel de Contreras Castrillo Ramírez de Arellano, marquesa viuda de Villanueva de Duero (1740). Libro.

- Capitulación del patronado de la capilla mayor del Monasterio de San Agustín de Segovia (1660). Libro.

1895 - Segregación del mayorazgo de los de la Torre (1739). Libro.

- Censo contra Juan Ramírez de Arellano (1611). Libro.

- Venta judicial de casa en la c/. de la Madera de Madrid (1653). Libro. 
- Provisiones del Consejo de Castilla a favor del marqués contra su villa de Villanueva de Duero por la abolición del concejo abierto y nombramiento de regidores, como pretendía el marqués (1760). Libro.

- Libro-registro de documentos del Edo. de Villariezo.

1896 - Venta judicial de la casa de c/. de la Madera Alta, de Madrid (1739). Libro.

- Libro-índice de propietarios seculares en la granja de Lozares (XVIII).

- Cuentas del mayorazgo de Meneses (XVII). Libro.

- Apeo de bienes en Rabé de Diego de Riaño y Gamboa (1657).

1897 - Memorias impresas de pleitos.

- Ejecutoria en el pleito en Madrid por el patronato de la capilla del convento de San Jerónimo el Real, fundado por Pedro Fernández de Lorca tesorero de Juan II (1656). Libro, incluye documentación del XV.

- Testimonio de la posesión de ia dehesa de Salinas (1571). Libro.

- Compraventas de casas y tierras en Burgos (1530 y 1542), del Edo. de Villariezo. Pergamino.

1898 - Ejecutoria del mayorazgo de Villaverde, segundo tomo (XVIII). Libro muy voluminoso. Incluye documentación de comienzos del XVI.

1899 - Juros de los Ramírez (XVI).

- Cartas de pago del Edo. de Villariezo (XVII).

- Recibo de dote de una monja, hermana de Diego de Riaño, por éste (1654).

- Alegación jurídica del conde de Murillo en segunda suplicación (1785). Impreso.

- Provisión de la Chancillería de Valladolid en apoyo del decreto del marqués de Villanueva de Duero para que en esa villa no se den fiestas culinarias más que en las celebraciones de la Iglesia (1757). Libro.

- Testamento de Villariezo (1601).

- Encabezamiento de alcabalas de Tardajos (1659).

- Memorial impreso de la Puebla del Maestre.

1900 - Testamentos de los Moneda (1523-1762).

- Cartas de pago a favor de varios monasterios y distintos señores en varios sitios (XVI-XVIII).

1901 - Testamentos de la casa de Villanueva de Duero, con índice (XVII).

- Documentos del mayorazgo de Barrasa (XVIII).

- Cartas de pago de las zonas de Zamora y Aranda (XVI-XVII).

- Cartas de pago varias (XVI-XVIII).

- Índice del antiguo legajo 8 del Edo. de Villanueva de Duero (XVI-XIX).

1902 - Felipe IV vende a Sebastián Antonio de Contreras Mirtarte, señor de Villanueva de Duero, la jurisdicción de dicha villa (1638). Un libro con muchos otros documentos.

- Títulos de juros, acciones, etc. del Edo. de Bornos (XIX).

- Título de compra de un olivar en Puebla de Alcocer (1872).

- Testamentos del Edo. de Villanueva de Dueró (XV-XVI).

1903 - Papeles de la capellanía de doña Alberta de Barrasa (XVIII-XIX).

- Libro de gastos de enfermería del Hospital de la Latina (1655).

- Privilegio real de caza, compraventas y testamento del Edo. de Villariezo (XVI-XVII).

- Libro de cuentas del Hospital de la Latina (1566-81). 
1904 - Memorial genealógico de los Tello de Meneses (1696). Libro; se cita documentación desde el siglo XII.

- Inventario de documentos del conde de Murillo (1776). Libro; documentación desde el XIV.

1905 - Censos (XVI) y compraventa de solar (1627) del Edo. de Villariezo.

- Apeo de bienes de Baltasar de la Hoz en Villariezo, comprados por Diego de Riaño y Gamboa (1622).

- Nombramiento del conde de Villariezo como juez conservador de las rentas reales en Burgos (1668-69).

- Cuentas de la obra pía de Francisco de Meneses (1745).

- Autos sobre nombramientos de curas en Alcanadre por su señor (1625).

- Libro-registro de testamentos del Edo. de Villariezo (XVI).

1906 - Pleito por un censo de los Carvajal-Meneses (1621). Libro.

- Memorial del pleito entre varios Porres por el mayorazgo de Cidad, Virtus y Valle de Valdebezana (1626). Libro impreso. Cita documentación del siglo XV.

- Compraventa, ejecución y apeo del Edo. de Villariezo (1500, 1531 y 1646).

- Libro-registro de documentos del Edo. de Villariezo.

1907 - Herencias, compraventas, cuentas y requisitorias del Edo. de Villariezo (XVI-XVII).

- Censo contra el conde de Bornos (1650). Libro.

- Cuenta de bienes recibidos por Diego de Riaño, por la muerte de Francisco de Riaño, para sus hijos (1649). Libro.

- Información de los derechos del abad de Alcanadre (1560). Libro.

- Cuentas del mayorazgo de los Moneda (XVI-XVII). Libro.

- Memorial impreso del pleito por la Puebla del Maestre.

- Transacción con el concejo de Talavera por los límites de la finca de la Fuente la Cierva (1468), del Edo. de Villariezo. Pergamino.

- Partición de bienes de Catalina Sánchez, mujer de Pedro de Peñalosa (1482).

- Inventario de documentos de Talavera (XV-XVI).

- Cesión de censo a la marquesa de Villacastel (1740). Libro.

1908 - Libro-registro de particiones e hijuelas del Edo. de Villariezo (XV-XVII).

- Apeos del mayorazgo de Losada. en Montamarta, San Cebrián de Castrotorafe y Fontanillas de Castro (1846-60). Libro protocolizado.

1909 - Memorial impreso del pleito por varios mayorazgos, fundados a fines del XV (1780).

- Ejecutoria de hidalguia de Francisco de Benavente, vecino de Medina del Campo (1572). Libro en pergamino. Traslado.

- Relación de bienes del Edo. de Murillo en Cintruénigo y Arguedas (1706). Libro.

- Apeo de bienes de Francisco de la Torre en Torrelobatón (1568). Libro.

- Dos libros-registro de documentos del Edo. de Villariezo.

1910 - Títulos de propiedad de las casas de Talavera (1579). Libro.

- Apeo de bienes del Conde de Villariezo (1719).

- Títulos de propiedad de casa en Medina del Campo, en el arrabal de la c/. Barrionuevo, compradas en 1564 por Gabriel de la Torre (1509-63). Libro encuadernado con los títulos originales. 
- Privilegios reales de los Rojas-Contreras (XVII-XVIII), sobre cargos en Tordesillas, Jaén, Cambil y Alhabar y Toledo. Libro.

- Mayorazgos de los Contreras en Jaén (1613-65). Traslados. Libro.

1911 - Relación de huérfanas dotadas por la memoria de Antonio Meneses (Talavera 1771-1853). Libro.

- Cuentas de cabañas de Pizarro y Rojas (1811-24). Libro.

- Censo redimido del conde de Villariezo contra la iglesia y concejo de Santibáñez de Zarzaguda (1664-68). Libro.

1912 - Capitulaciones entre la villa de Ausejo y su señor y pleito por las mismas ante la Chancillería de Valladolid (1679).

- Memoriales impresos de pleitos.

- Méritos y servicios de Juan Francisco Tello, Dávila, Guzmán y Trasmiera (1689 y 1726).

- Poder de Juan de Salcedo (Talavera, 1506).

- Inventario de bienes de Catalina de Herrera (1557).

- Cuentas de cabañas (1801-12). Libro.

1913 - Títulos de propiedad de casa en la c/. Zapatería de viejo. en Madrid (1642) Libro.

- Libro-registro de documentos del Edo. de Villariezo.

- Relación de la hacienda de Diego Dávila (XVII). Libro

- Informes de archivo (mediados del XIX).

- Compra de la jurisdicción de Villayuda y Castañares por el conde de Villariezo (1735).

- Pleito por el que se atribuye al conde de Murillo la explotación de las minas de hierro de Molina, por fallecimiento de Hugo de Urries (1624).

1914 - Libro de ganado vacuno (1841-54).

- Libro de ganado mular y caballar (1847-53). En su interior además regestas de documentos del Edo. de Villariezo (1423-1525) .

- Pruebas del conde de Murillo sobre la propiedad de la Abadía de Alcanadre (1573). Libro.

- Cuentas del Hospital de la Latina (1675-82) Libro.

1915 - Títulos de propiedad de la casa del mayorazgo de Fernando Ramírez de Madrid (XVI). Libro.

- Memorial impreso de la Puebla del Maestre.

- Inventario de los documentos de Villanueva de Duero (XV-XVIII). Libro completo.

- [Según Cooper, documento de Beatriz Galindo (1518)].

1916 - Apeo de la dehesa de Salinas (1781). Libro.

- Apeos de los bienes de Diego de Riaño (1611 y 1668). Libro.

- Cuentas del Hospital de la Latina (1654). Libro.

1917 - Memorial impreso del pleito de la Puebla del Maestre (1754). Libro.

- Libro de cuentas, acuerdos y visitas del Hospital de la Latina (158099).

1918 - Memorial impreso del pleito de la Puebla de Montalbán. Libro.

- Hijuela del conde de Bornos (1852). Libro protocolizado. 
1919 - Libro encuadernado con los documentos del mayorazgo de Diego Moreno, regidor de Segovia, del Edo. de Villanueva de Duero (1502-48).

- Inventario de bienes dejados por Diego de Rojas y Ortega, hecho por su esposa María de Contreras (1734). Libro encuadernado.

- Inventario de documentos del Edo. de Villacastel (1525-1774). Libro encuadernado.

- Inventarios antiguos por legajos, del Edo. de Villanueva de Duero (XV-XVIII).

1920 - Ejecutoria de la Chancillería de Valladolid a favor de Antonio José de Riaño Orovio y Guzmán, conde de Villariezo, contra el convento de San Ginés, de predicadores, en Talavera, por la propiedad de las casas en la c/. Empedrada, en esa localidad (1775). Libro encuadernado.

1921 - Libro de fes de bautismo del Edo. de Villariezo (en blanco).

- Otro similar, usado en parte (XVII-XVIII).

- Dos ejemplares encuadernados juntos del Memorial del pleito del Condestable con el duque de Osuna por los Edos. de Velasco (XVIII).

1922 - Títulos de propiedad de las casas de la c/. del Pez, en Madrid, de Jacobo de Flon (1622-65). Libro encuadernado, con un plano de situación sencillo.

- Información de limpieza de sangre e hidalguía de Juan y José de Olivares, hijo de Juan de Olivares y Mariana Brito, para oponerse a la elección de procurador de Cortes por Madrid (1655).

1923 - Testamento de María Isabel de Contreras Castrillo Ramírez de Arellano, marquesa de Villanueva de Duero, viuda de don Diego de Rojas y Ortega, conde de Villariezo (1736).

- Ejecutoria a favor del conde de Murillo contra su villa de Ausejo sobre residencias (1635).

- Ejecutoria del pleito entre Teresa de Olivares y Cepeda, marquesa de Villacastel y condesa viuda de Murillo, difunta y su hija Diega Ramírez de Arellano, esposa de Ramón Rufino Patiño Osorio, conde de Belveder, con el conde de Bornos, Joaquín Ramírez de Haro y su esposa, María Josefa Ramírez de Arellano, también hija de la marquesa de Villacastel, por los 5.322.210 reales en que la Hacienda compró a la marquesa las fábricas de Liérganes y La Cavada (1805).

1924 - Títulos de propiedad de las casas de la c/. Valencia, en Madrid (XVII).

- Títulos de propiedad del Pinar de las Torres, en Medina del Campo, del mayorazgo de los de la Torre propiedad de Francisca Victoria de Salcedo y la Torre (1746).

- Censos contra el Edo. de Villanueva de Duero y Villariezo (XIX).

1925 - Memorial del pleito entre los descendientes de Cristóbal Colón por su mayorazgo (s.a ). con árbol genealógico.

- Inventario de documentos de Juan de la Moneda Tacín Lerma Heredia. regidor de Burgos. tesorero y maestro de Cámara de don Juan de Austria (XVI-XVII).

- Títulos de propiedad de las casas de la cl. del Pez, en Madrid, propiedad de Jacobo de Flon (1610-1723)

1926 - Libro de fes de bautismo del Edo. de Villariezo (XVIII), casi en blanco.

- Pleito ante el alcalde mayor de Motril, entre Luis Ramírez de Haro y varios vecinos de Motril (1598). Libro muy voluminoso. 
1927 - Apeo de las fincas del conde de Villariezo en Rabé de las Calzadas (1703).

- Diversos reconocimientos de censos del Edo. de Villariezo (XVII).

- La Reina Juana, a petición de Pedro Arias Dávila, capitán general de la Mar Océana, ordena que no se viole su privilegio de las salinas de Duernas, en Córdoba (1513, julio 28. Valladolid).

- Residencia tomada a Francisco de Riaño y Gamboa como gobernador y capitán general de la Habana (1633-40).

1928 - Relación de fincas de los Salcedo, en Sepúlveda (1802).

- Idem de Villariezo en Talavera (XVIII-XIX).

- Idem de varios linajes en Zamora (Mercados) y Guadalajara (Condado de Murillo) (XVIII).

- Idem, apeos y censos de Villariezo (XVII-XVIII).

- Censos del conde de Villariezo en los Ausines (XVII).

1929 - Tomas de posesión del Edo. de Villanueva de Duero (XIX).

- Censos a favor del Edo. de Villanueva de Duero, en Medina del Campo, Tordesillas y Segovia (XVI-XVIII).

1930 - Compraventas de Villariezo en Talavera (XV-XVII).

1931 - Apeo de bienes de Antonio de Quintanadueñas, del Edo. de Villariezo (1513-98).

- Ejemplar del Bulario de la Orden de Calatrava, de Ortega y Cotes. Impreso.

- Expediente de hidalguía de los Lantadilla, vecinos de Sevilla, procedentes de Trasmiera, ante la Chancilleria de Granada (XVI).

- Compraventa de heredad en Talavera (1501).

1932 - Memorial del pleito en segunda suplicación entre Gonzalo Antonio de Carvajal, regidor de Badajoz, y el conde de Murillo, los unos bienes en Alcanadre, Ausejo y Toro (1783). Impreso.

- Pedimiento en segunda suplicación entre el conde de Montijo y otros, en el pleito sobre la sucesión del mayorazgo de la Puebla del Maestre (1754). Impreso.

- Papeles del patronato de los Brito en el convento de la Merced calzada de Madrid (XVII).

- Pleito entre el duque de Frias y el conde de Benavente por el mayorazgo de Velasco (XVIII). Impreso y encuadernado.

- Venta real de Peñarrubia a Juan de Guevara (1575), del Edo. de Peñarrubia y Murillo.

1933 - Memorial de pleito sin encabezamiento. Impreso (el de Montijo).

- Papeles del mayorazgo de Juan de Guevara (XVI-XVII). Libro encuadernado.

- Ejecutoria a favor de Onofre Ramírez de Haro contra Antonio Gaytán de Ayala por el mayorazgo de Francisco Ramírez (1778).

1934 - Compraventas de Villariezo (XVII).

- Ejecutoria a favor de Antonio de Mercado y Tapia, vecino de Olmedo, por el mayorazgo de Pedro de Robles (1765).

- Censo del Edo. de Murillo (1674).

- Papeles de los Torre-Andino (XVI), con dictamen. 
- Documentos de Juan de Guevara (1571).

- Testamentos modernos (XIX).

1935 - Papeles de nobleza de los Ramírez de Arellano.

- Herencias del Edo. de Villanueva de Duero (1720).

- Información de limpieza de sangre de Juan y José de Olivares (1655).

- Compraventas de Villariezo (XVII).

- Autos de demolición y reconstrucción de la ermita de N.S. de Valdelengua, en la dehesa de Salinas, por parte del concejo de Pepino (Toledo) (1762-65).

- Testamentos de los de la Torre y Trillo (XVII).

- Papeles de los Totanes y Quevedo (XVII).

- Testamento de María Ventura de Contreras, marquesa de Villanueva de Duero (1733)

1936 - Censos y compraventas de Villariezo (XVI-XVII)

1937 - Censos y compraventas de Villariezo (XVI-XVII).

- Libro de tutelas y curadurias de Villariezo (en buena parte en blanco).

- Apeo de fincas de Juan Tello (Arévalo, 1753).

- Apeo de fincas de Bartolomé de Somoza (Villagonzalo, 1698).

1938 - Memoriales impresos de varios pleitos (XVIII-XIX).

1939 - Memoriales impresos de varios pleitos (XVII-XVIII)

1940 - Memoriales impresos de varios pleitos (XVII-XVIII)

1941 - Ordenanzas y reales órdenes (XVIII-XIX). Impresos

- Arrendamientos del Valle de Alcudia (XVIII) Impresos

- Memoriales de pleitos (XVIII).

- Privilegio a Alonso de Losada (XVIII).

- Apeo de fincas en Torrelobatón (1786).

- Hijuela de Diego de Rojas y Contreras (1740)

- Testamentaria del mismo (1740).

- Testamento del Edo. de Villariezo (1611).

1942 - Compraventas de Villariezo (XVI).

- Papeles de los Olivares, Quevedo, Guevara. Almunias-Brito, Cepeda y otros (XVI XVII).

- Índice del antiguo legajo 39 de Villariezo, de asuntos judiciales (XVII).

- Memorial del pleito por el mayorazgo de Meneses. Con árbol genealógico (s.a.).

- Real cédula (1776).

- Ejecutoria del Consejo a favor de José Ramírez de Arellano, conde de Murillo, contra el de Peñaflorida (1737).

- Otros memoriales y reales cédulas (XVIII).

1943 - Escudo de armas coloreado.

- Árboles genealógicos de los Ramírez de Arellano y otros.

- Mayorazgo de Carlos de Arellano (1490)

- Privilegio de hidalguía de Moreno (1570), con miniatura en incípit.

- Papeles de los Tello y de Villariezo (XVI-XVIII).

- Índice del antiguo legajo de los mayorazgos de los Ávila y Cuadra, del Edo. de Murillo (XVI-XVIII).

- Padrón de refacción de los hidalgos de la ciudad de Jaén (1566). 
- Papeles genealógicos diversos.

- Papeles de los Olivares (XVII-XVIII) y los Ramírez (XVIII).

- Patronato de la iglesia de Torme (Burgos, 1587).

- Denuncia contra vecinos de Gamonal (1638).

- Papeles de los Salazar, Mercado, Delgado. Helguero, Olivares, Trillo, Trasmiera, Pérez, Cepeda y otros (XVII-XVIII).

- Apeo de los Ávila (XVII).

- Papeles de los Moneda y Ávila (XVII-XVIII).

- Índice del antiguo legajo 3 de los Trasmiera (XVI-XVII).

1944 - Privilegio de venta real de Villanueva de Duero a Sebastián Antonio de Contreras y Mitarte (1633). Libro en pergamino.

- Libro de venta de casas de Juan Moreno, en la c/. de la Zapatería de viejo, de Madrid; incluye privilegio de exención de huéspedes de Felipe IV. con sello colgante (1647).

1945 - Títulos de Contreras Mitarte de los derechos en la Viña de los Llanos, en Medina del Campo (1607). Libro encuadernado.

- Compraventas de Villariezo (XVI).

- Testamento de Antonio de Riaño y Avendaño (1638).

- Documentos y papeles genealógicos varios.

- Papeles de los Cepeda, Tello, Tapia y Moneda (XVI-XVII).

- Papeles de nobleza del Edo. de Murillo.

- Árboles genealógicos (del mayorazgo de Tofiños).

- Documentos de los Deza en Sevilla, Segovia y Granada (XV). En gran número.

- Papeles de las casas de la c/. de la Madera, n. 27 y 29, con certificados de deslindes del arquitecto Wenceslao Gaviña (1868). Sin planos.

1946 - Venta de la dehesa del Tomilloso, en la Serena, por la Hacienda real a la duquesa viuda del Arco, condesa de Montenuevo, del linaje de los Enriquez (XVIII). Libro encuadernado voluminoso.

1947 - Ejecutoria de la Chancillería de Valladolid a favor de Manuel Fulgencio Ramirez de Arellano contra el marqués de Sardeñola por el mayorazgo de Butrón, fundado en 1449 (1782). Contiene los documentos medievales.

1948 - Cuentas del mayordomo del Hospital de la Latina (1622-31 y 1725-42). Dos libros encuadernados.

1949 - Tres libros-registro de documentos, mandados formar por Antonio José de Riaño y Orovio, conde de Villariezo, conteniendo regestas y traslados de documentos sobre mayorazgos, tomas de posesión y concordias, respectivamente (XV-XVI).

1950 - Dos libros-registro del conde de Villariezo sobre compraventas y testamentos (XV-XVI).

1951 - Documentos relativos al mayorazgo de Riaño, sobre el señorío de Villayuda y Castañares (XVII). Libro voluminoso en pergamino.

1952 - Ejecutoria del Consejo de Hacienda a favor del conde de Murillo contra sus villas de Ausejo y Murillo, sobre el derecho a nombrar oficiales en esas villas (1777). Libro voluminoso. 
1953 - Ejecutoria de la Chancillería de Granada a favor de Juan de Guevara contra Córdoba, por las salinas de Duernas (1578).

- Árboles genealógicos de los Ramírez de Arellano y de los Ramírez de Guzmán, condes de Villaverde.

- Memorial del pleito por el mayorazgo de Cristóbal Colón (s.a.). Impreso.

- Venta real de Villanueva de Duero (1633). Libro en pergamino.

- Privilegio real para renunciar juro en Ciudad Real (1534).

- Memorial del pleito de Diego Dávila (s.a.). Impreso.

- Ejecutoria de nobleza a Zuazo (1537). Libro en pergamino.

- Ejecutoria de nobleza a Mitarte (1569).

- Venta de censo de Villariezo (1527). Libro en pergamino.

- Ejecutoria de hidalguía a Herrera (1565). Libro en pergamino.

- Privilegio de cesión de servicio real en Tardajos y otros pueblos al conde de Villariezo 11660). Libro en pergamino.

- Información de nobleza de Castrillo (Talavera 1568).

- Información de hidalguía de Rojas (Antequera, 1568) Libro.

1954 - Mayorazgo de Murillo (1490). Libro en pergamino.

- Genealogía de Diego Francisco Riaño. Impreso.

- Autorización de Felipe IV para enajenar realengo (1633). Libro en pergamino.

- Información sobre pertenencia de la ermita y del Prado de Valdelengua a la dehesa de Salinas (1500). Libro.

- Títulos de propiedad de fincas en Tordesillas (XVII). Libro.

1955 - Libro de cuentas de Bornos (1806).

- Residencias tomadas en Villagonzalo y Villariezo (1657 1717) Libro.

- Índice de documentos de los Ramírez.

- Pleito por la dehesa de Miravella (Talavera, 1605).

1956 - Compra de la dehesa de Barrero, en Velada (Toledo) por el conde de Bornos (1851). Libro.

- Inventario de documentos del conde de Murillo (XI-XVIII). Libro.

- Inventario de documentos de Meneses (XV-XVIII). Libro.

- Memorial del pleito por el condado de Villaverde (1804). Impreso.

- Fundación del patronato en la iglesia del Espíritu Santo de Madrid, por Álvarez de Perea (1630). Libro.

- Juro a favor de Juan de Arcaya (1669). Pergamino.

- Fundación del mayorazgo de Borja-Trasmiera (1639). Libro con árboles genealógicos.

- Fundación del mayorazgo de Sebastián Vicente, regidor de Madrid (XVII). Dos ejemplares manuscritos.

1957 - Bula a Antonio Téllez Girón (1585).

- Bula a la Abadía de Alcanadre (XVI). Sello maltratado.

- Memorias de diversos pleitos.

- Papeles genealógicos con árboles, entre otros de los Ramírez de Guzmán.

- índice del antiguo legajo del mayorazgo de Borja (XVIII-XIX).

- Dictámenes (XVII-XVIII).

- Actas de Cortes de 1624. Libro impreso. 
- Partidas de bautismo de los Quevedo (XVII).

- Copias de papeles de Borja (XVII).

- Documentos diversos (Tello, etc.) (XV-XVII)

1958 - Papeles genealógicos.

- Cuentas del Hospital de la Latina (1851-52).

- Testamentos de los Borja (XVII).

- Documentos de los Olivares (1724).

- Memorial del pleito por el mayorazgo de la Puebla de Montalbán (1721). Impreso.

- Pergamino del obispo de Ávila (XVII).

- Real cédula a Sebastián Antonio de Contreras (1638). Pergamino.

- Sancho de Rojas vende a Pedro García Orense, regidor de Burgos, censo (1472). Pergamino.

- Censo perpetuo del concejo de Mazuelo a los condes de Alba (1524). Pergamino.

- Título de juez conservador de la encomienda de Segura de la Sierra (1504). Pergamino.

- Ejecutoria de hidalguía de Martín Ruiz de Mitarte (1572). Pergamino

1959 - Cuentas del Hospital de la Latina (1843 y 1846-67).

- Papeles del patronato del convento de Gracia, fundado por el contador Dávila (Ávila, XVI-XVII).

- Regestas de documentos de Ávila, Guadalajara, Pueblanueva y Sepúlveda.

1960 - Cuentas y correspondencia de cabañas (1845-46)

- Correspondencia varia (XIX).

- Libro con correspondencia internacional sobre créditos (1869-73).

- Dos libretas, una de gastos (1861-62) y un diario personal (1857).

1961 - Correspondencia entre el conde de Villariezo y don José Terrones (fines del XVIII).

- Cuentas de la Casa de Villariezo (1823).

- Pleito del marqués de Villanueva de Duero y Villariezo con Manuel de Alvaro Benito, canónigo de Segovia, sobre varios derechos en los Millares del Real, en el Valle de Alcudia (1828).

- Cuentas de venta de lanas (1841-1842).

1962 - Cuentas de las casás de Madrid, de Villariezo (1822-32).

- Libro diario personal (1858).

- Balance de los libros de Antonio Escandón (1875).

1963 - Árboles genealógicos, en gran número y tamaño, de Ramírez de Arellano, Manrique, Cárdenas, Guzmán, Contreras, etc.

1964 - Primer libro de acuerdos para las Juntas de Minas de Guadalcanal (1725).

- Libro de cuentas del Hospital de la Latina (1603-20). Ambos de gran tamaño.

2407 - Cuentas dadas al marqués de Villanueva de Duero de todas las rentas de la encomienda de la villa de Fuente de Cantos (1795-1822).

- Cuentas al mismo de las tierras de su propiedad en la misma villa (1819-1848).

2412 - Cuentas de Cambil (1867-1875). 
2413 - Cuentas de Cambil (1857-1866).

2414 - Documentos judiciales, Madrid (XIX).

- Censos del conde de Bornos en Zamora (XIX)

- Censos de Arévalo (XVI-XVIII).

- Censos de Aranda de Duero (XVI-XVIII).

- Documentos judiciales, Motril y otros (XIX)

2415 - Reales autorizaciones (XVIII).

- Censos en Camarma de Esteruelas (XVIII).

- Censos varios.

- Cartas reales del Edo. de Villanueva de Duero (1740-1789)

- Documentos judiciales, Motril (XIX).

- Capitulaciones matrimoniales (XVI).

- Juros (XVII-XVIII).

- Testamentarías, cartas dotales, herencias, etc. del Edo. de Villanueva de Duero (XVII-XVIII). Índice del antiguo legajo 18, correspondiente a los Ramírez de Haro.

2477 - Documentos sobre la Pradera de San Isidro, en Madrid (1811-1889).

2582 - Cuentas y correspondencias varias (Zamora, Madrid, Motril, Lavadero de Rojas, etc.) (XVIII-XIX).

2583 - Correspondencia del conde de Bornos (XIX).

- Libro de registro de ganado del conde de Bornos y Villariezo y marqués de Villanueva de Duero (XIX).

- Correspondencia del conde de Bornos (XVIII-XIX). 